\title{
COMMUTE AS RITUAL Wellington Harbour Ferry Terminal
}

\author{
Andrew R. Mitchener
}




\section{ACKNOWLEDGMENTS}

$\mathrm{T}$

hank you to Chris McDonald for your guidance, Mary Daish for your support, Chris Moller for scrambling my brain, Patricia Bruner for reassurance, Paul and Judy Mitchener for emotional support, and Ruth Mitchener for everything. 
- For Ruth -

Who makes everything amazing 


\section{ABSTRACT}

$\mathrm{T}$

ransport infrastructure is the template upon which we build our inhabitations.

Decisions regarding street arrangements, block sizes, and larger scale infrastructure design for example have an enduring and profound affect on the quality of our spatial environments. The conceptual framework we apply when generating and subsequently manipulating this template sets the parameters by which it is judged.

By convention, transport infrastructure is considered a purely technical undertaking, within which designers rarely play any meaningful part. The spaces of mobility are thus from their very genesis conceived as instrumental in nature, judged as mere conduits whose function is to join meaningful places such as work and home, fulfilling an economic imperative.

Recent research has shown however that affective, symbolic factors play a greater role than instrumental considerations in modal choice of commuters, suggesting that, to the end user at least, transport possesses a value beyond simple utility. Indeed, mobility itself is often cited as a defining characteristic of the modern world, implying a highly symbolic status.

This gap between the instrumental conceptual framework we apply to transport infrastructure and the symbolically loaded experience of mobility is an opportunity for design to enrich the experience of users, framed in this research as commuters. Through 
investigation of the commute as a quotidian, secular ritual greater consideration is given to extra-economic value in the spaces of transport infrastructure.

This research analyses the nature and function of ritual in contemporary secular life and argues for the applicability of a ritual framework for understanding value in transport infrastructure. The spatial implications of ritual (defined as symbol + action and exhibiting the key sociocultural functions of mnemonic and liminality) are explored through the design of a harbour ferry terminal for Wellington. 
300034316

Text by Andrew Mitchener 2012 .

Images by Andrew Mitchener unless specified otherwise.

Document design by Ruth Mitchener.

Andrew Mitchener has asserted his right to be identified as the author of this work in accordance with the specifications for completion of a Master of Architecture (professional).

All rights reserved. No part of this publication may be reproduced, stored in a retrieval system, or transmitted in any form or by any means, electronic, mechanical, photocopying, recording or otherwise, without the permission of the author.

Printed and bound in New Zealand. 


\section{CONTENTS}

$\begin{array}{ll}\text { ABSTRACT } & 4\end{array}$

1 INTRODUCTION 11

2 BACKGROUND

in which the status quo of transport infrastructure work is critiqued

3 AN ALTERNATIVE FRAMEWORK in which ritual is proposed as an apt conceptual basis for an alternative framework for the generation and manipulation of transport infrastructure

4 CONTEXTUAL ANALYSIS

in which the political and physical contexts for the design intervention are established and the site for intervention is explored

5 INTERVENTION

in which the design of a harbour ferry terminal is presented and addition works the terminal precinct are proposed

6 CONCLUSION

in which the intervention is critiqued and the efficacy of ritual as a conceptual

framework for the architecture of transport infrastructure is reflected upon 
ses

ist. (1)

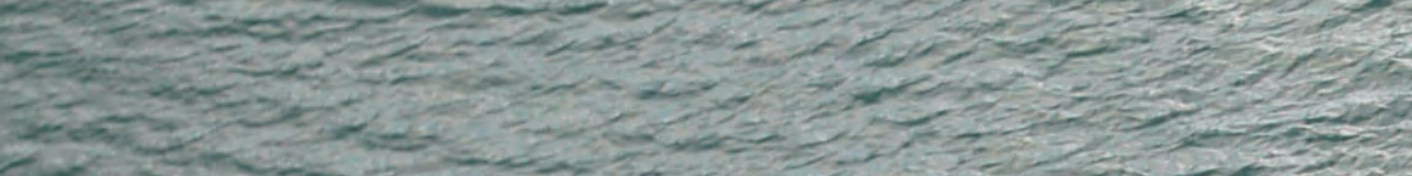

(n) - ils

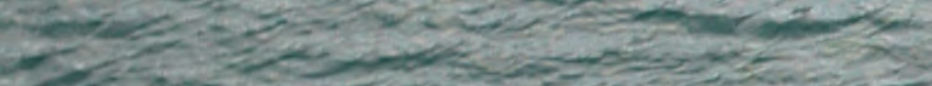

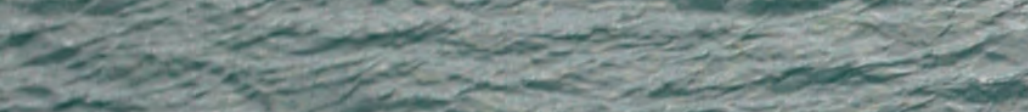

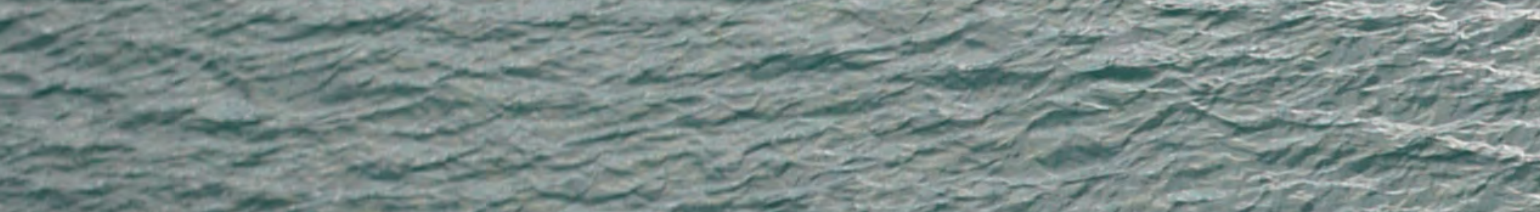

It

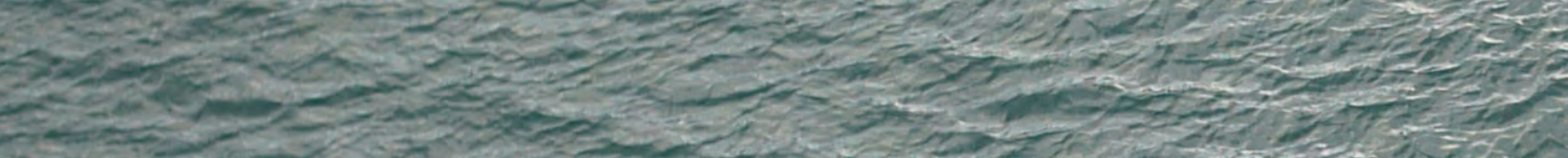
Soner:

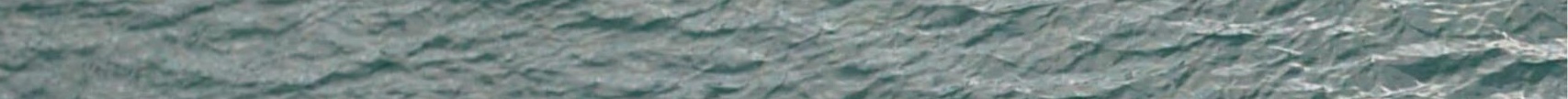

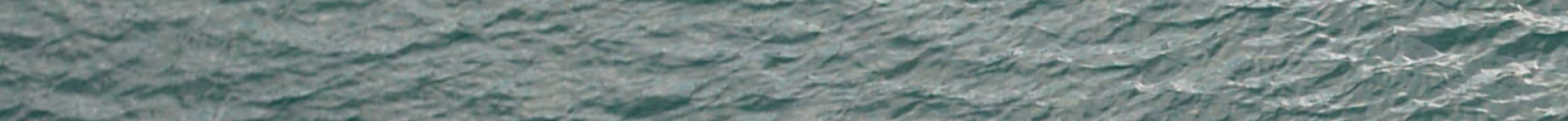

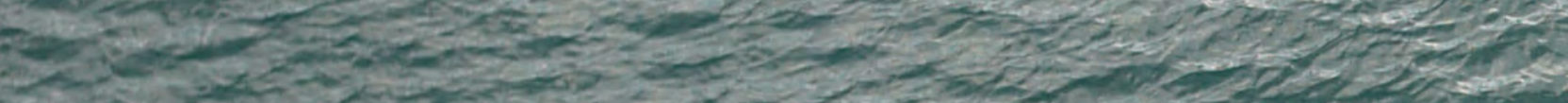

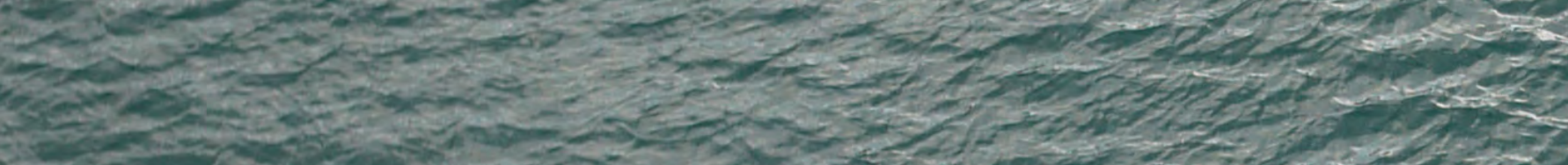

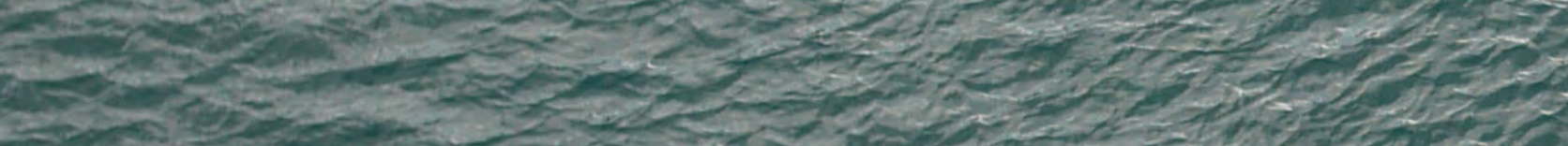

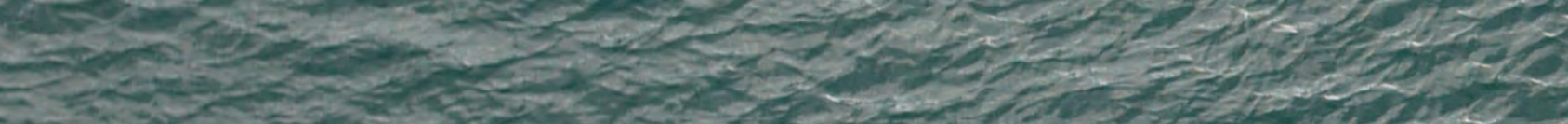

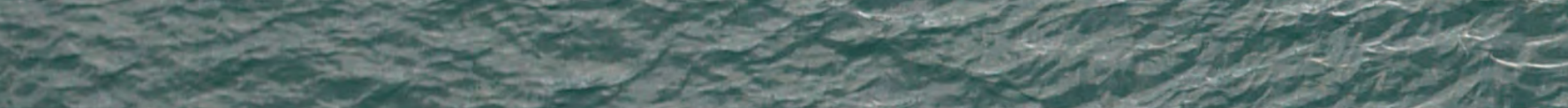

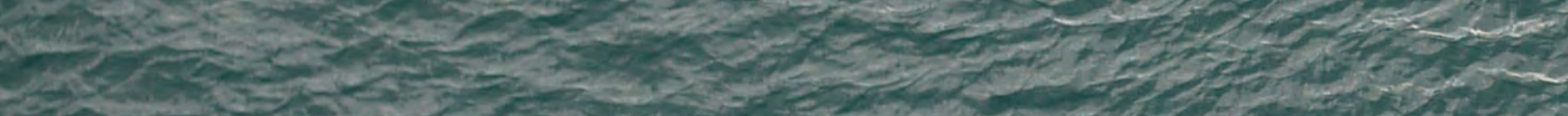

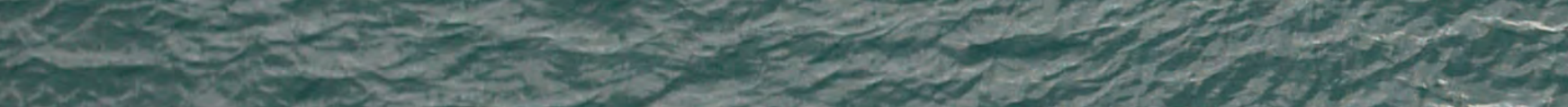

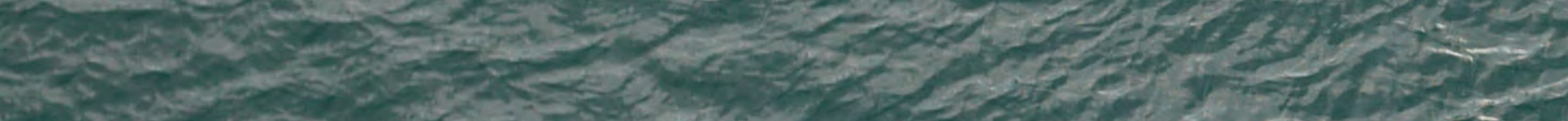

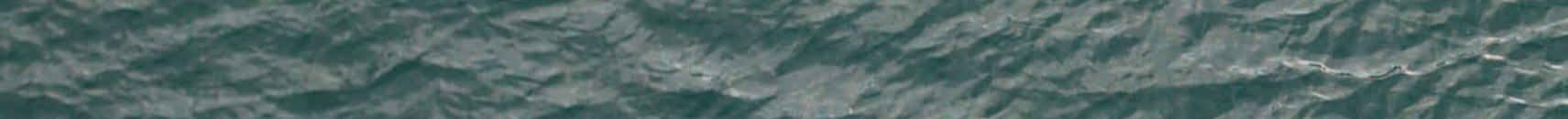

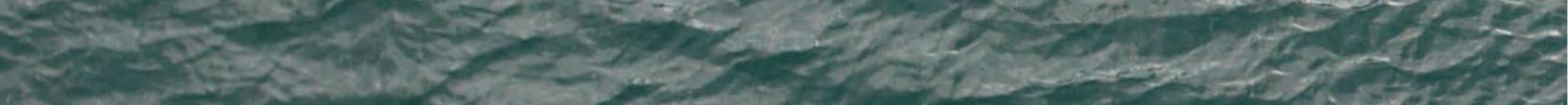
Wer

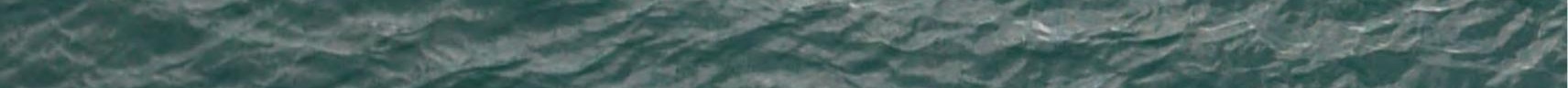

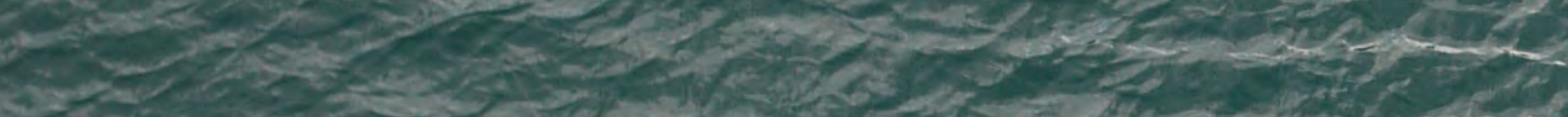
so selas 60

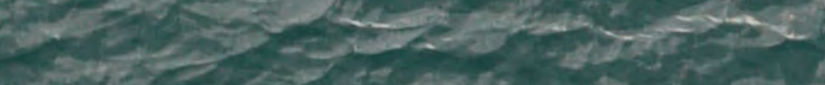

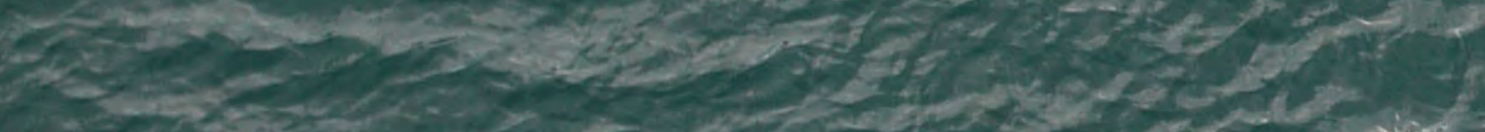






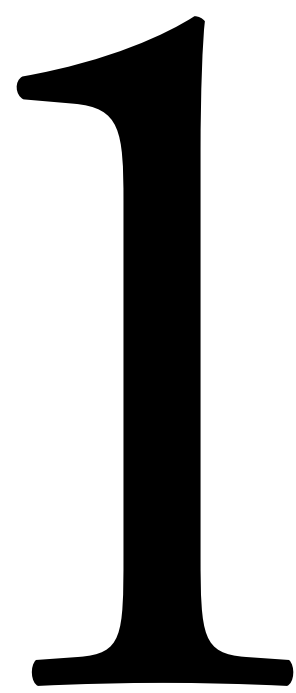

INTRODUCTION 
$\mathrm{T}$

ransport infrastructure is one of the primary means by which we define the shape of our inhabitations. Decisions regarding the generation and manipulation of transport infrastructure have broad, lasting, and profound spatial implications, and yet by convention transport infrastructure design is considered to be predominantly, if not wholly, a technical exercise. As such the spaces of transit are imbued from their very conception with an instrumental remit ahead of qualitative and experiential considerations.

Research has shown however that symbolic factors play a much larger role in our use of transport infrastructure (restricted in this research to the commute) than the instrumental framework infers, suggesting that the commute performs a function beyond the utilitarian act of shifting between work and home. Ultimately, the instrumental view belies the symbolic, affective value of transport infrastructure through the application of an economic imperative.

The symbolic and affective function of transport infrastructure can be understood as a sociocultural operation, an idea that is captured by the Oxford American Dictionary definition of infrastructure itself as "the basic physical and organizational structures and facilities... needed for the operation of a society..." (Oxford University Press 2012). The current conceptual framework for infrastructure works, which prescribes an economic imperative (which is indicative of the instrumental view), does not, I will argue, capture 
this broader definition. Instead, the instrumental framework affirms a model for transport infrastructure works that fails to recognize, and therefore fulfill, this broader remit.

In order to realign transport infrastructure with its sociocultural function, the sociological concept of ritual is applied to the commute, and a design intervention is proposed based on the criteria suggested by a ritual framework.

Chapter Two discusses the instrumental framework of transport infrastructure, its conceptual origins, and how it fails to adequately capture value in transport infrastructure.

Chapter Three looks at the nature of ritual and its sociocultural role, with particular reference to the secular and quotidian. This sets up an alternative conceptual framework for transport infrastructure and criteria for the architecture of transport infrastructure are drawn from this.

Chapter Four examines Wellington's transport infrastructure, its political and geographical context, and the site for the proposed intervention, a harbour ferry terminal, is introduced.

Chapter Five outlays the proposed intervention with ramifications at a number of scales, discussed as regional, urban, and local. 
Chapter Six draws conclusions from the design investigation and discusses the merits of ritual as a conceptual framework for transport infrastructure in contrast to the current instrumental framework. 



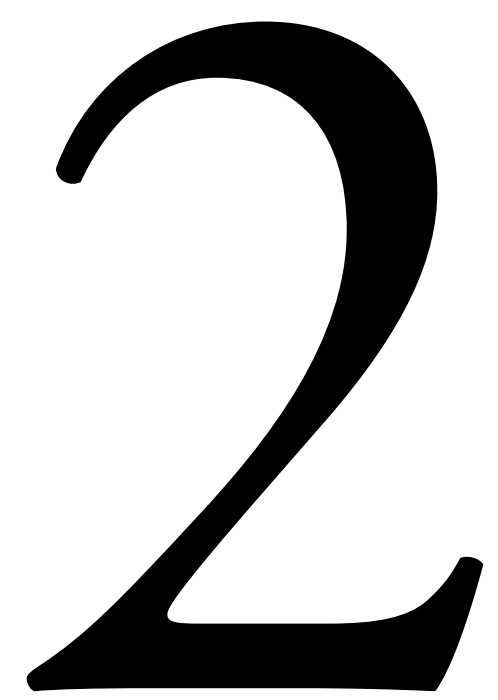

\section{BACKGROUND}

- The Instrumental Conceptual Framework for Transport Infrastructure - 
"... regional science, and the whole edifice of economic infrastructure modeling based on it, 'remains enraptured with that desolate, asocial, self-centered individual, homo economicus..."' (Graham and Marvin 2001: 106).

$\mathrm{T}$ ransport infrastructure is the template upon which we build our inhabitations ${ }^{1}$. Factors concerning transport infrastructure, such as street width and block proportions for example, are some of the most resilient design decisions made about cities and towns. The conceptual framework within which we generate and subsequently manipulate this template profoundly affects the spatial qualities of our inhabitations, by setting down the criteria against which transport infrastructure projects are measured.

Inherited wisdom suggests however that our transport infrastructure is a technical concern - primarily a tool for accommodating expeditious movement - establishing an instrumental charter for the spaces of mobility. As a result the qualitative, experiential aspects of the spaces of transport infrastructure come second (if indeed they are considered at all) to the technical requirements of transport. As Francine Houben has pointed out, "... all this space for traffic, this huge network of public spaces in which countless people spend many hours day after day, has come into being with such apparent casualness. The construction of mobility routes seems to be primarily a technical matter, reserved for traffic planners, engineers and politicians, in which designers play no part." (Houben and Calabrese 2003: 12).

The instrumental framework espoused by such technicians implies that transport

\footnotetext{
${ }^{1}$ This statement is supported by a recent New York Times article, 'The Grid at 200: Lines That Shaped Manhattan', that describes the Manhattan street grid as “...a creative template” (Kimmelman 2012: 1).
} 
infrastructure holds little inherent value as inhabitable space. Considered to be merely conduits, the spaces of mobility are ultimately measured by their efficacy of function, by their ability to facilitate movement of people and goods "between two significant points and a meaningful existence" (Hoete 2003: 16).

In New Zealand, the conception of transport infrastructure as a primarily economic concern is indicative of this instrumental view. The economic imperative is evident when considering the political structure of transport infrastructure works, where the defining measure applied to individual projects is potential economic value. This suggests that transport infrastructure is ultimately an instrument of the economy - a means of generating financial wealth.

Yet, "[p]ublic space [of which transport infrastructure is a large part, as Houben states] is not just a matter of profits and popularity. In both calculable and incalculable ways, public facilities have an impact on the quality of life" (Leighninger 1996: 230). Furthermore, public infrastructure, in its most basic definition, is concerned with "the basic physical and organizational structures and facilities... needed for the operation of a society..." (Oxford University Press 2012) - a definition that implies a far broader remit than simply economic function. 


\section{THE ECONOMIC IMPERATIVE IN NEW ZEALAND}

The economic imperative in New Zealand's transport infrastructure is explicit at a fundamental level in the political structuring of infrastructure works. As Arthur Grimes explains, "[w]hile many New Zealand government agencies are involved in some form of infrastructure, it is the Treasury that acts as the "guardian" of the evaluation process" (Grimes 2010: 3).

As Grimes goes on to point out however, the economic analysis tools employed by Treasury can fall short in capturing even the economic potential of a given project. Grimes suggests manipulation of the method to correct these deficiencies, but other evidence points to a systemic issue - that economic analysis cannot fully capture value in transport infrastructure because of its broader purpose.

The use of an economic framework for the generation of an entity with a broad social remit represents a conceptual non sequitur that can be understood when we appreciate that economics is but one of the operations of a society. As Pierre Bourdieu states, " $[t]$ he science called 'economics' is based on an initial act of abstraction that consists in dissociating a particular category of practices, or a particular dimension of all practice, from the social order in which all human practice is immersed." (Bourdieu 2005: 1).

The misconception of this narrow, particular science as broadly applicable is often 
referred to as 'economic imperialism', and is symptomatic of the Globalist epoch from which we are now emerging.

\section{THE GLOBALIST NON SEQUITUR}

Globalism, as John Ralston Saul defines it, was a political ideology concerned primarily with the "reconceptualization of civilization through the prism of economics" (Saul 2004: 37). This can be understood as the acme of economic imperialism, the phenomenon of economics being used to describe aspects of human practice not traditionally associated with it.

New Zealand was particularly vehement in adopting this ideology, as Saul suggests when describing this country as " $[t]$ he only Western democracy to have formally embraced the full ideology of Globalization". (Saul 2005: 210). This manifested itself "[i]n the 1980s, [when] New Zealand underwent a series of changes to its economic, political, and social policies that radically restructured the basis of the nation's life. The main thrust of these changes was toward a more market-driven and competitive society" (Thorns 1997: 190). The economic imperative in transport infrastructure is one lingering symptom of this.

The Globalist view is problematic as “...the commercial sphere always has been 
derivative of and dependent on the cultural sphere" (Rifkin 2000: 11). Thus, "[w]hen the commercial sphere begins to devour the cultural sphere... it threatens to destroy the very social foundations that gave rise to commercial relations." (Ibid: 12). While undoubtedly polemic, this argument shows the economic imperative of transport infrastructure in a new, troubling light.

Pierre Bourdieu goes so far as to suggest how this non sequitur might be corrected, stating that, "[t]o break with the dominant paradigm, we must... attempt to construct a realist definition of economic reason as an encounter between dispositions which are socially constituted... and the structures, themselves socially constructed..." (Bourdieu 2005: 193). More simply put, economic relationships need to be recontextualised as a constituent of the social milieu.

The recontextualisation of economic relationships as socially constituted, and therefore the incongruity of an economic imperative in socially chartered structures such as transport infrastructure, can be considered the conceptual basis for this thesis.

\section{THE PROBLEM OF THE INSTRUMENTAL VIEW}

The problematic nature of transport infrastructure as a purely instrumental, technical concern has long been recognized in urban studies, with the street in urban environment 
generally accepted to have a broader remit than efficient traffic flow. According to Fanziska Bollerey, Camillo Sitte's concern in City Planning According to its Artistic Principles of 1889 " ... was with movement within public space, by which he clearly meant something other than just the smooth transport of goods and people as propounded both then and now by traffic planners, whom he referred to disparagingly as 'witch doctors'." (Mare and Vos 1993: 1).

More recently the discussion of transport's broader role has expanded beyond the urban boundary, encompassing a larger scale of transport infrastructure. The first architecture biennale of Rotterdam in 2003, titled 'Mobility: A Room With a View', explored "the impact of mobility on our daily lives, ... [examined] how mobility relates to city and landscape, and ... [revealed] the consequences for the contemporary culture of design" (Houben and Calabrese 2003). The result was Houben and Calabrese's book of the same title, which proposed 'the aesthetics of mobility' as a means to promote greater architectural investment in the spaces of transport infrastructure ${ }^{2}$.

\footnotetext{
${ }^{2}$ Houben's contribution finds an antecedent in Appleyard, Lynch, and Myer's The View from the Road of 1964, and later Anthony Hoete expanded on Houben's thesis in his Reader on the Aesthetics of Mobility of 2003.
} 


\section{EXTRA-INSTRUMENTAL VALUE IN TRANSPORT}

The instrumental / symbolic binary that is inferred by such works has been investigated recently using empirical research methods by Linda Steg, who's study focused on commuter motives for modal choices in the Netherlands ${ }^{3}$. Her findings suggest that symbolic motives play a much larger role in modal choice for commuters than received wisdom suggests.

Steg's research indicated that "...it appeared that commuter car use was most strongly related to symbolic and affective motives, and not to instrumental motives" (Steg 2005: 1). Steg goes on to state that, "[t] hese results suggest that policy makers should not exclusively focus on instrumental motives for car use, but they should consider the many social and affective motives as well." (Ibid).

Following on from Linda Steg's work in the Europe, an empirical study into the extra-economic value of the commute has recently been carried out in New Zealand. Importantly, this study states that, "[c]urrently, economic appraisal in New Zealand and elsewhere assumes that travel time, irrespective of the mode used, has a disutility to the

\footnotetext{
${ }^{3}$ By way of demonstration of the applicability of Steg's research, the Netherlands registers at 20th and New Zealand 4th on the World Bank's list of passenger cars per 1000 people (World Bank 2008), suggesting that Steg's findings may be even more relevant in this country.
} 
individual and a cost (in time and money) to be reduced or minimized." (Wallis and O'Fallon 2012: 7). This is contradicted by the research findings that "[o]ne-third (33\%) of commuters were contented with their time spent commuting, enjoying it and finding it a useful transition between work and home." (Ibid: 9).

The disutility of the commute that the instrumental charter assumes fails to capture the significance of the commute, and thus transport infrastructure, as a sociocultural device.

\section{CONCLUSION}

The instrumental framework by which we generate and ultimately measure the value of our transport infrastructure belies its broader sociocultural significance. Research suggests that transport infrastructure is not primarily an economic tool, but is in fact concerned with supporting the social relationships that give rise to the economic. As Bourdieu, Rifkin, Saul, and others have pointed out, economic relationships are embedded deeply in, and dependent upon, sociocultural context. The economic imperative misconceives the broad remit of infrastructure by measuring its success (potential or actual) by only one facet of human practice - the economic.

This is represented by a gap between the conceptual framework by which policy makers understand the value of transport infrastructure and the value ascribed by the commuter. 
Under the Oxford definition, and following Rifkin's thesis, a more apt conceptual framework for transport infrastructure would be as a mechanism for supporting the functioning of society as a whole. Transport infrastructure under an instrumental imperative not only struggles to measure up to its own criteria as an economic entity, it fails to adequately recognize the broader role, and therefore potential, of transport infrastructure as a sociocultural device.

Discussion of transport infrastructure as something other than an instrumental concern has thus far been rather speculative about alternative criteria for the generation of transport infrastructure. As Lee Stickells explains in regard to Houben and Hoete's writing on the aesthetics of mobility, "...these texts are more circumspect on the qualities of mobility that a new architecture is exhorted to take up" (Stickells 2010: 43).

It seems clear that there is a need to reframe how we think about transport infrastructure and its function in society. Another way of thinking of the commute (the peak period of activity for transport infrastructure) that may prove useful in realigning transport infrastructure with its social remit is as a ritual.

The following chapter examines ritual as a phenomenon and tests its utility as the basis of a conceptual framework for the architecture of transport infrastructure. Ritual, as we shall see, provides a useful framework for understanding value in extra-economic terms, a shift that could have a profound effect upon our transport infrastructure and 
thus our inhabitations. By identifying factors that support and enrich pre-commercial relationships, ritual offers a corrective vantage to the instrumental view that restricts our understanding the value of our transport infrastructure. 



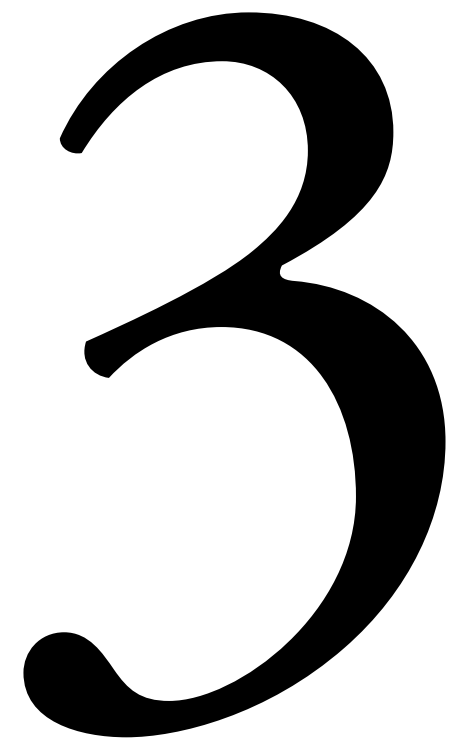

AN ALTERNATIVE FRAMEWORK

- Ritual as a Conceptual Framework for the Architecture of Transport Infrastructure - 


\section{RITUAL}

Components of concept: Action Symbol Symbolic Interaction Theory

Fig. 01 - Diagram explaining structure and hierarchy of chapter three 
"When he began his design for the Library at Phillips Exeter Academy, Louis Kahn first asked himself what a library should be. His goal, at least in part, was to discover the essential meaning of "ibrary" and to let this meaning guide his design process." (Wiggins 1997: 11).

$\mathrm{T}_{\mathrm{h}}$ he inadequacies of an instrumental framework for transport infrastructure, as discussed in the previous chapter, give cause to ask fundamental questions about the nature and remit of such works. Following the example set by Kahn in approaching the design of Phillips Exeter Academy Library, this research asks what is the meaning of "commute"?, with the aim of generating an alternative conceptual framework for transport infrastructure.

We can quite reasonably state that the commute is in essence an event concerned with the movement of people into and out of the city. Conventional wisdom holds that this is a purely instrumental concern and the commute as a result is ultimately considered a disutility to be mitigated as much as practicable. Yet recent research has shown that the commute actually represents a valuable parcel of time to the commuter that is imbued with symbolic qualities.

This chapter frames the commute as a ritual and explores the implications and potential benefits of doing so, thus proposing an alternative conceptual framework for transport infrastructure. This is achieved through an examination of the concept of ritual itself, with particular reference to the role of ritual in secular life. Ritual is necessarily broken down into its constituent parts, identified as action and symbol, and these components are explored using the sociological theories of performativity and symbolic interaction. These are subsequently assessed for their architectural potential. 
The additional, resultant ritual qualities of liminality and mnemonic are in turn introduced as concepts related to action and symbol respectively to further embellish and differentiate the proposed conceptual framework.

Ritual, as we will see, is a valid, poorly understood, and undervalued aspect of contemporary secular life. Furthermore, it offers spatial cues to an architecture of transport infrastructure that can enrich our lives in a way the instrumental framework fails to achieve, and fulfil the remit of transport infrastructure as a sociocultural device.

\section{RITUAL}

"Cultures are most fully expressed in and made conscious of themselves in their ritual..." (Schechner and Appel 1990: 1).

Ritual is an essential element of human practice, whether the subject of that ritual is sacred or secular, grand or mundane. As one of the primary mechanisms by which human beings generate, question, and affirm culture, ritual enriches daily life by communicating cultural meaning and framing identity.

Yet the significance of ritual in contemporary society is poorly understood, and as a 
result the term often used as a mere "synonym of habit" (Augé 2002: 27). Furthermore, the spatial implications of ritual, particularly in a secular urban setting, are to date inadequately addressed by architectural research and practice, which "... has generally ignored the topic of ritual" (Kohane 2001: 87).

This dearth of precedent suggests that an investigation of the nature and function of ritual itself is necessary if we are to adequately define and implement it as a conceptual framework for the architecture of transport infrastructure.

\section{BREADTH OF THE CONCEPT}

"Rituals have been considered: 1) as part of the evolutionary development of animals; 2) as structures with formal qualities and definable relationships; 3) as symbolic systems of meaning; 4) as performative actions or processes; 5) as experiences. These categories overlap." (Schechner 1993: 228).

Traditionally associated with the sacred or mystical, ritual has more recently been discussed by sociologists and anthropologists as a meaningful part of secular life. It would be reasonable to suggest that, in effect, the declining relevance of religion in 
society has exposed the base function of ritual as a cultural agent ${ }^{3}$.

The description of ritual in the quote that introduces this section and graphically in figure 02 is indicative of the breadth that the concept has achieved since released from a dogmatic association with religion. Indeed, the identification of ritual in secular life has lead to an almost ridiculous expansion of activities that fall within its boundaries. For example, it has been argued that the concept encompasses activities such as "teeth cleaning" and "taking the dog for a walk" (Bocock 1974: 15).

The implication is that ritual has grown to include "[a]ny ordinary behaviour transformed through sequencing, repetition, and rhythm into a structured event" (Tiwari 2010: 16). Such a loose definition, as Jack Goody has argued, results in a “... disutility of the concept of ritual" (Moore and Meyerhoff 1977: 27). Goody goes on to ague that when so much of human practice can be identified as ritual, “... what's the point? We then have a category that includes almost all action that is standardized in some way or other, and we then have to begin all over again breaking it down into some more meaningful categories" (ibid).

\footnotetext{
${ }^{3}$ While a discussion of this hypothesis falls outside the scope of this research, recognition of this phenomenon is useful in identifying the continuing relevance of ritual.
} 


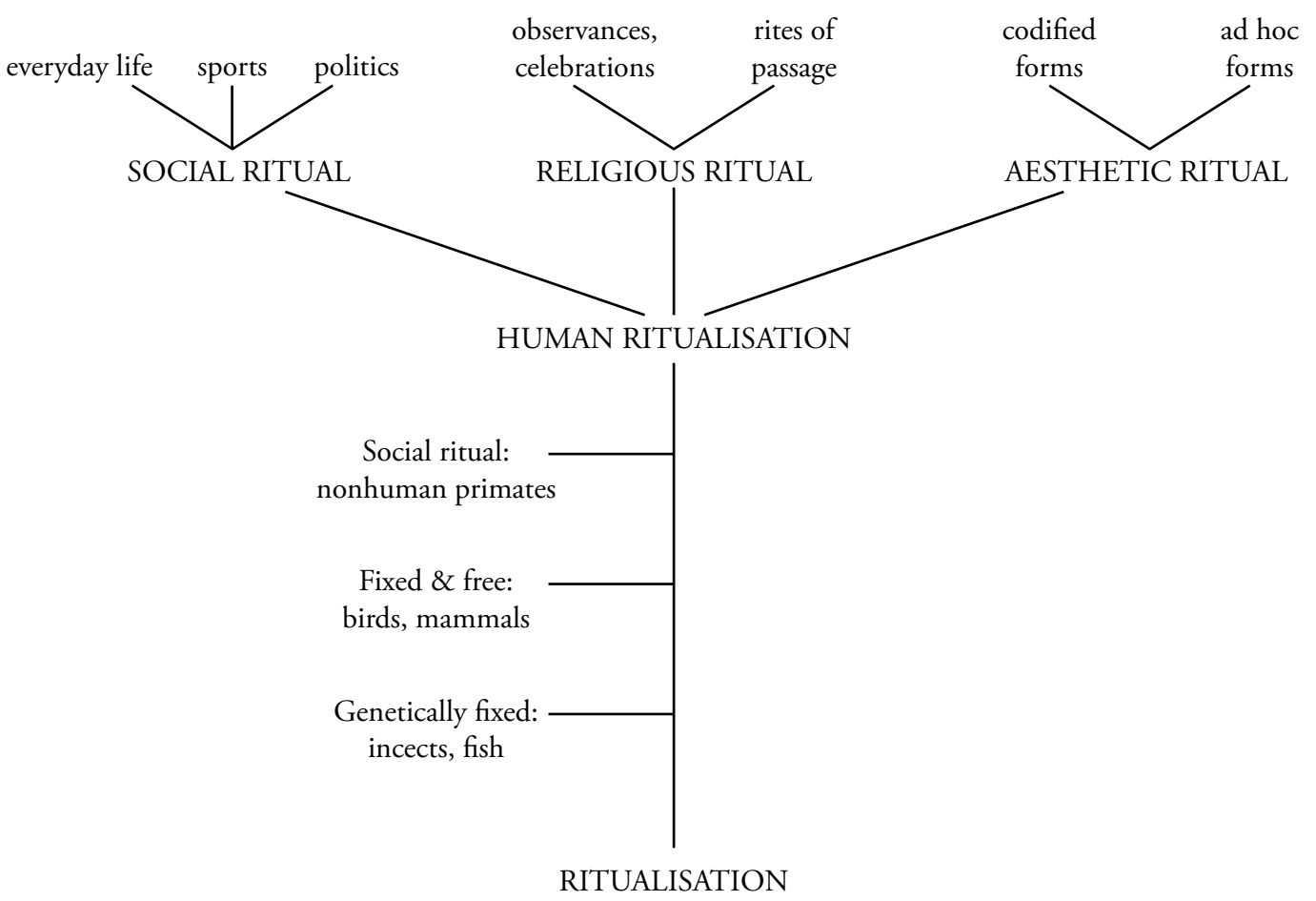

Fig. 02 - 'Ritual Tree' adapted from Richard Schechner's The Future of Ritual (1993). 


\section{DEFINITION}

The disutility of the concept of ritual that Jack Goody describes as resultant of its expanding scope calls for an examination of ritual's basic function in order to achieve useful definition.

The central role of repetitive action in ritual has been established. Willem Frijhoff expresses the importance of symbolism in ritual when he states, "[r]itual spaces are symbolic spaces. There can be meaning (i.e. myth, legend) without ritual, but there is no ritual without meaning" (Mare and Vos 1993: 93). The addition of the symbolic criteria adds a valuable dimension to the concept of ritual, and we can thus state that sequential, repetitive, and rhythmic action in relation to the symbolic constitutes ritual.

Robert Bocock captures this neatly when he argues that, "[s]imply expressed, 'ritual' is ... bodily action in relation to symbols." (1974: 36). Bocock's definition is adopted for the purposes of this research and is simplified further to the equation ritual $=$ action + symbol. Case study one examines a rare, and elemental, expression of this in architecture.

One could reasonably argue that the symbolic is subjective, that for some individuals teeth cleaning may hold symbolic value beyond its hygienic function. Ritual's communal nature is also worth considering here as it further clarifies the concept in relation to 


\section{CASE STUDOY I}

\section{Phillips Exeter Academy Library, Indianapolis}

Frank E. Brown and Louis Khan provide an exception to the poverty of ritual expression in secular architecture, and in doing so confirm the definition of ritual provided by Bocock as action + symbol. As Peter Kohane writes, the Phillips Exeter Academy library, New Hampshire, exemplifies Kahn's interest in the spatial implications of ritual.

As Kohane states, "[f]or Brown and Kahn, a ritual involves action of some sort" (2001: 92). An example of the architectural application of this is evident in Khan's Exeter library, where “... movement to the light and the act of reading in its presence were two facets of an inspired ritual" (Ibid: 93). Glen E. Wiggins expresses the elemental nature of this when he states that, "[i]n many ways this seemingly simple statement describes the Library's entire design" (1997: 11).

The Exeter example can thus be read as a basic spatial expression of ritual's fundamental action + symbol equation, with light playing the role of key symbolic entity and movement into that light as the action. The apparent simplicity of the arrangement has the effect of rendering the ritual generic enough to both facilitate interpretation and appeal to the broader spectrum of secular society.

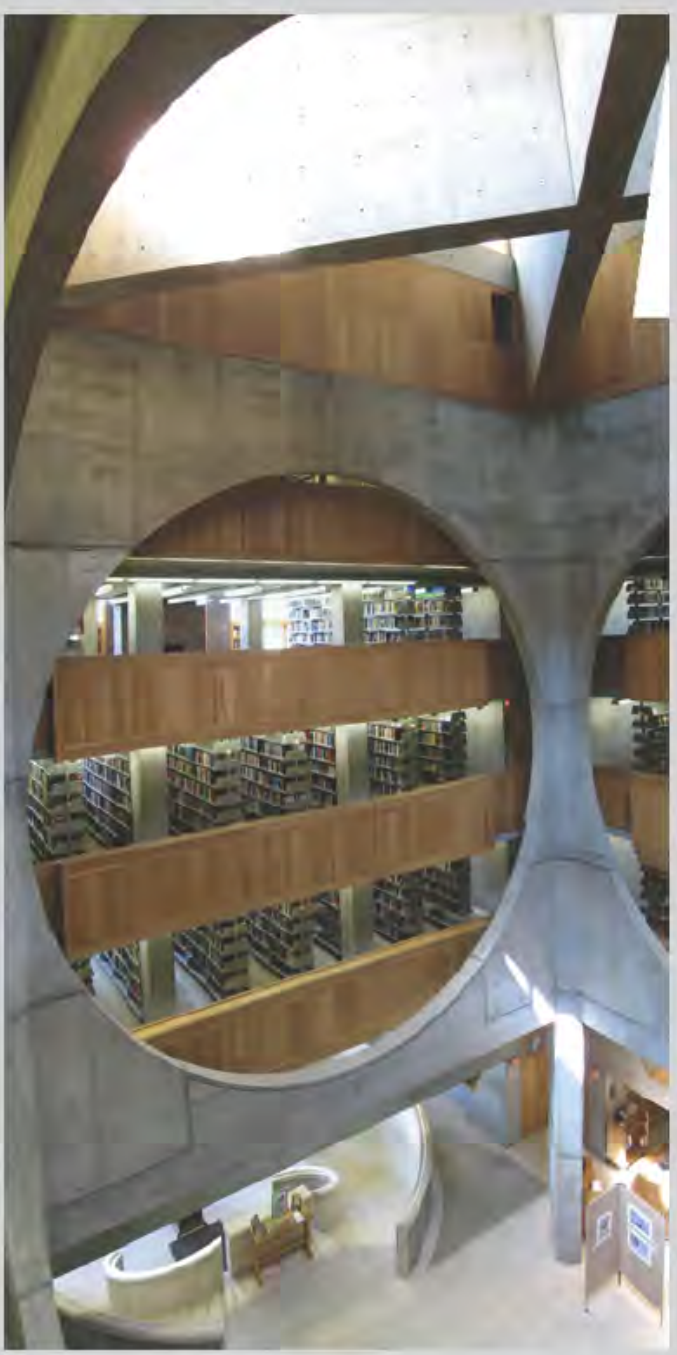

Fig. 03 - Phillips Exeter Academy Library 
this subjectivity. As Bocock states, ritual “... involves groups of people who share some sets of expectations in common..." (1974: 36), suggesting that the symbolic in ritual is representative of a communally held beliefs or aspirations. This is particularly valid when discussing something as communal as transport infrastructure.

\section{RITUAL IN CONTEMPORARY SOCIETY}

"In everyday life, we tend to use the word ritual for what goes on in a cathedral, but not for activities associated with the bicycle shed. For anthropologists, however, there is no easy distinction; repeated and ordered behaviour is everywhere and always has meaning." (Jones 1996: 22).

Despite being so widespread, relatively little has been written about the role of ritual in contemporary secular life compared to the wealth of information garnered from the study of 'exotic' cultures by the sociological and anthropological fields ${ }^{4}$.

\footnotetext{
${ }^{4}$ This brings into view the tendency of anthropology to focus on exotic cultures, which is the basis of much critique of the field.
} 
Of particular relevance to this research is a recognised poverty of writing on the spatial implications of ritual. As Jan Pieper has commented, "[c]ompared to the enormous bulk of social anthropology, very little consideration has been given to the physical and spatial aspects of cultural phenomena, such as settlement patterns, urban ritualism, ... and culture-specific habits related to the built environment." (Melhuish 1996: 7).

The anthropologist Marc Augé is perhaps the foremost exception to this rule. In particular, his writing on the Paris Metro (Augé 2002) is relevant in that it explores the cultural significance of transport infrastructure as a quotidian entity encountered in contemporary occidental life 5 .

While Augés analysis is focused particularly on the Metro, he acknowledges the generic quality of the phenomena he describes thus; "Except for a few cultural details and a few technological adjustments, every society has its subway, and imposes on each and every individual itineraries in which the person uniquely experiences how he or she relates to others." (Augé 2002: 70).

\footnotetext{
${ }^{5}$ In particular Augé writes, "Were we to speak of ritual in respect to subway trips, and in a meaning different from what the term takes in common expressions when it is devaluated, a simple synonym of habit, it would perhaps be on the basis of the following observation, which sums up the paradox and the interest of all ritual activity: recurrent, regular, and without surprise to all who observe it of who more or less passively are associated with it, it is always unique and singular for each one of those who are more actively involved." (Augé 2002: 27)
} 
The poverty of anthropological study into the spatial implications of ritual has largely been reciprocated by the architectural sphere, which Peter Kohane describes as ignoring the role of ritual in architecture, as stated earlier. A lack of research into the role of ritual in contemporary urban life and its spatial implications represents a missed opportunity to enrich the experience of the modern urban environment. Furthermore, investigation of this gap has the potential to benefit both the architectural and sociological fields.

In light of the poverty of explicit architectural precedents, and following the suggesting of Jack Goody that we must " $\ldots$ begin all over again breaking [ritual] down into some more meaningful categories" (Moore and Meyerhoff 1997: 27), a discussion of the component parts of ritual follows. The goal of which is to set up some basic principles by which ritual architecture can be recognized and judged, and the relevance of framing the commute as a ritual can be further explored.

\section{ACTION}

The action component of the ritual equation refers quite simply to a purposeful movement that is sequential, repetitive, and rhythmic (a definition, it must be noted, that also broadly captures the commute event). Case study two examines Zaha Hadid's BMW Central Building as illustrative of movement as a key design driver. As suggested 


\section{BMW Central Building, Leipzig}

The BMW Central Building in Leipzig, designed by Zaha Hadid Architects, is part of a complex of buildings that house the car giant's primary production facility. The 'Central' building acts as a conduit between the previously disconnected fabrication, painting, and assembly buildings, while also accommodating new staff facilities.

As the central building was devised programmatically as a connecting device, movement between the existing buildings became the key design driver. This movement was represented graphically through the mapping of 'vectors', creating a pattern that was carried through to the realisation of the building. As project architect Patrik Schumacher explains, "[a]ll of the structure was oriented to trace the lines of movement through the building, to emphasize these linear trajectories... You will notice many instances where the steel roof beams are curved to follow the flows. These are not the most efficient ways to span these distances, but as the structure is such a major component of the visual field, we felt it necessary that it work beyond its role as support to become an orienting device within the space." (Spencer 2010: 203).

Such a method provides an apt precedent for this research, not only for addressing the technical requirements of circulation necessary in a transport building, but in particular for addressing the 'action' component of the ritual equation. In effect, the vector mapping method exemplified by the BMW Central Building promotes movement through a space to the front end of the

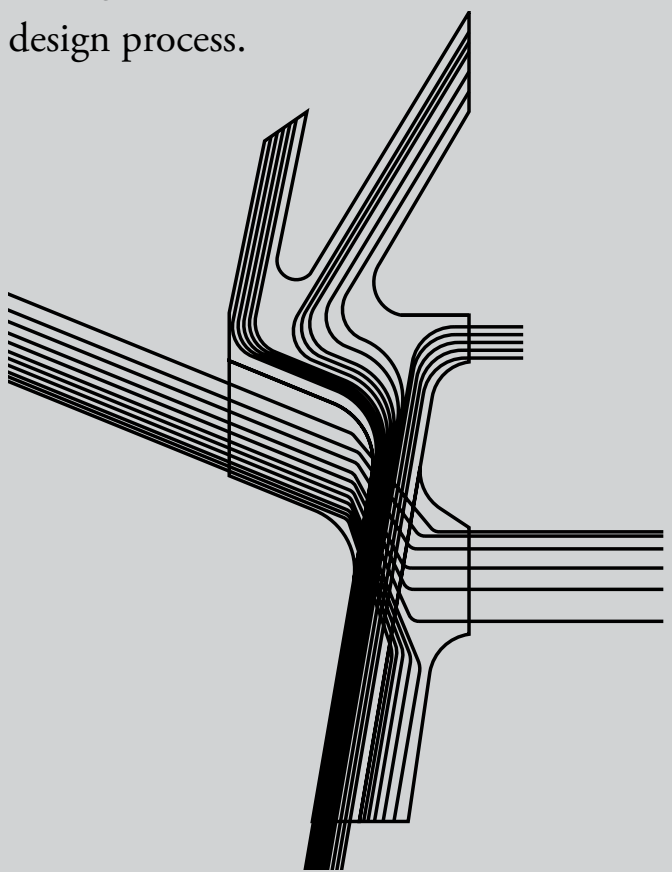

Fig. 04 - Vector diagram of flows between areas of fabrication at BMW Leipzig 
by Linda Steg's studies, this movement is not purely instrumental - movement in the commute carries meaning beyond its utilitarian function.

The repetitive, meaningful movement of ritual finds a secular analogue in the theory of performativity, as evidenced by Judith Butler's description of performativity as “... reiterative and citational practice" (1993: 2) ${ }^{6}$. Performativity describes the normative, agentic relationship of language and other expressive phenomena (including body movement) to culture. As such performativity is one important sociological theory that considers meaning in body movement, and is adopted here as a means of investigating movement in the commute as a valuable phenomenon in itself, in contrast to the instrumental view.

\footnotetext{
${ }^{6}$ While Butler (who's work was carried out in the gender studies field) writes in reference to the performative function of language, a similar effect has been identified in movement (see Farnell 1999, Schechner 1990 and 1993, for example).
} 


\section{PERFORMATIVITY ${ }^{7}$}

“... [DJynamically embodied signifying acts... in symbolically rich spaces are the dialogical, intersubjective means by which persons, social institutions, and cultural knowledge are socially constructed, historically transmitted, and revised and so are constitutive of culture and self" (Farnell 1999: 344).

As Brenda Farnell states above, the manner in which we move carries a wealth of sociocultural information. When this movement becomes habitual it functions as a performative act. The repetition that forms habit (which is also fundamental to ritual, and evident in the commute) is central to the concept of performativity, as “... performativity must be understood not as a singular deliberate "act", but, rather, as ...reiterative and citational practice ...” (Butler 1993: 2).

\footnotetext{
${ }^{7}$ The relationship of performativity to ritual has been discussed by Susanna Rostas, who states that ritualisation "...lies at the heart or core of performativity. It constrains performativity but is at the same time affected by it: the two are in a dialectical relationship to each other. And it is performativity that enables ritualization to change". (1996: 21). Within the context of this research, performativity is merely used to discuss the function of action in a secular ritual.

${ }^{8}$ Butler here refers to the related sociological field of performance studies, which is differentiated from performativity by the latter's banality. Reena Tiwari expresses this another way when she states that, "... ritual is an event upon which its participants depend; theatre is an event which depends on its participants" (2010: 18).
} 
Movement as performative action is a deeply entrenched and common aspect of human practice, as Farnell explains, "[h]uman beings everywhere engage in complex structured systems of bodily action that are laden with social and cultural significance" (1999: 343). When viewed from this perspective, bodily movement can be seen as part of a system of practice that is concerned with the fundamental generation of culture and definition of social groups.

This implies that movement as performative action is normative, as Butler suggests when she defines performativity as "...that reiterative power of discourse to produce the phenomena that it regulates and constrains." (1993: 2).

Framing movement in the commute as a performative action helps to focus our attention on the space between two places, and leads to an understanding of the importance of transport infrastructure that the instrumental framework fails to capture in construing this movement as a disutility. 


\section{PERFORMATIVITY AND ARCHITECTURE}

"Ritualized bodies appropriate and write the socio-cultural aspects on the built environment. The city is thus written by the inhabitants' action" (Tiwari 2010: 26).

The subject of body movement as performative action is not restricted to culture, but extends to our understanding of the built environment. Simon Parker suggests this when he states that, "[d]ifferentiations [and conversely similarities] of cultural, symbolic and social capital are deeply inscribed into the urban unconscious, not just in the cultural practices of various classes and social groups or the symbolic worth of different urban sites, but also in the bodily rituals of how people stand, walk, talk, dress, flirt, or argue" (Parker 2004: 143).

Just as the relationship of body movement to culture can be described as a dialogue, the relationship between culture and architecture can similarly be framed. Smith and Bugni express this when they state that, "Winston Churchill reflected a double reality about architecture when... he made the simple observation, "We shape our buildings and afterward our buildings shape us." We could appropriately extend the quote to read "and then after use, we may choose to shape the buildings still again..." (2006: 132). 
Thus bodily movement, through culture, is in an affective relationship with the built environment.

The most basic spatial implication of movement as performative action is a visual connection, as captured in common parlance by the phrase 'people watching'. When framed a performative action, people watching during the commute takes on new meaning.

The built environment provides the context of this visual relationship and in doing so performs a crucial function in the performative action. To address this Brenda Farnell quotes Best as stating that, " $[\mathrm{M}]$ ost of what we may want to know about a person's intentional action cannot be understood by a narrow concentration upon his physical movement but by... standing back from it and seeing it in context" (Farnell 1978: $360) .{ }^{10}$

\footnotetext{
${ }^{9}$ People watching is an important part of the commute, as implied by a recent empirical study that found “...93\% of commuters who were 'polychronic' (undertaking one or more activities at the same time as travelling) were listening to music/radio, window gazing/people watching, and chatting with people around them." (Wallis and O'Fallon 2012: 8).

${ }^{10}$ Best here discusses context of action in the same way a quote is contextualised within a broader passage. The close relationship of the built environment and culture renders architecture relevant in this consideration.
} 


\section{PERFORMATIVITY AND THE COMMUTE}

Under the instrumental framework for transport infrastructure the commute represents a period of non-productive time that additionally incurs a financial cost to the user, and thus is construed as a disutility to be minimized as much as practicable.

However, the presence of 'non-productive' time in our day is actually of significant value. Barry Schwartz elucidates this when he describes waiting (one of the types of 'pauses' Snow and Brissett identify) thus: “The waiting period (pause),... is not merely a residual phase - a quantum of time representing default in the coordination of the end of one activity with the beginning of another; rather this phase contains its own functional justification,... Waiting periods (pausing)... represent part of the connective tissue by which interactions are held together and ordered, according to the principle that the temporal separation of engagements constitutes the very condition of their inner coherence." (Snow and Brissett 1986: 3).

This is represented empirically by the finding that, "[o]ne-third (33\%) of commuters were contented with their time spent commuting, enjoying it and finding it a useful transition between work and home." (Wallis and O'Fallon 2012: 9), which suggests that many commuters value the commute in a way not captured by the instrumental framework. 
The view that the commute represents a rarified parcel of 'non-productive' public time, and that this period is instrumental in the generation of culture, suggest that transport infrastructure may function in secular society as the church does in religious life. The decline of religious practice and its communal social rituals leaves precious few occasions for ritualised physical interaction; the commute is one of the most potent of these.

As a rarefied parcel of time in contemporary urban life within which this performative action occurs, the commute can be seen to play a vital sociocultural role. The movement of thousands of people - over 30,000 in Wellington City's case (Statistics New Zealand 2006: 2) - into and out of the city each working day at roughly the same time intensifies physical interaction, which through a performative lens is socioculturally constitutive, both spatially and temporally. Transport infrastructure provides the context within which this paradoxically dramatic and banal event unfolds.

\section{PERFORMATIVITY AND TRANSPORT INFRASTRUCTURE}

Sociologists and anthropologists have established the performative action of movement, discussing this in relation to the breadth of bodily movement, from facial expression to gait. 
The preceding sections of this thesis on performativity imply that this action is also evident in passive modes of transport - that the mechanical means by which our bodies are moved exhibits a similar performative effect to the 'organic' movement discussed by sociologists and anthropologists.

In this light, transport infrastructure takes on radical new meaning - rather than merely an instrument of the economy, it becomes an essential part of the mechanism of sociocultural generation and affirmation.

\section{IN SUMMARY}

Framing movement in ritual as a performative action is beneficial in identifying the commute as a period that holds sociocultural value in itself, and thus an alternative value in transport infrastructure. However, the spatial criteria this generates - essentially space to move, be seen moving, and watch others move - does not differ significantly from that created by the instrumental framework; transport infrastructure already achieves this.

The processional, transformative nature of ritual action and the commute offers spatial cues as to how this movement may be expressed architecturally in a manner that differs from, or builds upon, that already evident under the instrumental framework. 


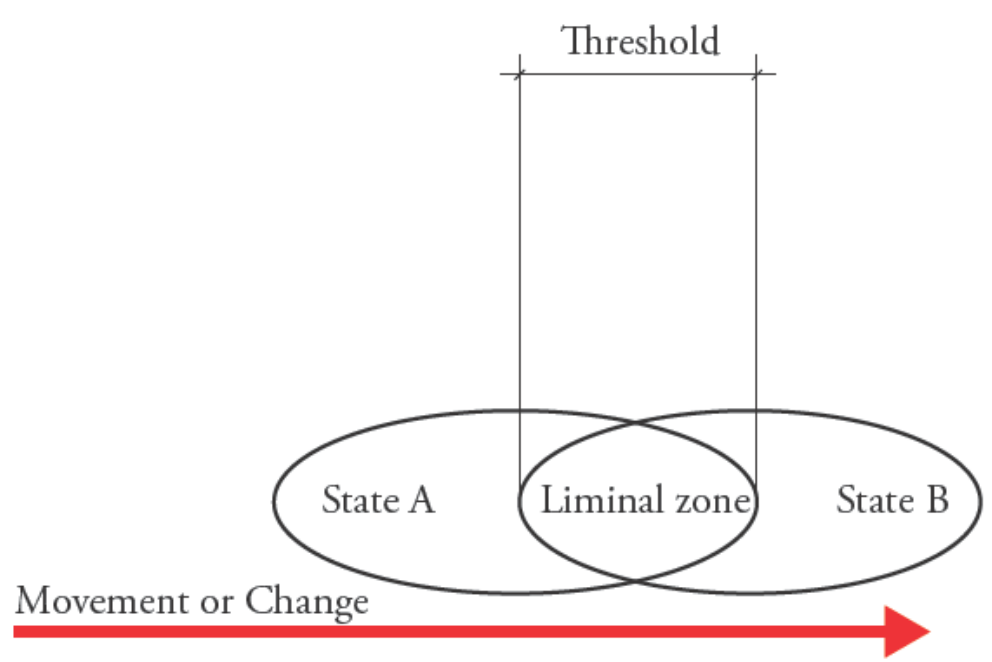

Fig. 05 - The processional nature of ritual implies liminality, as expressed in this diagram. 


\section{LIMINALITY}

Liminality is "... a matter of giving recognition to an essential and generic human bond, without which there could be no society." (Turner 1995: 97)

The processional, transformative nature of ritual action can be described as entailing movement across a threshold, from one state to another (figure 05). Victor Turner describes this quality as liminality, a term derived from the Latin 'limen' signifying "threshold". Paraphrasing Schechner and Appel, Tiwari defines liminality as, “...the process of transformation at work. It is a movement from one mental state to another..." (2010: 29), although the shift may be physical, as in a pilgrimage.

While the instrumental framework construes the commute as a geographic barrier to be overcome, the value of the commute as a period of metaphysical transition is not lost on the commuter. "The reason that people enjoyed their commute included [amongst other reasons] it being a transition time..." (Wallis and O'Fallon 2012: 8), suggesting the value of the commute as a space-time where a change in mental state can occur.

Liminality implies particular, and peculiar, spatial qualities as Victor Turner suggests when he describes liminal entities as "...neither here nor there; they are betwixt and between..." (1995: 95). The liminal aspect of the commute advocates an ambiguity that has architectural potential, as case study three illustrates. 


\section{SYMBOL}

In a ritual, the action described previously takes place in relationship to a symbolic entity. Symbolic interaction theory is one way of understanding the function of symbol in secular society and architecture, and is adopted here as a means to explore the symbol component of the ritual equation.

\section{SYMBOLIC INTERACTION THEORY}

"As one of the primary theoretical perspectives within sociology, symbolic interaction helps to explain fundamental connections between architecture and human thought, emotions, and conduct" (Smith and Bugni 2006: 124).

Symbolic interaction theory, as defined above, explores how symbols affect the individual and are thus influential in forming and defining identity.

Symbolic interaction theory argues that the "...designed physical environment is not merely a backdrop for our behaviour. Quite the contrary, because some designed physical buildings, places, and objects act as agents to shape our thoughts and actions..." 


\section{CASE STUDY III}

\section{Itsukushima Shrine, Hatsukaichi}

Itsukushima Shrine is a $16^{\text {th }}$ century Shinto shrine located near Hiroshima, Japan. The complex of buildings sits in the littoral zone, which can be understood as analogous with the liminal (a transitional space between land and sea). Positioning the complex in the tidal zone introduces an ambiguous quality to the architecture - sitting between land and sea, the shrine possesses qualities of both, but resists definition as belonging to either.

Itsukushima also exemplifies the processional quality of liminality. Pilgrims must approach the shrine through the gate (torii) that stands at the seaward edge of the littoral zone, which represents the first threshold of the shrine and forms a strong directional axis.

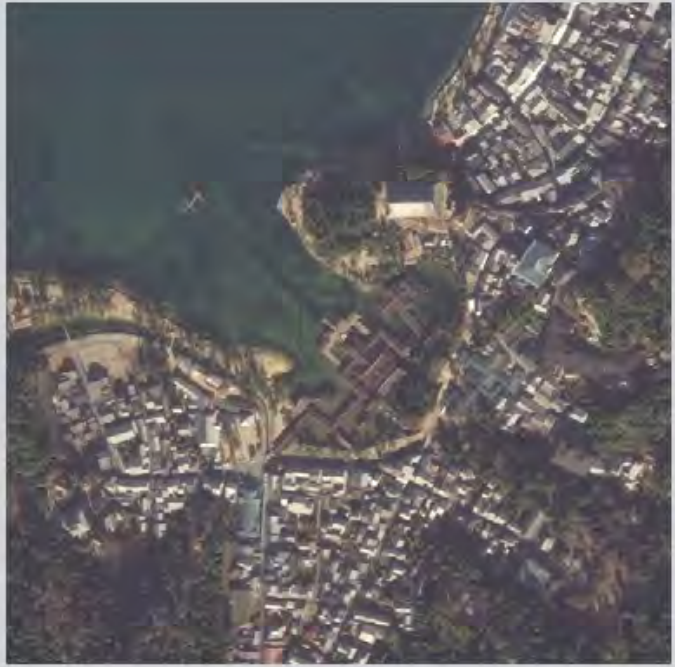

Fig. 06 - Satellite image of Itsukushima Shrine

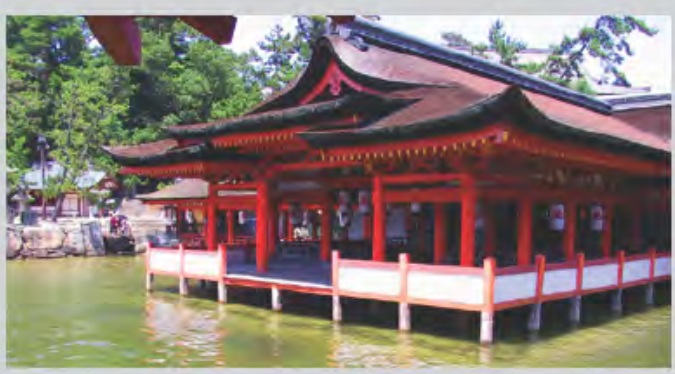

Fig. 07 - Itsukushima Shrine at high tide

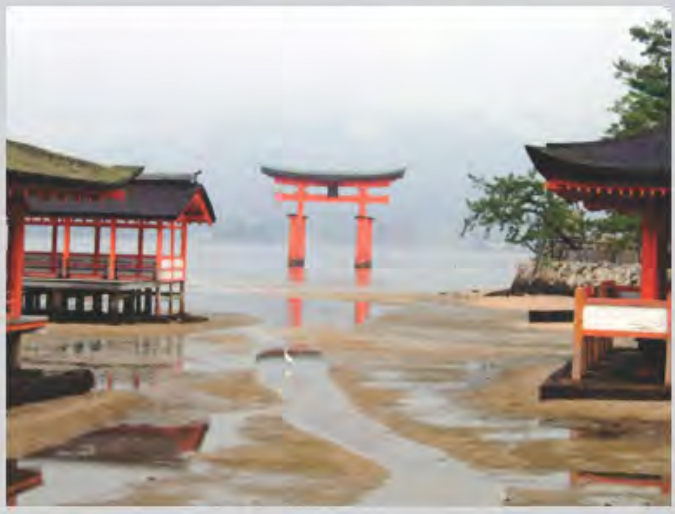

Fig. 08 - Itsukushima Shrine torii at low tide 
(Smith and Bugni 2006: 124) ${ }^{11}$.

Smith and Bugni go on to quote Mary Jo Hatch who states that, "[t]hose who adopt the symbolic view see the physical structure of an organization as shaping and maintaining a system of meaning that helps organizational members to define who they are and what they are doing" (2006: 133). If we frame cultural groups and society itself as 'organisations', this quote (particularly in relation to the view of transport infrastructure as symbolic) offers an alternative understanding of the role and function of transport infrastructure.

In particular, the symbolic view brings to mind Marc Augés argument that, "Except for a few cultural details and a few technological adjustments, every society has its subway, and imposes on each and every individual itineraries in which the person uniquely experiences how he or she relates to others." (Augé 2002: 70).

While symbols are influential in forming identity, it is worth noting that symbols do not merely dictate meaning, forging identity in the individual and the collective. Related to the performative, dialogical relationship of movement and culture to the

\footnotetext{
${ }^{11}$ This quote bares similarity to the earlier discussion of performativity and architecture. I have found no evidence that the two concepts (symbolic interaction theory and performativity) have previously been linked.
} 
built environment discussed earlier, symbols are constantly changing meaning, both in their interpretation and communication. As suggested by the Britomart case study that follows, this has implications for the deployment of symbol as an architectural tool, particularly as a ritual device. That is to say, the deployment of symbol should be sensitive to the fluid nature of symbolism as a social agent.

\section{SYMBOL IN TRANSPORT}

"Architecture works with cultural and social variables as well as with physical materials, and architecture's capacity to signify ${ }^{22}$ is one tool available to the architect working in the city." (Allen 1997: 53).

Symbol operates at a number of levels in transport infrastructure. At a meta level, the symbolic power of mobility itself is apparent, as Hoete suggests when he states that, "[m] obility is an indicator of quality of life..." (2003: 20).

At the other end of the scale, individual modes of transport carry symbolic weight. Linda Steg argues the symbolic is most potent in the private motorcar, which she

${ }^{12}$ To symbolise is here defined as to signify the abstract. 
describes as “... a symbol of freedom and independence, a status symbol...” (2003: 27). The symbolic value of other modes is less well explored, but can be inferred from the work of Augé.

Furthermore, symbolic power in transport is a greater factor than conventional wisdom suggests, as indicated by Steg's rather surprising conclusion to her study that, “... commuter car use was most strongly related to symbolic and affective motives, and not to instrumental motives" (2005: 147).

\section{SYMBOL IN TRANSPORT ARCHITECTURE}

A cursory examination of transport buildings shows that the deployment of symbolism is key to the typology - the embellishment of buildings such as Wellington Railway Station and, more recently, Britomart Transport Centre (amongst many other local and international examples) is representative of this. Case study four illustrates how symbol has been deployed the latter, New Zealand's most recent example of transport architecture.

As this case study suggests, such works raise questions concerning the symbolised in ritual architecture - most interestingly, is the mere presence of symbol sufficient, or is the symbolised material? 


\section{Britomart Transport Centre Railway Station, Auckland}

Auckland's Britomart Transport Centre, by Jasmax Architects in partnership with Mario Madayag Architecture, is exemplary of high symbolic expression in transport buildings. Conceived with the remit of promoting public transport in Auckland city, the development incorporates a bus terminal, an underground rail terminal, and a commercial area. The rail component of the project is of particular interest to this research, as it most powerfully embodies the symbolic impetus in transport architecture (figure 09).

One of the most striking features of this interior is the series of thirteen light wells that run the length of the ceiling, illuminating the underground platforms (figure 10). According to the architect's website, these are ".. descriptive of Auckland's many volcanoes" (Jasmax). The relevance of volcanoes to commuter rail raises the question of the symbolized in transport architecture - is the symbolized important, or is the mere presence of a symbol sufficient?

The abstraction of a local geographical feature deployed as a symbol could be read in many ways. It could well be argued that this is a mnemonic descriptor of place. Or, perhaps less convincingly, a reference to the relationship of geography to transport infrastructure ("Infrastructure's medium is geography." (Allen 1997: 54)). Ultimately, the ambiguity of the reference suggests that the symbolised is secondary to the presence of symbol.

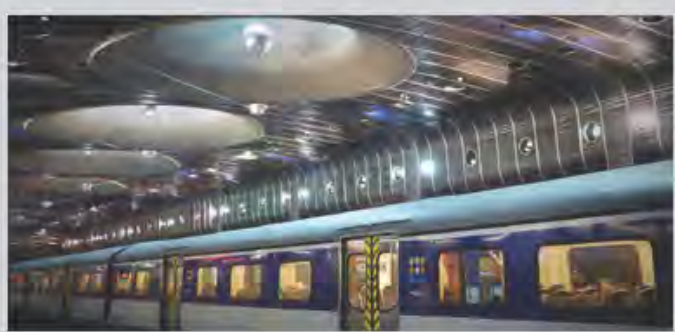

Fig. 09 - Britomart Railway Station

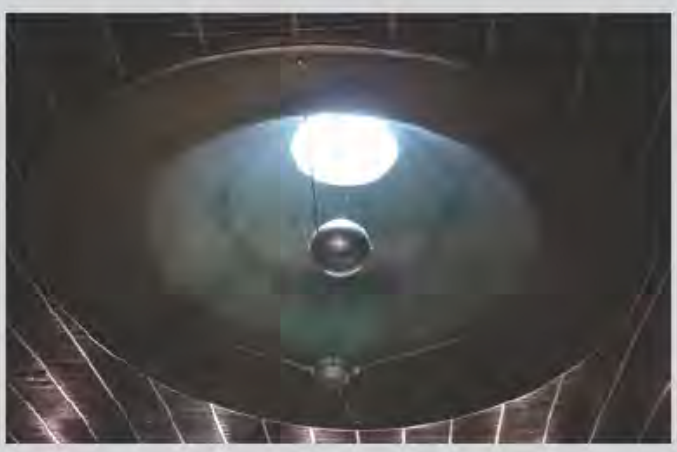

Fig. 10 - One of the volcano inspired light wells 
An in depth study of the semiotics of transport infrastructure architecture falls outside the scope of this research, which simply takes the following position:

The deployment of symbol is central both to transport architecture as a typology and to ritual architecture. In transport architecture the manner in which symbol is deployed falls within a bandwidth ranging between 1) the symbol rendered ambiguous enough to facilitate multiple interpretations, and 2) the symbolized being generic enough to elicit response in the greatest spectrum of society.

Britomart, by way of example, falls somewhere between these two statements - the symbolised is specifically the region's volcanoes (a generic identifier), yet the symbol is ambiguous enough to accommodate interpretation.

Such technicalities may well be lost on the commuter. Indeed, the mere presence of an awe-inspiring symbol appears to function perfectly well in Britomart's case. The question is well worth considering though from an architectural position, as to function as a ritual (that is, a socially constitutive phenomenon), the symbolized in transport infrastructure architecture may well need to be generic. In other words, to fulfil its broad social remit, the symbol should specifically reference common themes so that the broadest spectrum of society is included in the group that the ritual defines. 
As with the discussion of performativity and its place in the commute, the identification of symbol in transport infrastructure is limited in its architectural potential as part of an alternative conceptual framework - as the preceding sections have shown, symbol is already a functioning agent in transport infrastructure under an instrumental framework. One aspect of ritual that may prove fruitful in further defining how symbol is deployed is its mnemonic function.

\section{MNEMONIC}

As a phenomenon that facilitates sociocultural continuity, ritual exhibits a mnemonic quality. Architecture plays a central role in this, as “... buildings frame human activities by establishing a setting that acts as a mnemonic or prompter for the repeated actions that we call rituals." (Jones 1996: 22).

Despite recognition of the mnemonic function of architecture, very little has been written on the deployment of mnemonic as a design tool. One notable exception to this is Peter Fergusson's article on the treasury building at Christ Church, Canterbury, which discusses the role of history, expressed through typology in the design.

In particular, Fergusson frames the Treasury as exemplary of a design methodology intended to evoke memory through referencing of an archetype, captured by the 


\section{CASE STIUDY Y}

\section{Docks de Paris, Paris.}

The Docks de Paris project by Jakob + MacFarlane, located on the banks of the Seine in the thirteenth arrondissement, proves a useful case study for this research primarily in terms of it expression of the mnemonic potential of architecture.

The architects' decision to preserve the superstructure of the existing industrial building can be viewed as a mode of operation that expresses a mnemonic sensibility, with their intervention 'plugging over' the retained reinforced concrete frame. In this way the materiality and form of the disused building remains palpable, preserving the memory of the site's previous use.

\section{Docks de Paris functions as a major} entry point of a larger project (called the Zone d'Aménagement Concerté Paris Rive Gauche) to re-inhabit a disused industrial area. The technique has been adopted for projects throughout the site, and " $[t]$ he adaptive reuse projects of the ZAC Paris Rive Gauche reflect... [a] changing attitude and a keener appreciation for the role of industrial architecture as significant sites of collective urban memory." (Weiss 2009: 137)

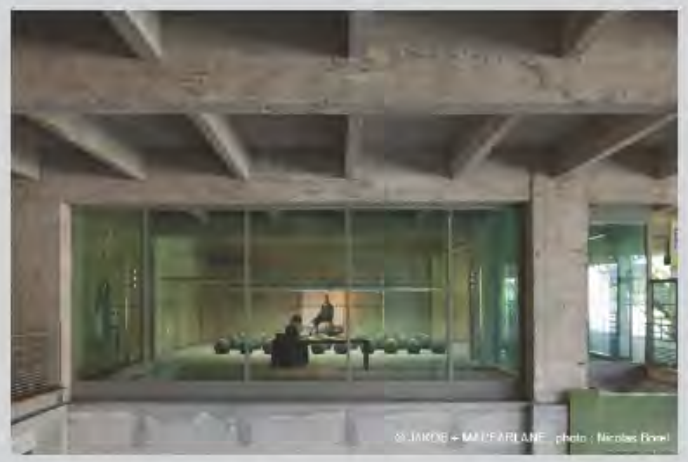

Fig. 11 - Adaptive re-use at Docks de Paris

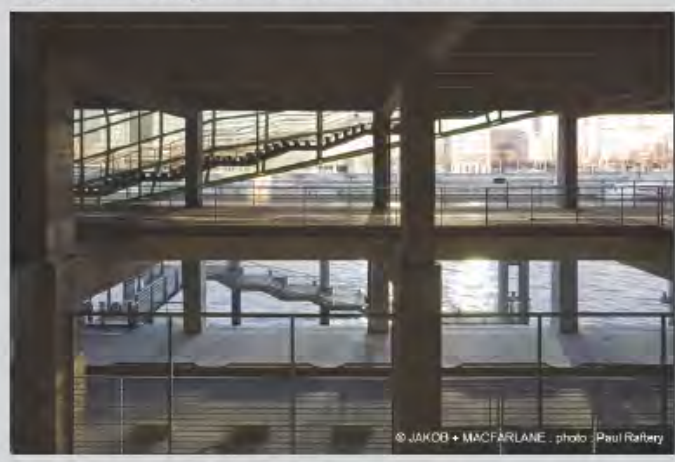

Fig. 12 - Looking through the retained super structure towards the Seine

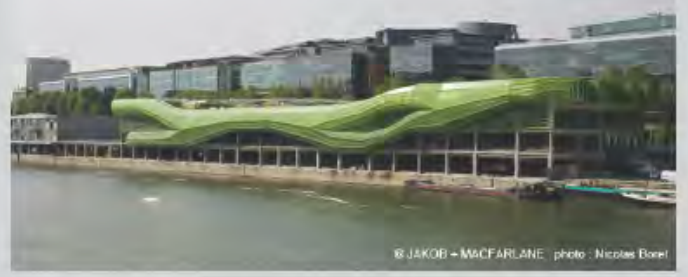

Fig. 13 - Looking across the Seine, showing the 'plug-over' concept 
statement that, "[a] building corresponding to such an archetype was intended to function as a mnemonic trigger." (2006: 64).

Such an method is problematic in relation to Kahn's approach (which has been adopted in this research) of discerning the essential nature of a program and letting that drive the design work, as the reliance on formal precedent renders engagement with an underlying purpose of the architecture less important.

Of particular relevance to the design work that follows, the mnemonic function of architecture has significant potential as a mode of operation for the adaptive reuse of urban industrial areas. Case study five shows how the perceived value of industrial heritage can be preserved through architectural means. This preservation has a mnemonic effect.

\section{IN SUMMARY}

Framing transport infrastructure as a multilayered symbolic entity helps us to identify the spaces of transit as inhabitable space deserving of greater architectural interest; space that performs an important sociocultural function. Clarity about the purpose of the symbolic in the architecture of transport infrastructure as a ritual device suggests how we might deploy symbol in an effective manner. 


\section{CONCLUSION}

Ritual is an active part of contemporary life in a very real sense. As a culture we recognise this in certain events (sporting events in particular) but rarely in the quotidian and the banal. When ritual is acknowledged in daily life its value underestimated, expressed as a mere "synonym of habit" (Augé 2002: 27). Yet structured, repetitive action in relation to an entity or space of symbolic value is part of human practice that helps us to identify collective meaning, and thus frame identity.

Ritual is thus concerned with the basic generation and affirmation of culture, and therefore can be seen as in remittal alignment with transport infrastructure - that is, the basic functioning of society. The commute clearly exhibits the key components of a ritual: the action of travelling between work and home is rhythmic, repetitive, and sequential; and this action occurs in relation to transport infrastructure, which is imbued with multiple layers of symbolic value.

As this suggests, the instrumental framework under which we currently conceive of transport infrastructure adequately accommodates this ritual. However, framing the commute as ritual implies different priorities for the spaces of mobility, priorities that have the potential to radically shift our understanding of the value of transport infrastructure to society. 
Specifically, framing the commute as a performative act that can be described as liminal (a recognised change of state between public and private selves) identifies the commute as holding value other than utilitarian and suggests a unique spatial quality (neither here nor there, as Turner describes). Likewise, discussion of symbolic expression in transport infrastructure (including, but not restricted to, individual buildings) suggests that architecture plays a central role in transport infrastructure as a sociocultural device and that this can be enhanced through deploying symbol as a mnemonic.

As explored earlier, discussion of the commute as a ritual act through the sociological theories of performativity and symbolic interaction shows transport infrastructure in a new light, but does not necessarily suggest spatial criteria that differ significantly from the instrumental framework. The introduction of liminality and mnemonic as functions of the ritual components begins to achieve this through identification and attenuation of distinctive ritual qualities present in the commute. 



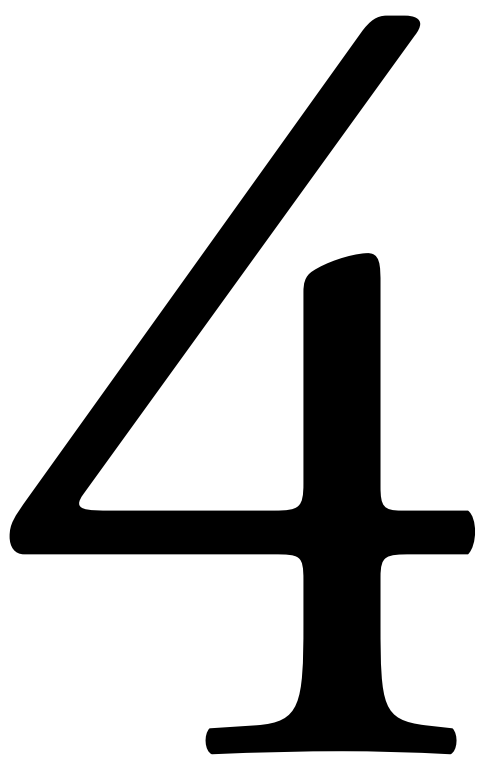

CONTEXTUAL ANALYSIS 


\section{INTRODUCTION}

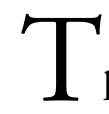

his chapter provides a brief analysis of Wellington region's transport infrastructure, its geographical and political setting, and a study of Wellington City's hub area, with a focus on public transport and in particular the role of waterborne transport in the harbour area. The goal of which is to provide the necessary background information for understanding the design work that follows in chapter five. 


\section{PHYSICAL CONTEXT}

\section{"Infrastructure's medium is geography." (Allen 1997:54)}

\section{W}

ellington City is situated on the western shore of a large sheltered harbour, Te Whanganui a Tara (Wellington Harbour), along a stretch of coast previously inhabited by several Māori pā. The harbour covers an area of 8,900 hectares, is 20 metres deep at its nadir, and 11 metres at its shallowest point near the harbour entrance. The favourable provision for transport offered by the harbour was key to both Māori and European waves of settlement.

Increasing availability of private motor vehicles and rising quality of roads saw a decline in the popularity of harbour transport during the mid-20th century, ultimately resulting in the closure of ferry services for a period . Currently, ferry services play a minor but burgeoning role in the region's transport infrastructure.

The primary commuter corridor into the city is from the north, running along a narrow strip of land between the hills and harbour. Wellington City's largest commuter groups lie to the north, and this section of motorway and railway currently plays a critical role in providing access to the city. 



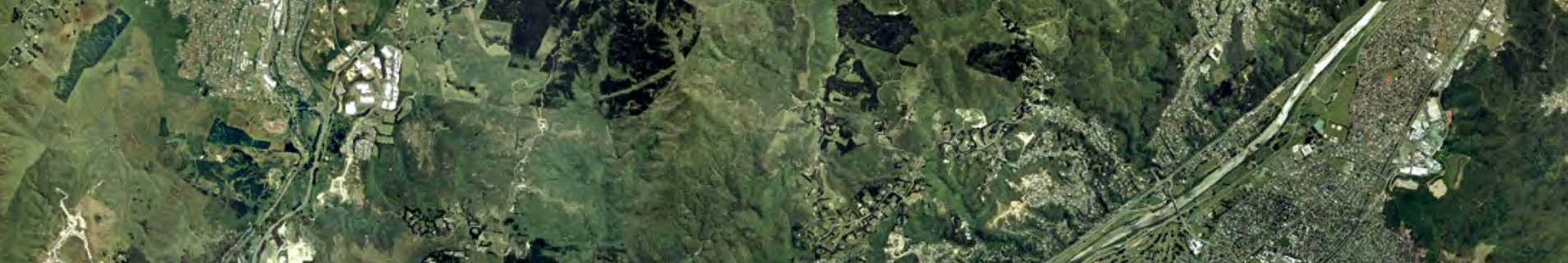

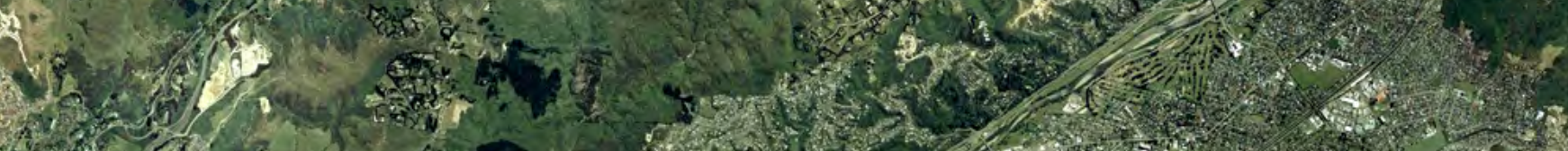

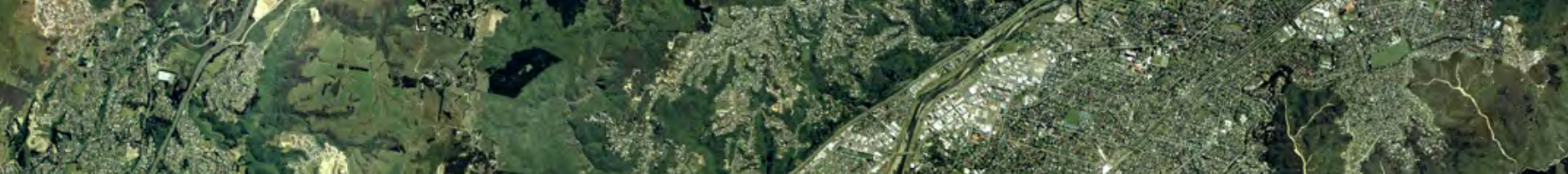

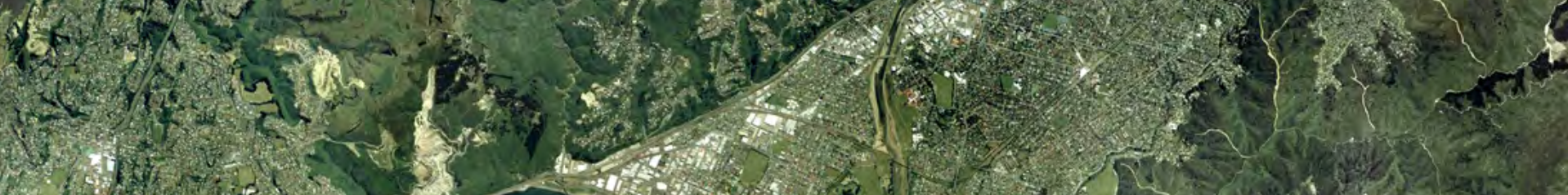

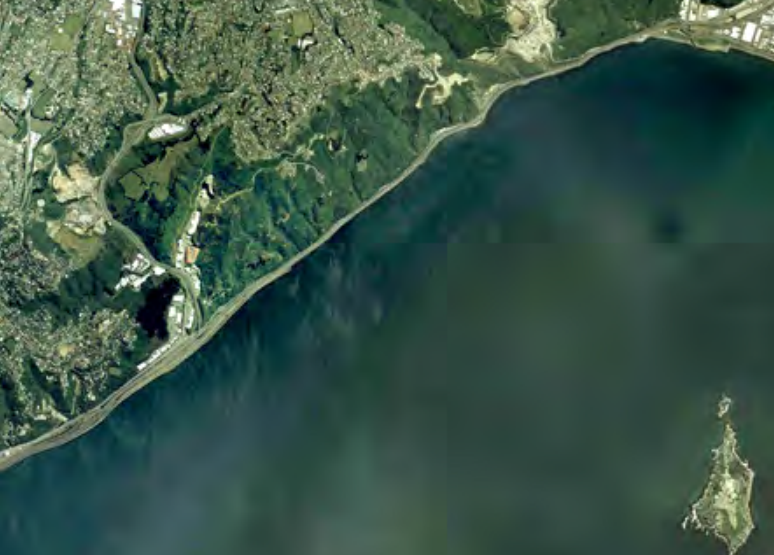

Fig. 14 - Satellite image of

south-western Wellington region showing

Wellington Harbour and context.

Wellington City is on the western shore.
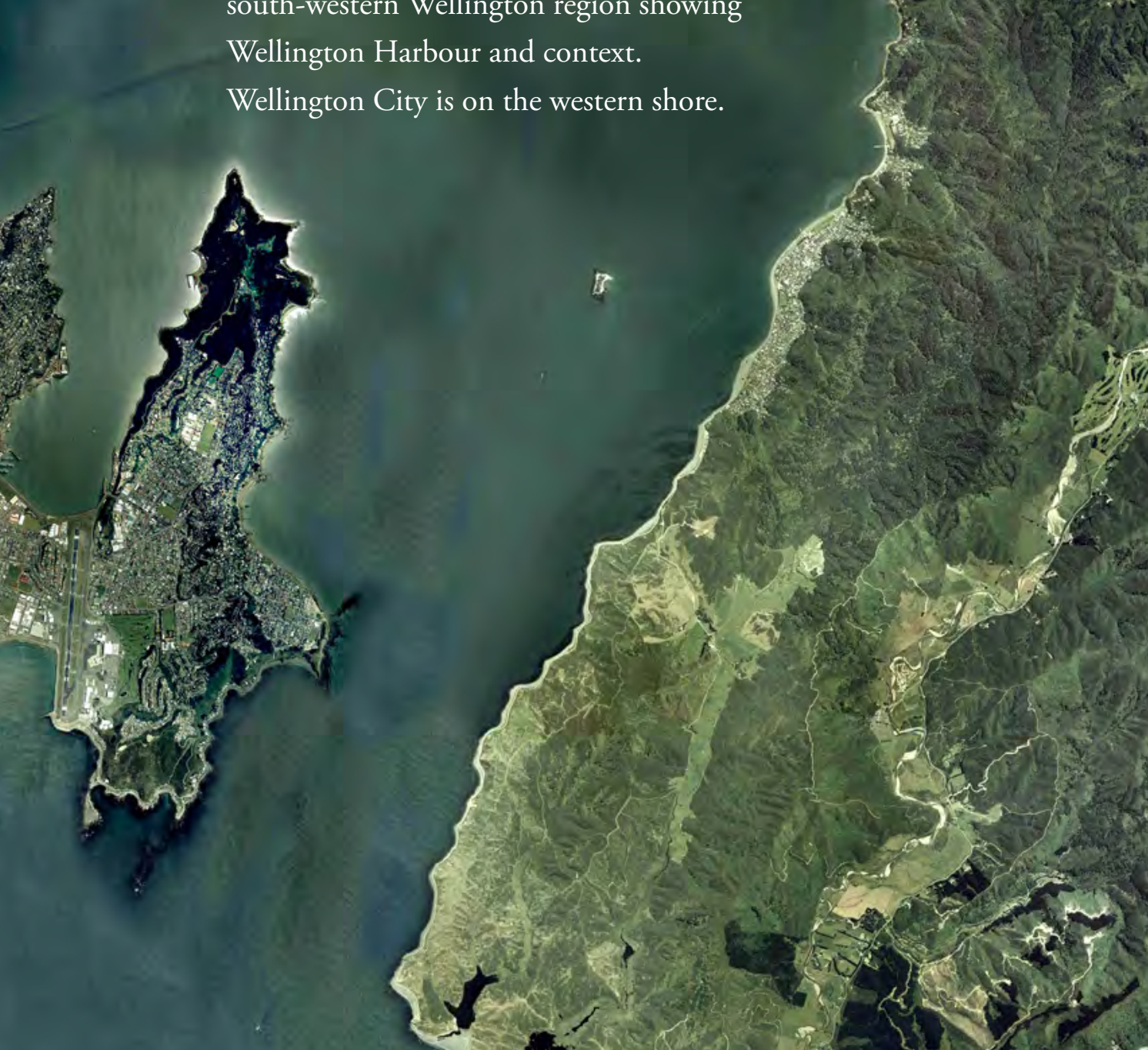


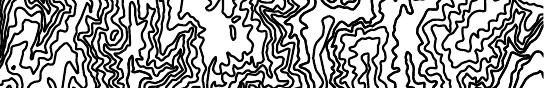

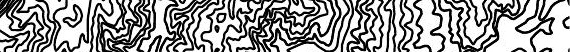
(6) 3$\}$ S b) 35 S

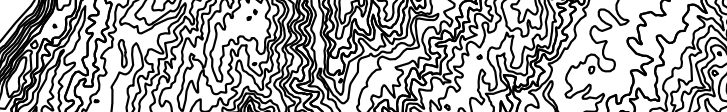
(1)

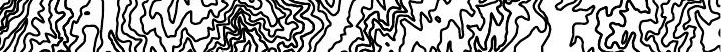
ᄂ

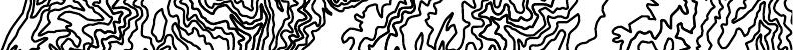

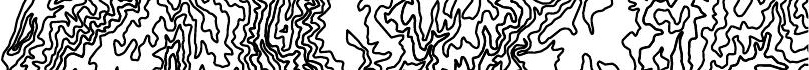
sens (3) (a)

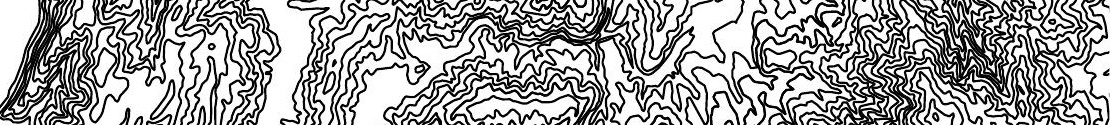

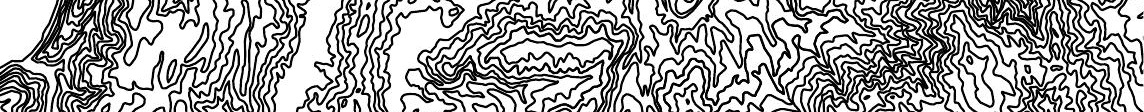
S 3)

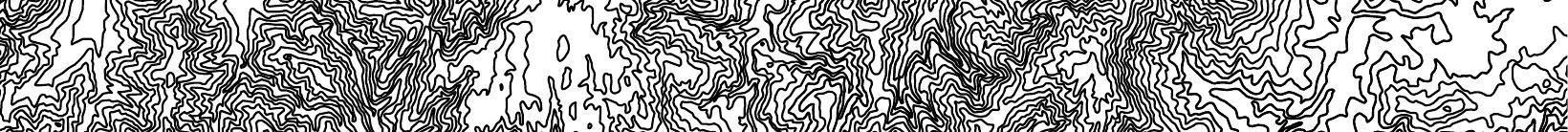
(1) (1)

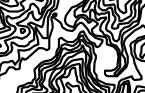

(I) S. (2)

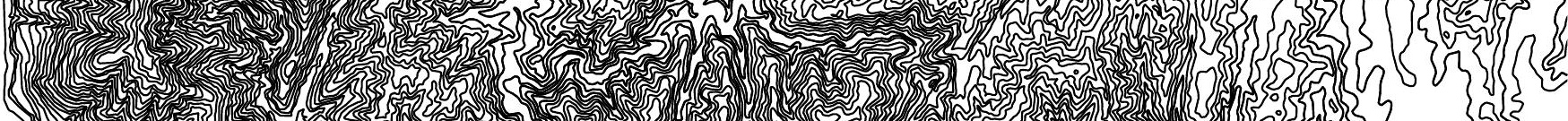
-

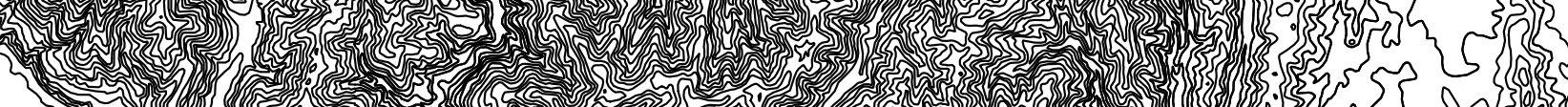
2.2.

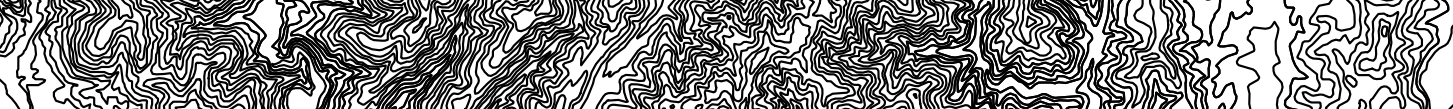
(1) 



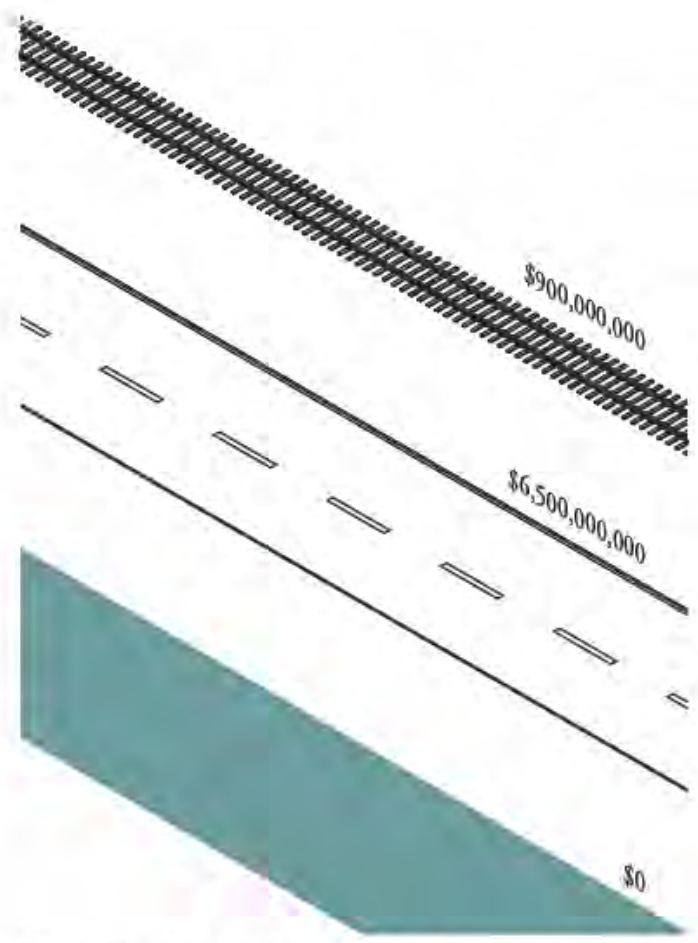

Fig. 16 - Central Government investment plan for $2011 / 12$ - 2014/15.

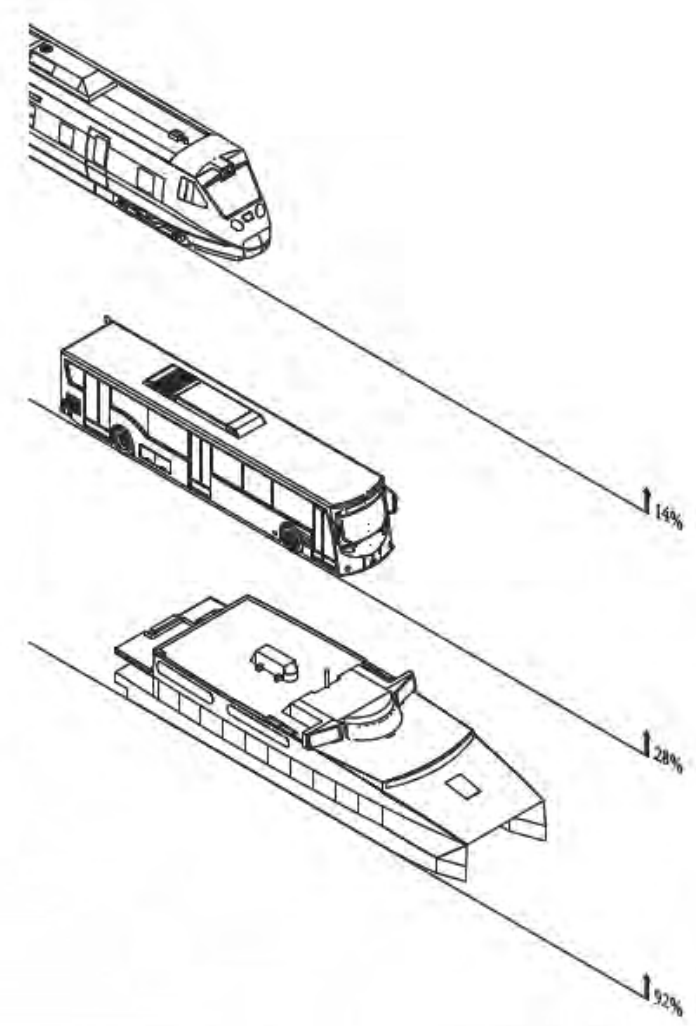

Fig. 17 - Change in passenger numbers of primary public transport modes in Wellington region, 2000 - 2009. 


\title{
POLITICAL CONTEXT
}

\begin{abstract}
$\mathrm{P}$ olitical factors are instrumental in directing the shape of our inhabitations through infrastructure - policies define the form of infrastructure, and in turn "[i]nfrastructural systems work like artificial ecologies. They manage the flows of energy and resources on a site, and they direct the density and distribution of habitat." (Allen 1997: 57). The series of maps on the following page (figures 18-21) show the region's political geography, and the relationship between inhabitation and primary transport infrastructure in the area.
\end{abstract}

The New Zealand Government's National Infrastructure Plan of 2011 projects capital expenditure of $\$ 6.5$ billion on roads and $\$ 900$ million on metro rail (including a $\$ 500$ million loan for Auckland rolling stock) over the next 3 years (figure 16) ${ }^{13}$. Ports receive no funding, with water based modes of public transport failing to register in central government strategy ${ }^{14}$.

Greater Wellington Regional Council (GWRC), the body responsible for the provision of transport to denizens, exhibits a similarly heavy land based transport bias. The

\footnotetext{
${ }^{13} \mathrm{~A}$ sum of $\$ 500$ million allocated to non-metro presumably contributes to KiwiRail's interisland ferry service, however this research focuses on commuter transit.

${ }^{14}$ While regional government is responsible for the provision of transport to their constituents, central government strategy is raised to illustrate the depth that road focussed infrastructure thinking is entrenched.
} 


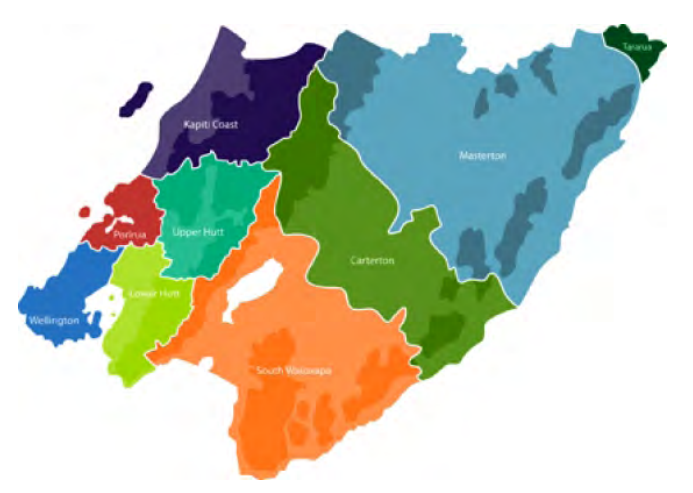

Fig. 18 - Political geography. The four cities of Wellington (Porirua, Upper Hutt, Lower Hutt, and Wellington) are clustered to the south-west of the region.

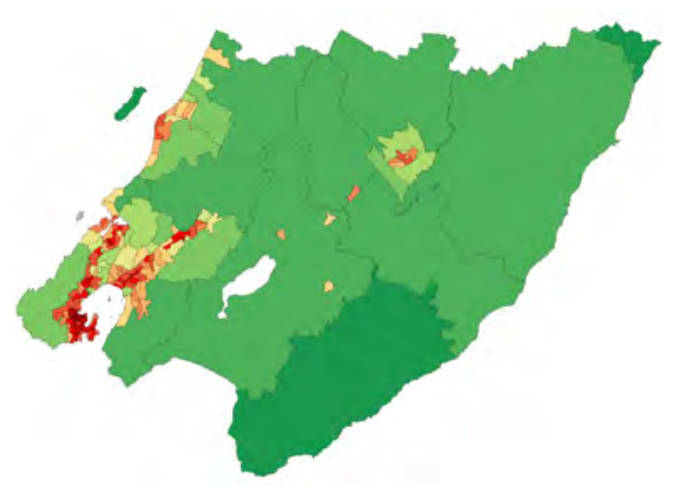

Fig. 19 - Population density

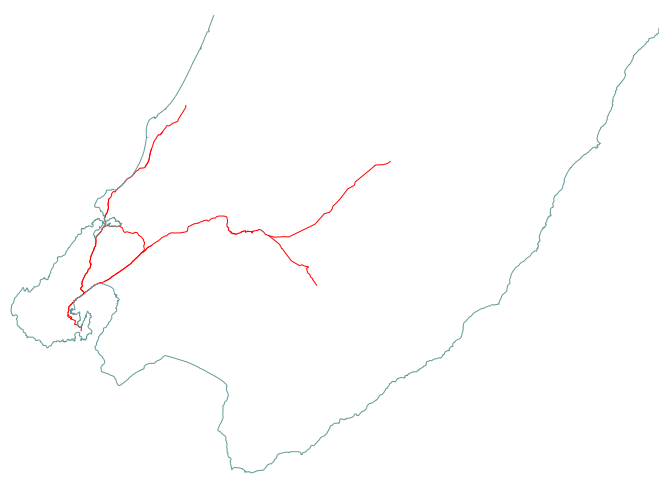

Fig. 20 - State highways

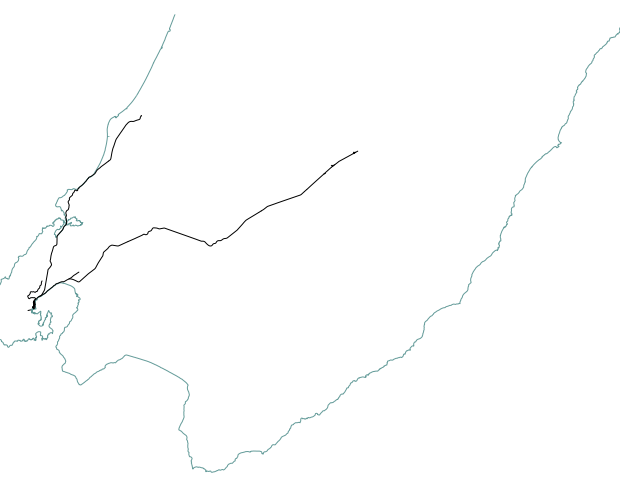

Fig. 21 - Rail lines 
council's network plan for the next decade (figure 22) indicates commuter ferry service will remain unchanged from the current model. This indicates that, in the eyes of strategy and policy makers, ferries only "...play a useful niche role in the provision of passenger transport in Wellington." (GWRC 2008: 10). No strategy for the region identifies the harbour as a resource that plays a meaningful part in our inhabitation of the area.

In contrast to this, ferry is the fastest growing mode of commuter transport in the region, in terms of ridership, over the past decade (figure 17). East by West ferries operates two catamaran type commuter ferries (the Cobar Cat and the City Cat) out of the Meridian Building in Kumototo. These two identical 100 passenger vessels cater for less than half a per cent of total public transport patronage, but at a much higher passenger growth rate than land based modes.

The central government's heavily road biased transport infrastructure strategy is problematic for a number of pragmatic and quantifiable reasons that have been identified in other research, such as the relatively low environmental impact of water based mass transit for example ${ }^{15}$. The preference for investment in infrastructure

\footnotetext{
${ }^{15}$ See Alan Tran's unpublished thesis Ferry Oriented Development: A Miramar Case Study 2011 for an analysis of the relative benefits of ferry transport over comparative land-based modes.
} 


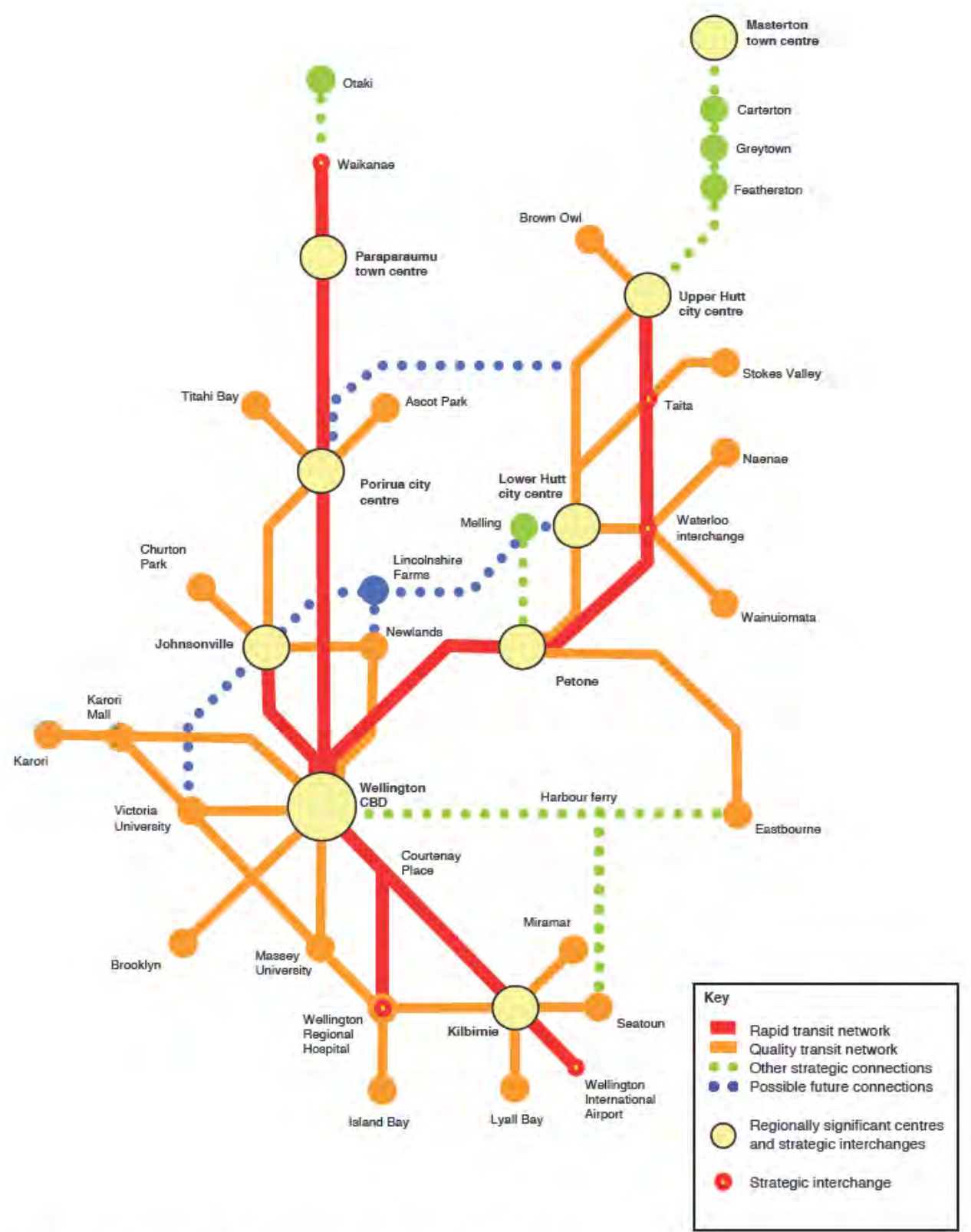

Fig. 22 - GWRC public transport plan for the next decade. 


\section{Long-term direction for Urban Development}

Our 50-year growth concept

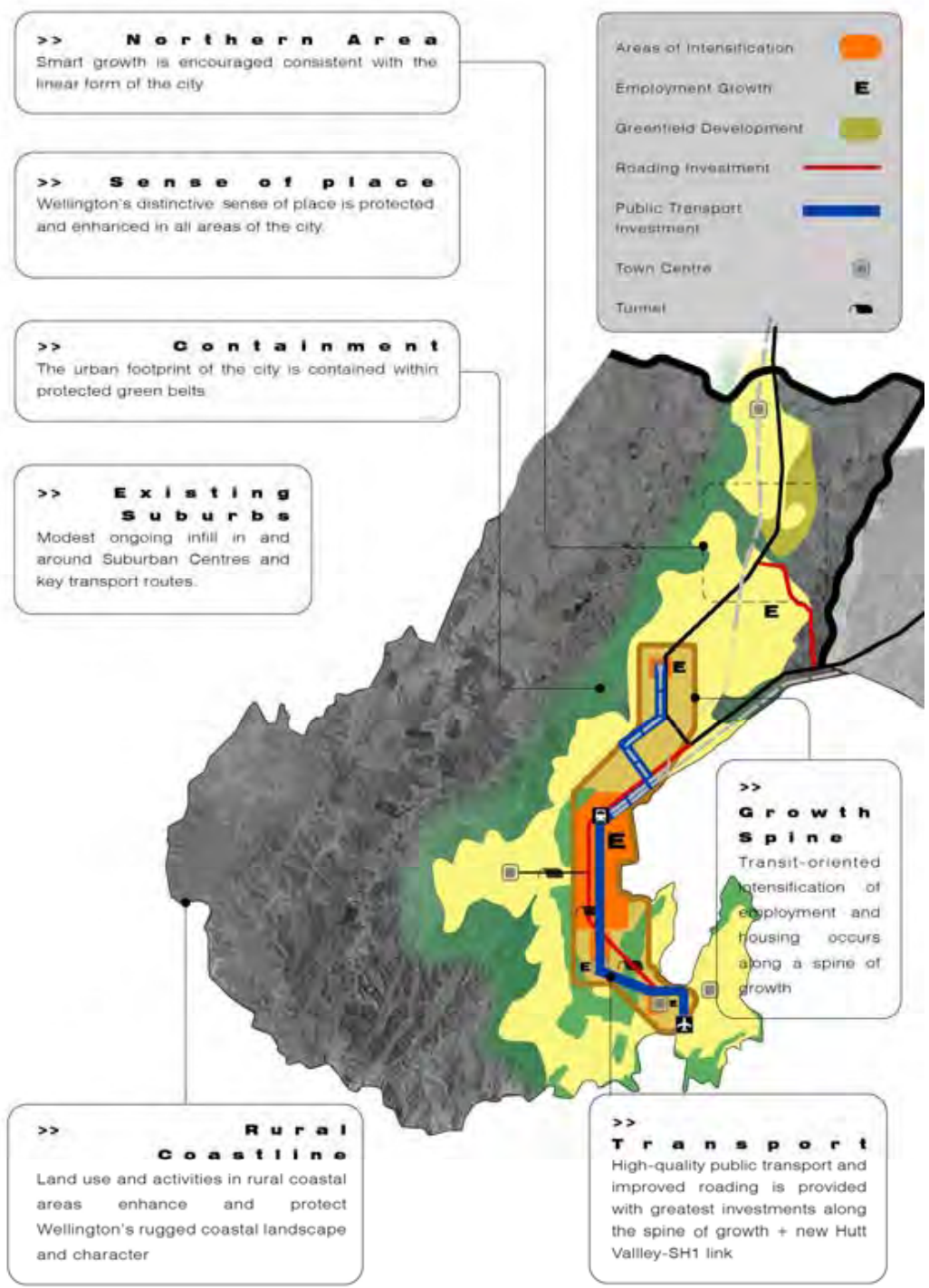

Fig. 23 - WCC urban development strategy, showing explicit link to GWRC plan 
that promotes private car use is also problematic from the point of view of a ritual framework, due primarily to the deindiviation caused by private motorcar use.

Deindividuation describes how social norms break down under conditions of anonymity, a phenomenon that has been linked with private motorcar use (Adams 2011). Ritual in contrast is concerned with the strengthening of social bonds (as discussed in chapter three), with the creation and affirmation of the very norms that deindividuation undermines.

As the images on the previous page illustrates, Wellington City Council (WCC) strategises urban development in relation to the GWRC transport plan (figures $22 \&$ 23). As with the higher levels of strategy, WCC exhibits a land based transport bias exemplified by a preference for urban development around the existing land transport corridor.

The current extent of water based transport in Wellington is captured in the public transport map (figure 24), which clearly shows how the ferry network is disconnected from the land based networks. 


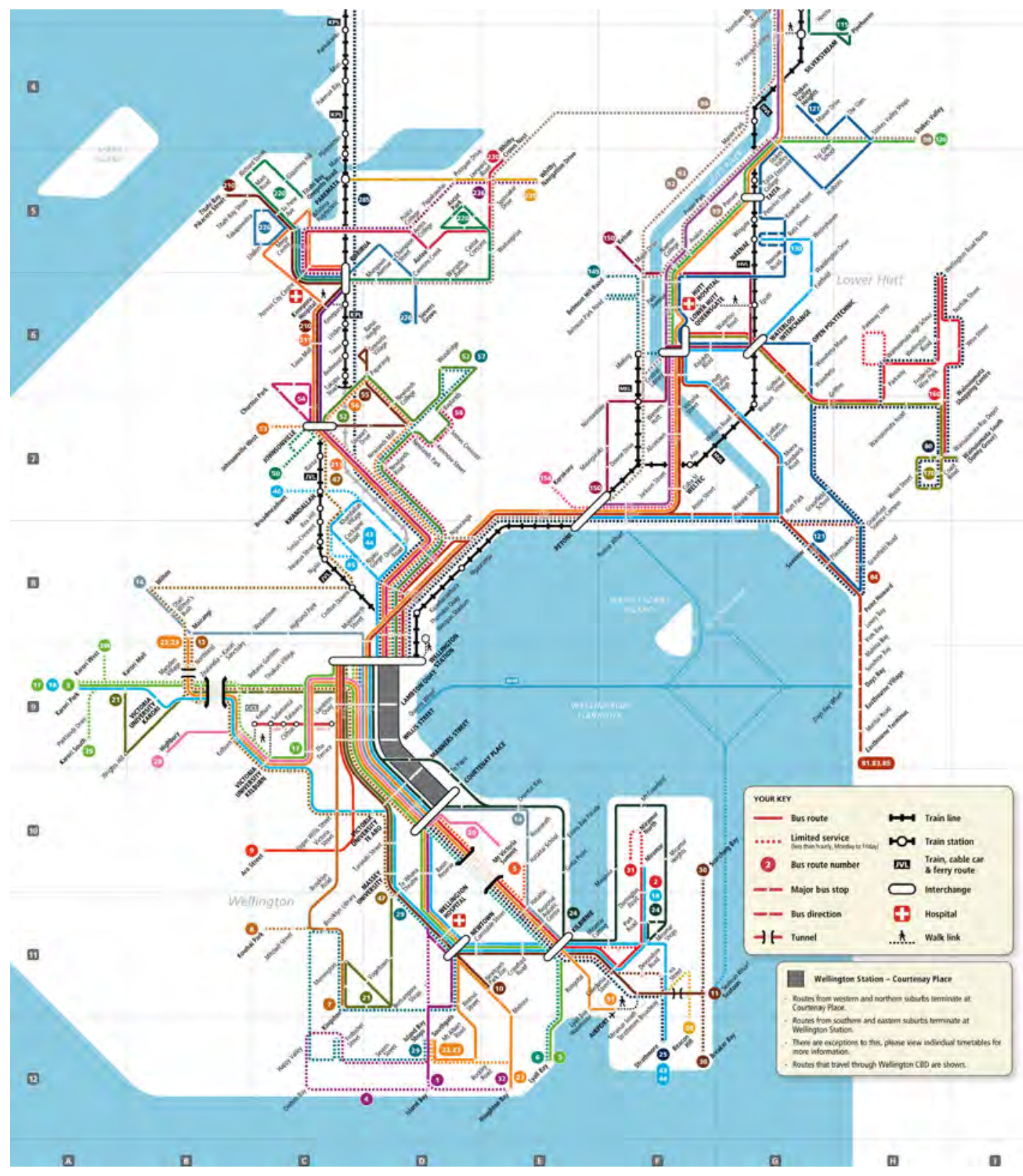

Fig. 24 - Wellington public transport map, showing Wellington Railway Station as the hub and the disconnection of ferry from land based modes. 


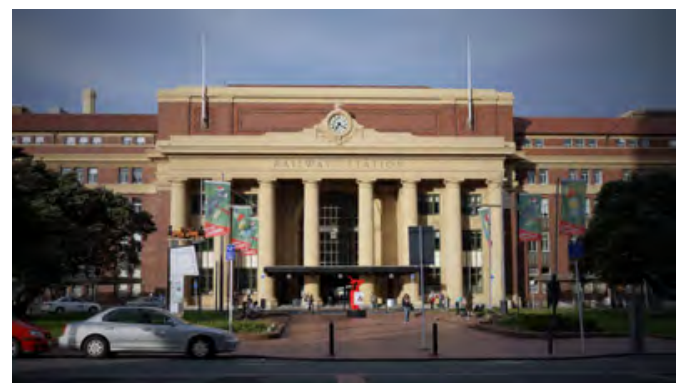

Fig. 25 - Wellington Railway Station. The hub of the city's public transport network.

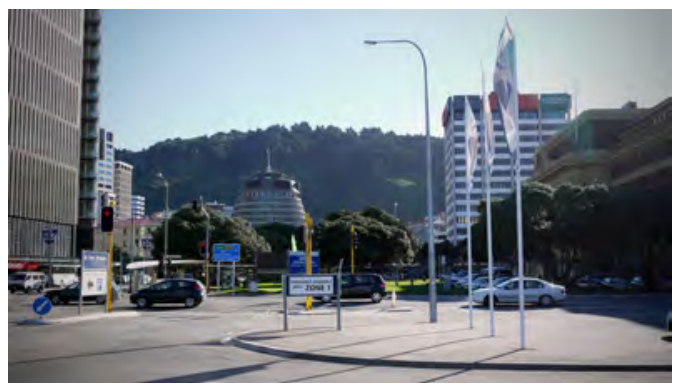

Fig. 26 - Looking northwest from the Bluebridge ferry terminal the Beehive is prominent.

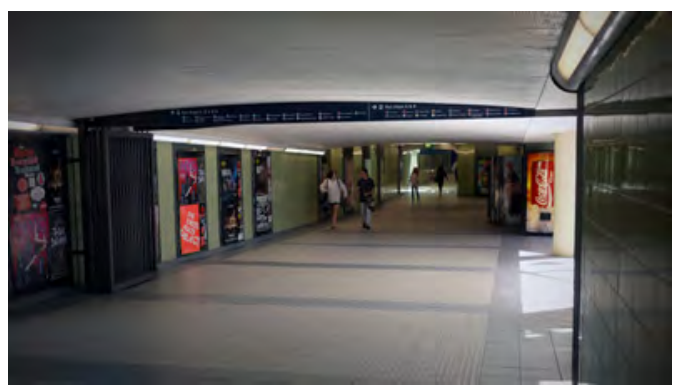

Fig. 27 - To the northwest of the Railway Station a pedestrian underpass links to the bus terminal.

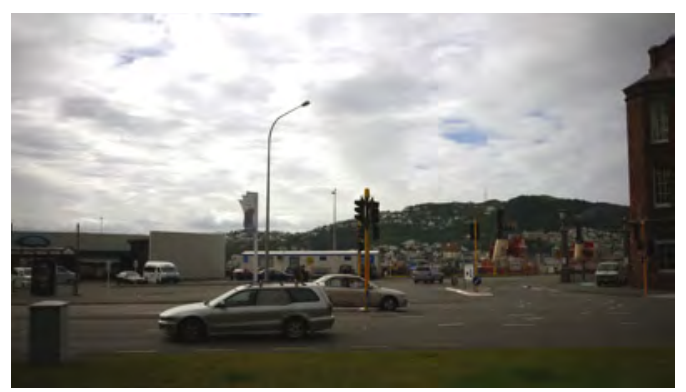

Fig. 28 - Looking south-southwest from the Railway Station towards Mount Victoria, the barrier effect of Waterloo Quay is apparent. At this point the road is six lanes wide (approximately 21 metres), with a single narrow pedestrian crossing designated. On fine days this is a popular commuter pedestrian route to the waterfront promenade. 


\section{WELLINGTON'S PUBLIC TRANSPORT COMMUTER HUB}

\footnotetext{
$T_{1}$ he proposed intervention is situated at the point of greatest activity in the network, Wellington City's transport hub, with the aim of connecting water based public transport more effectively with land based modes. This section provides a brief introduction to the area's physical attributes and modal organisation.
}

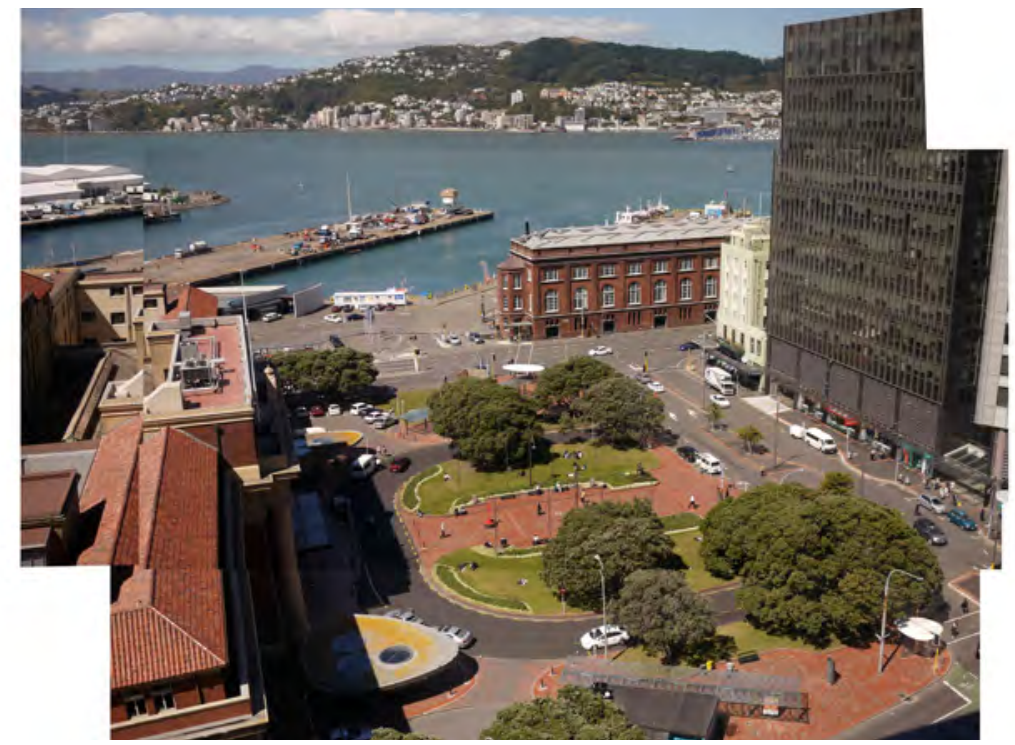

Fig. 29 - Aerial view of the Railway Station forecourt. 

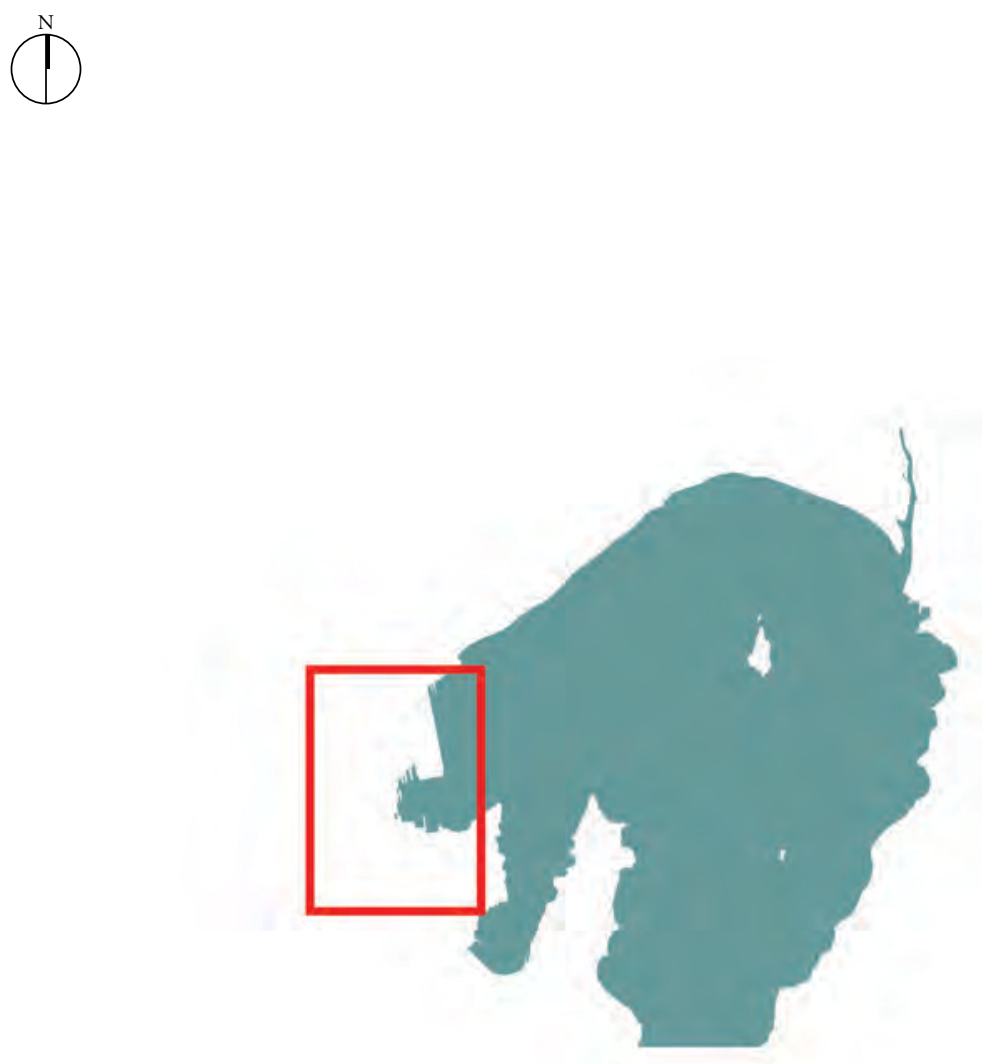

Fig. 30 - Wellington Harbour, with mapping area (Wellington City) identified

Mapping of the urban context for the proposed intervention.

1. Study Area

2. Satellite image

3. 1 metre contours

4. Building footprints (Railway Station shown in red)

5. Road hierarchy

6. Kerb lines

7. Railway lines

8. $\quad 500$ metre $\& 2$ kilometre radii

9. Green space

10. Streams / culverts

11. Industrial portion (black) of reclaimed land (grey)

12. Current industrial area, indicating changing land use 

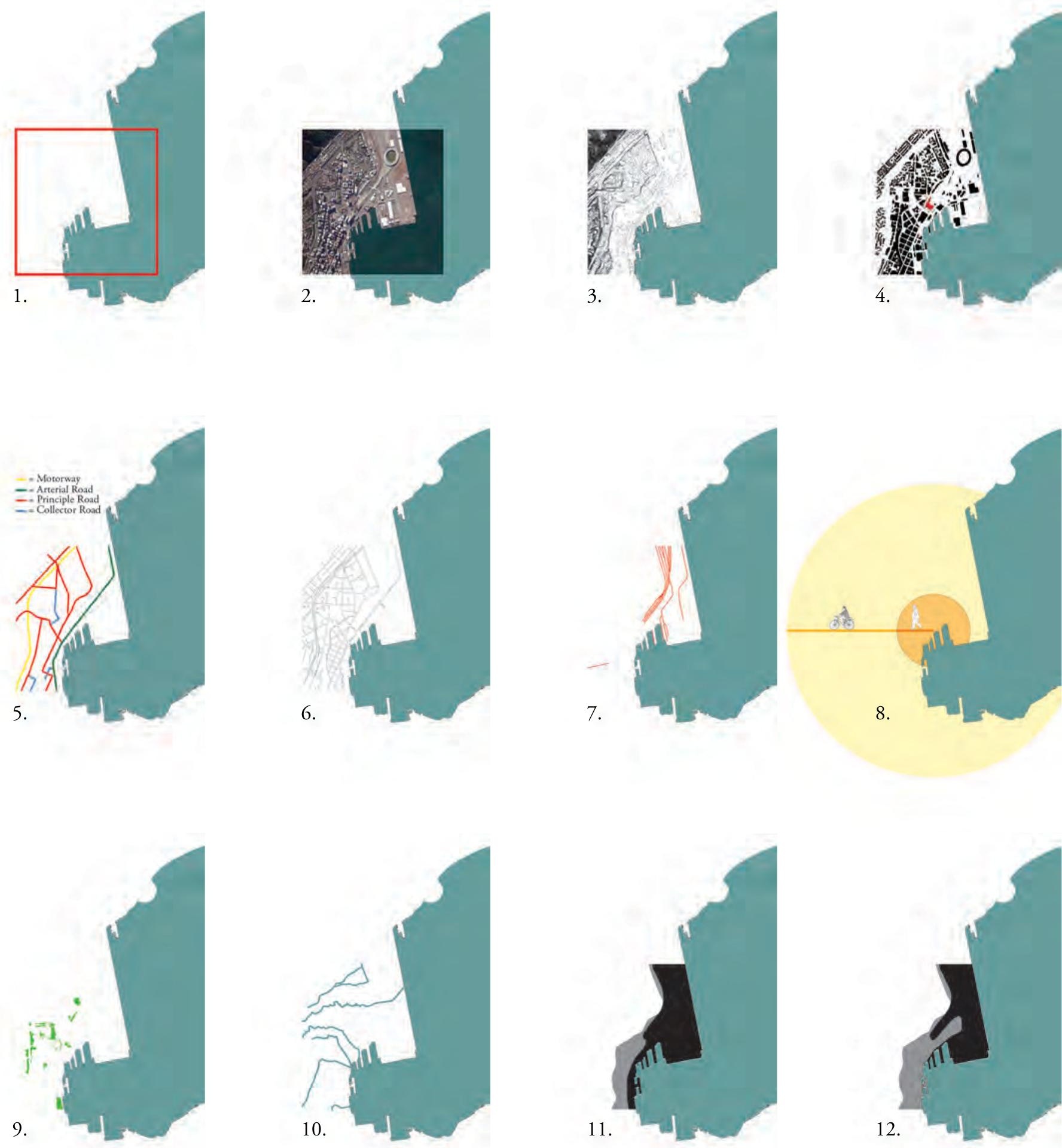

Fig. 31 - Mapping of study area 


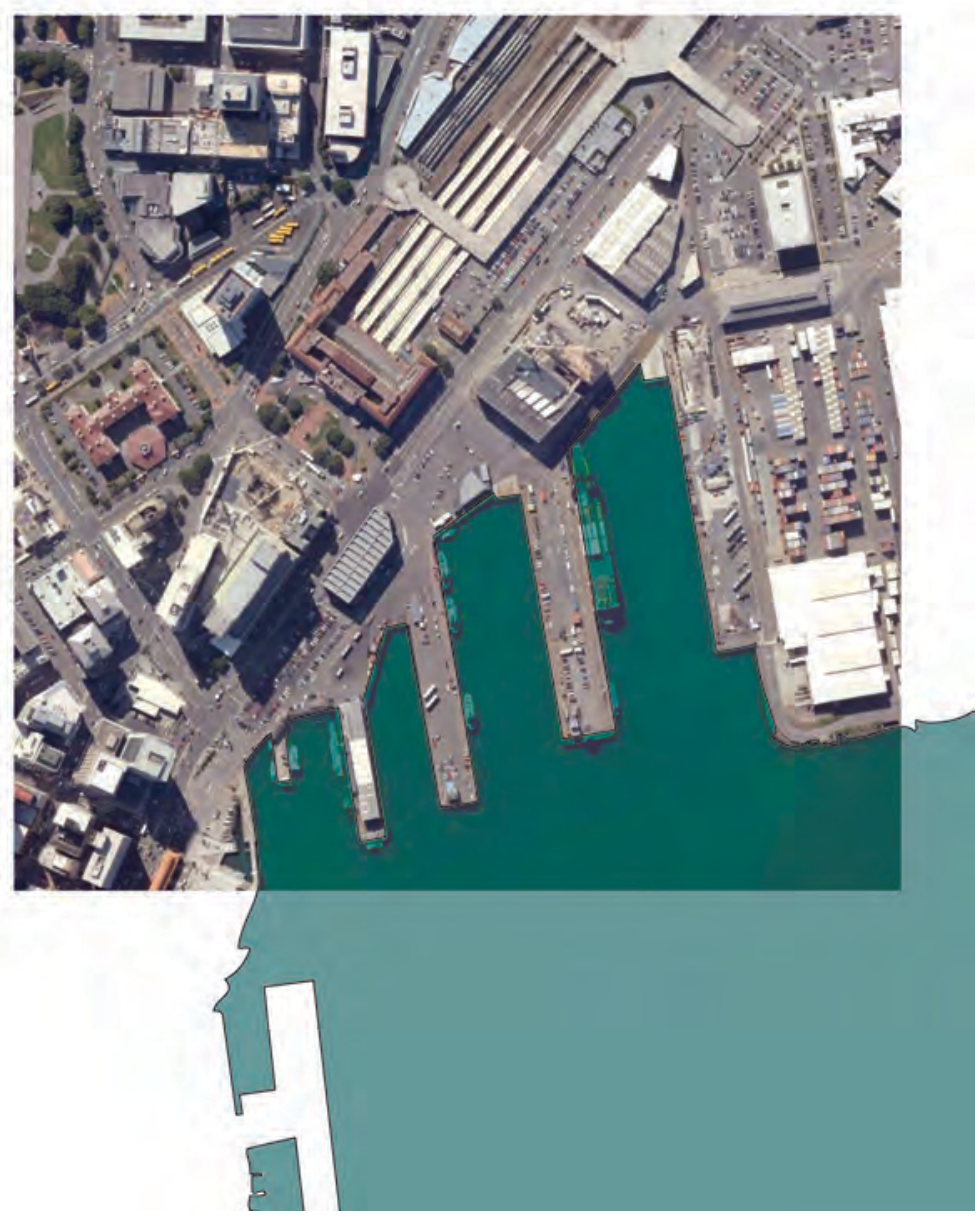

Fig. 32 - Satellite image of public transport hub area. 1:10,000 


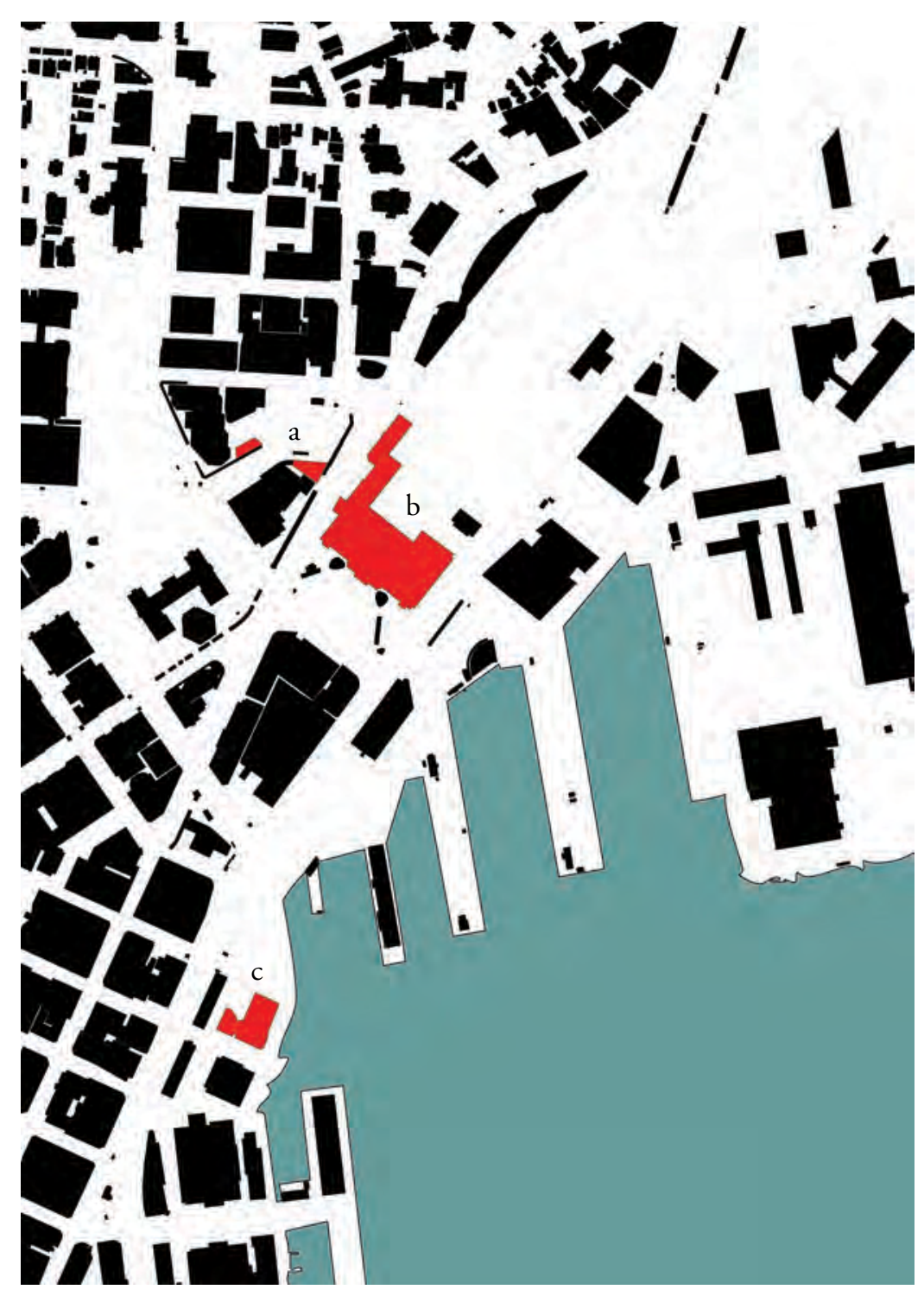

Fig. 33 - Figure / ground showing buildings associated with public transport in context. 1:10,000 a - Bus terminal b - Railway Station c - Harbour ferry terminal 


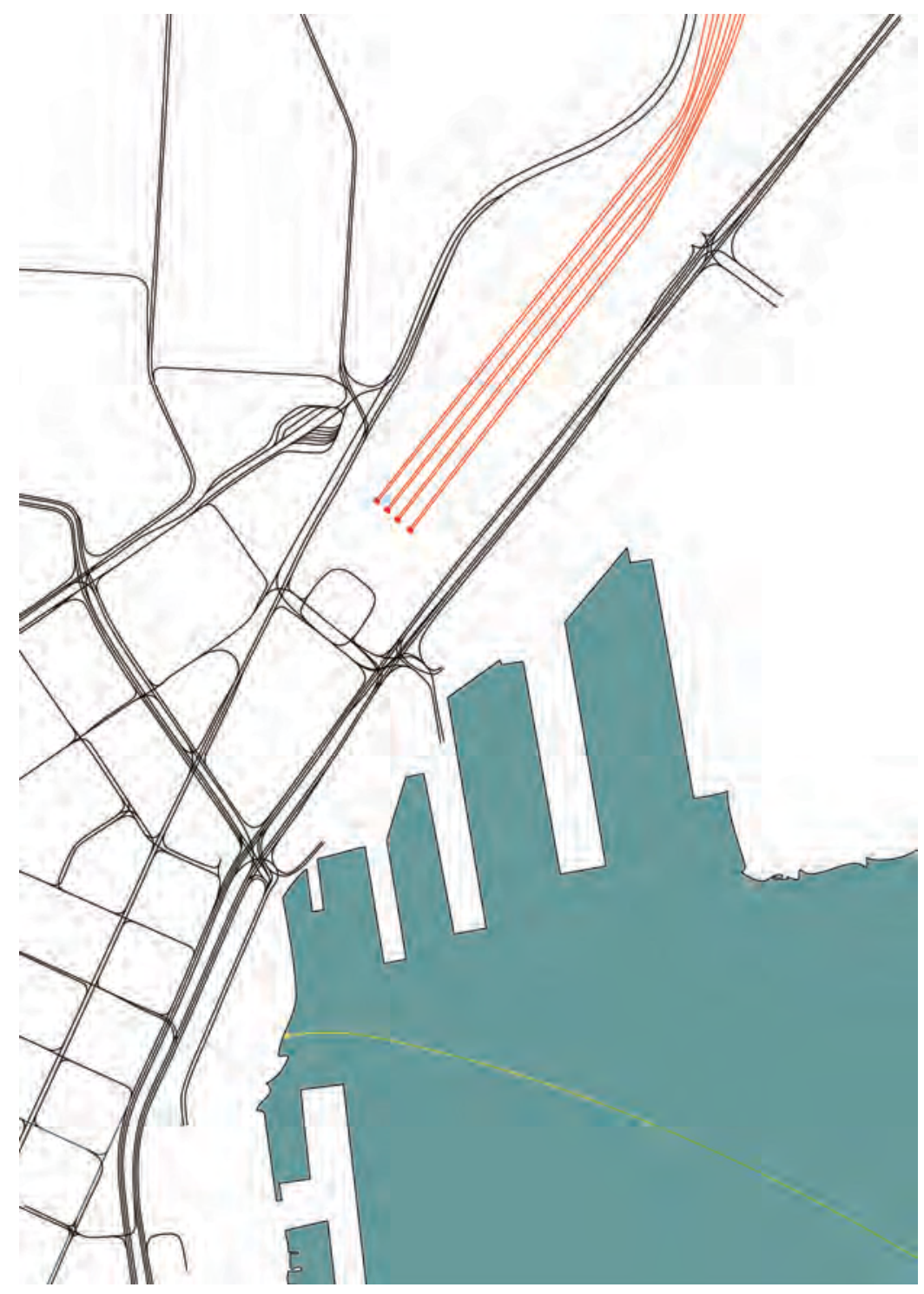

Fig. 34 - Vector analysis of passive modes 1:10,000

- red $=$ rail

- black $=$ road

- yellow $=$ ferry 


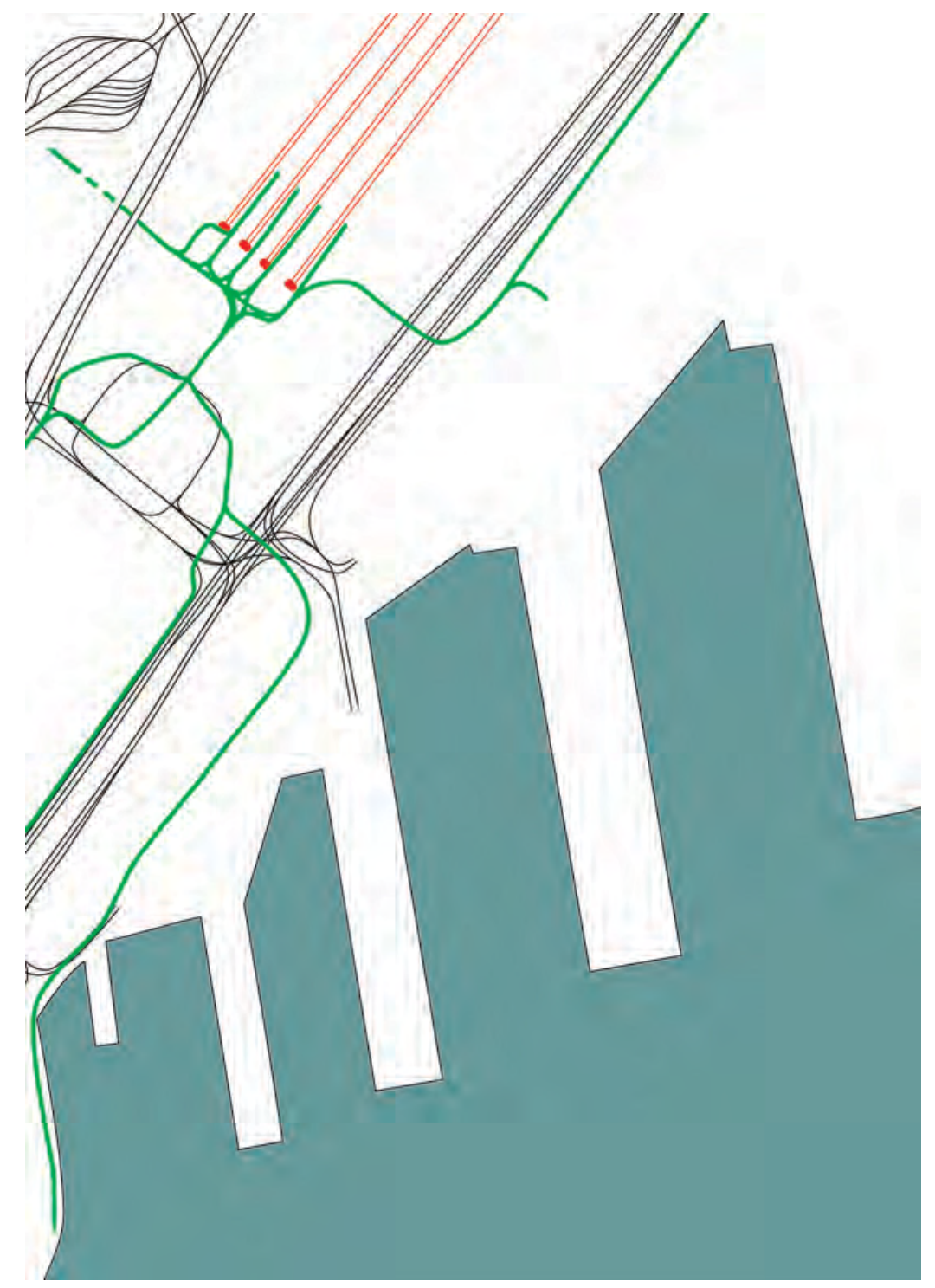

Fig. 35 - Vector analysis of commuter flows 1:4000 - pedestrian movement shown in green 


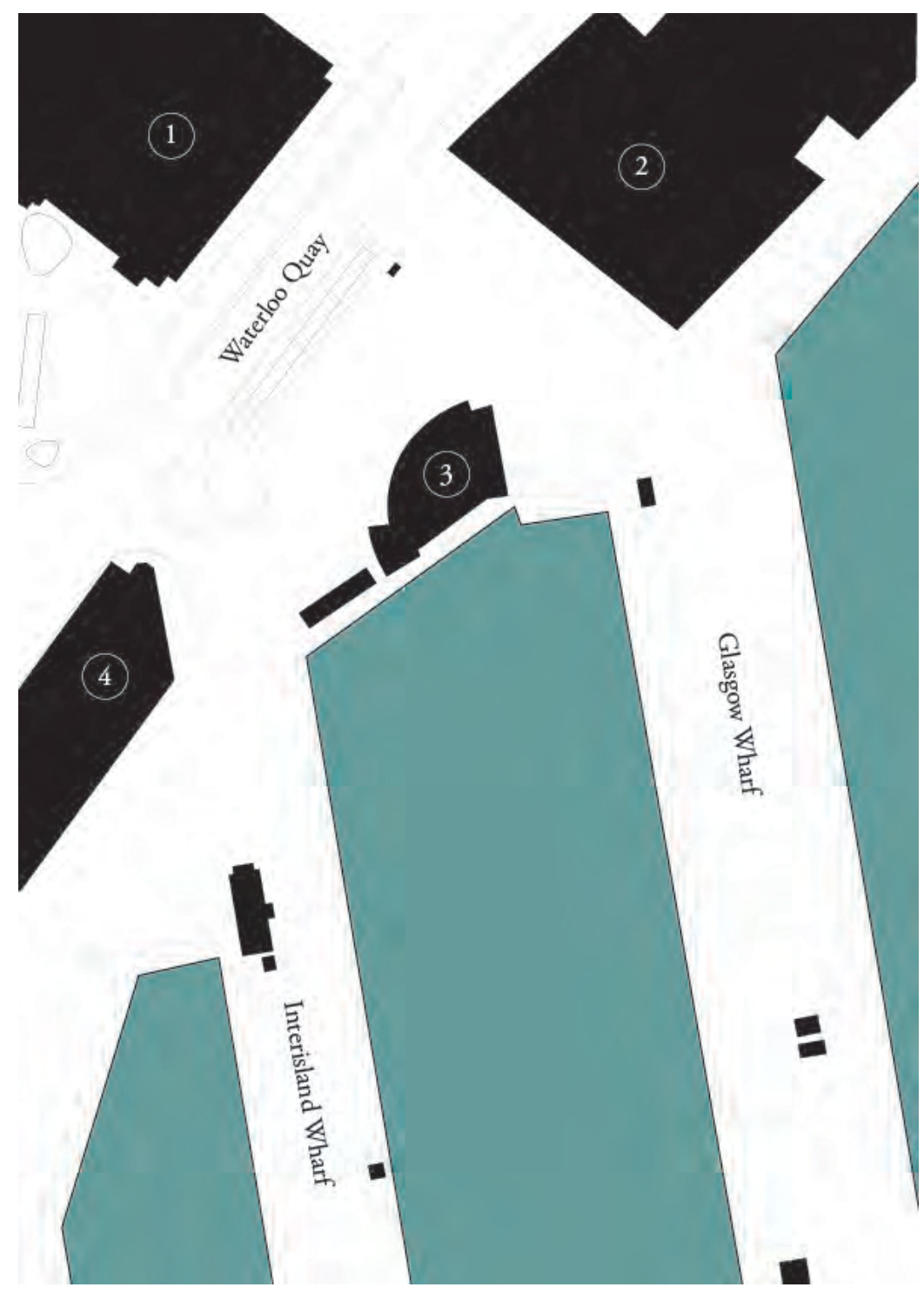

Fig. 36 - Site figure-ground. 1:2000
1. Wellington Railway Station
2. BNZ
3. Bluebridge
4. Shed 21 


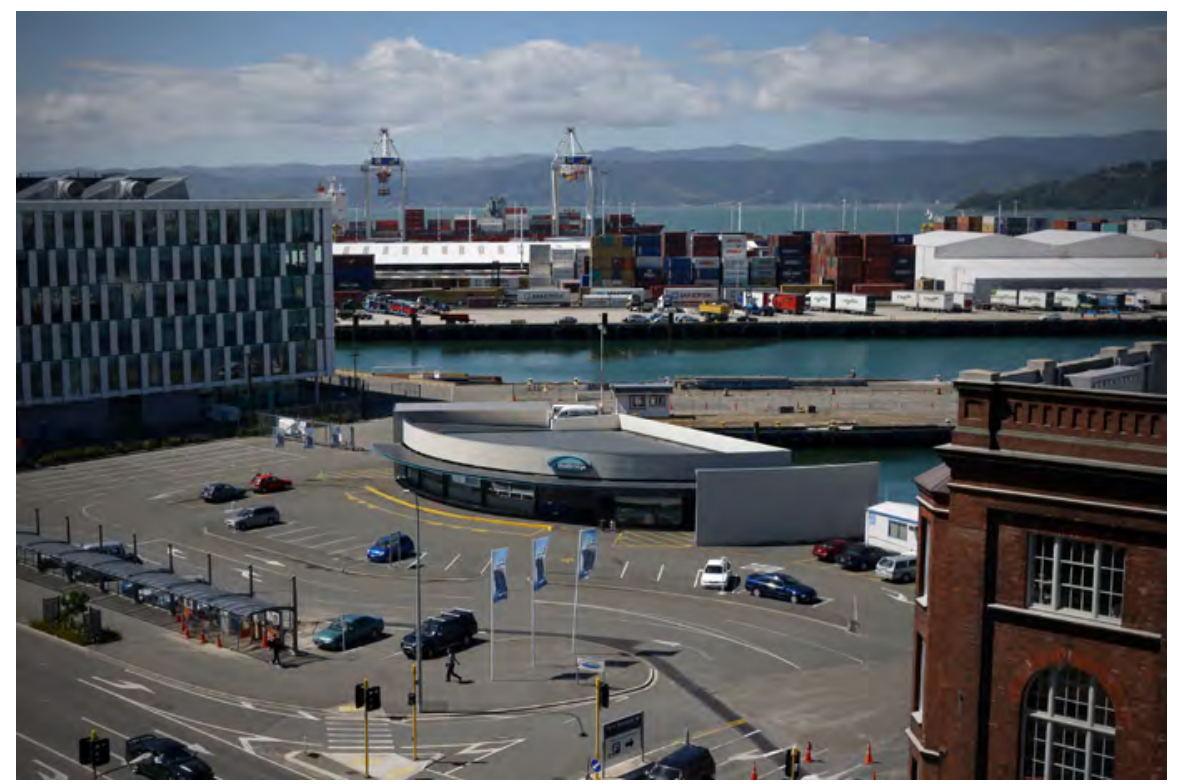

Fig. 37 - Aerial view of the Bluebridge terminal, illustrating the expanse of car prioritised area at the site.

The proposed site for intervention is at water's edge between Glasgow and Interisland Wharves, a site currently occupied by Bluebridge interisland ferry terminal ${ }^{16}$ and a port-o-cabin that accommodates the harbour master and tugboat operators. This site offers the best possible proximity to the existing hub for land based modes of public transport.

${ }^{16}$ Bluebridge currently operate two interisland freight and passenger ships from this building - the hub design work proposes their operations shift to Kings Wharf and the eastern side of Glasgow Wharf, with a new terminal building to the north-east of the BNZ. 


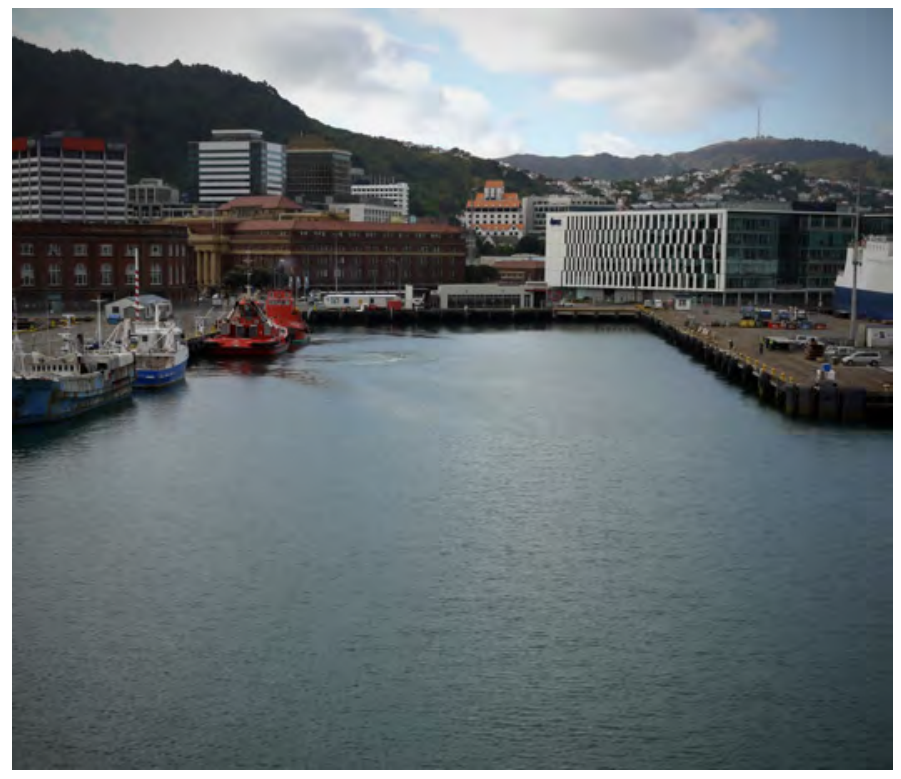

Fig. 38 - Site from the south, framed by Glasgow Wharf to the east and Interisland Wharf to the west.

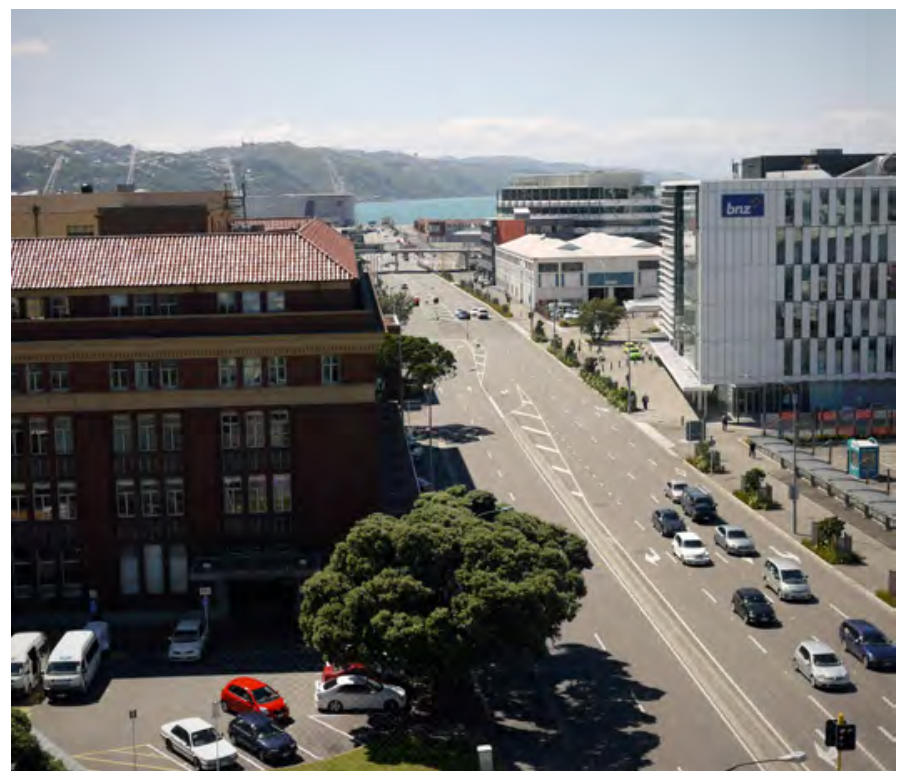

Fig. 39 - Looking northeast along Waterloo Quay 


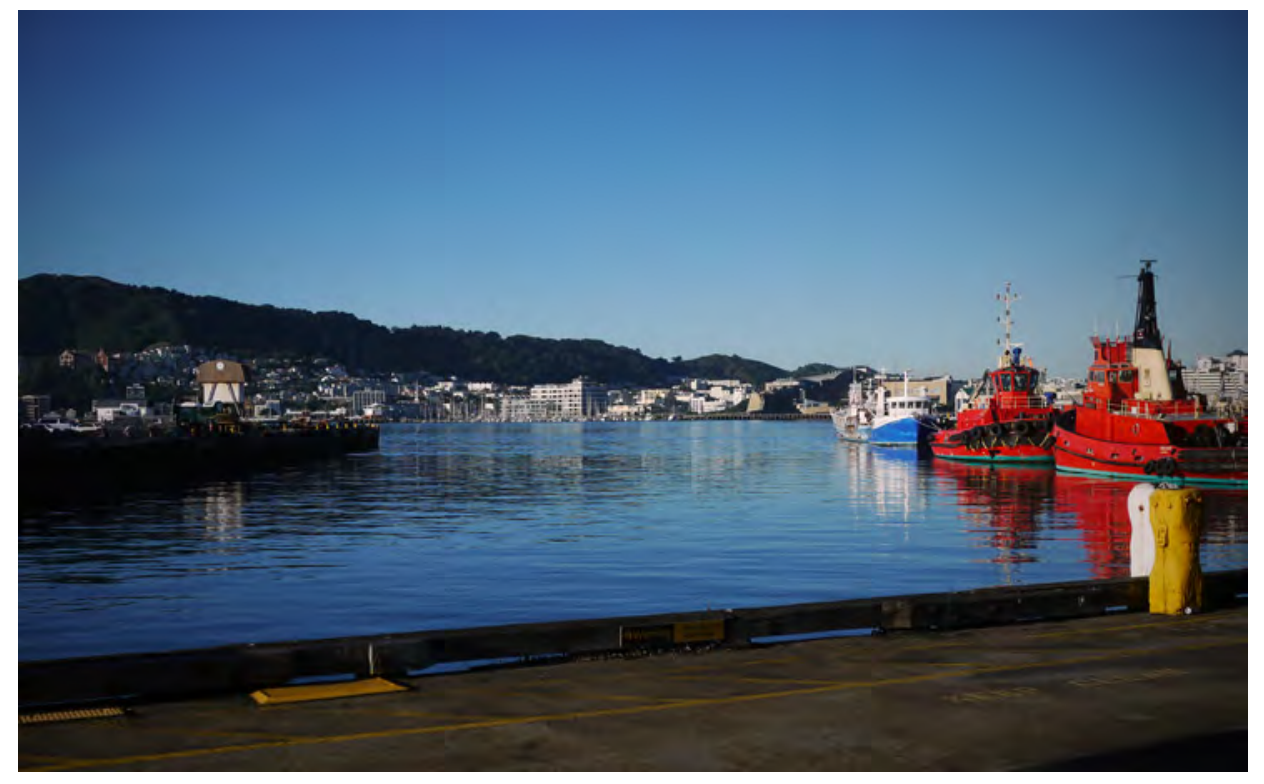

Fig. 40 - Looking south from the site, towards Te Papa and Mount Victoria.

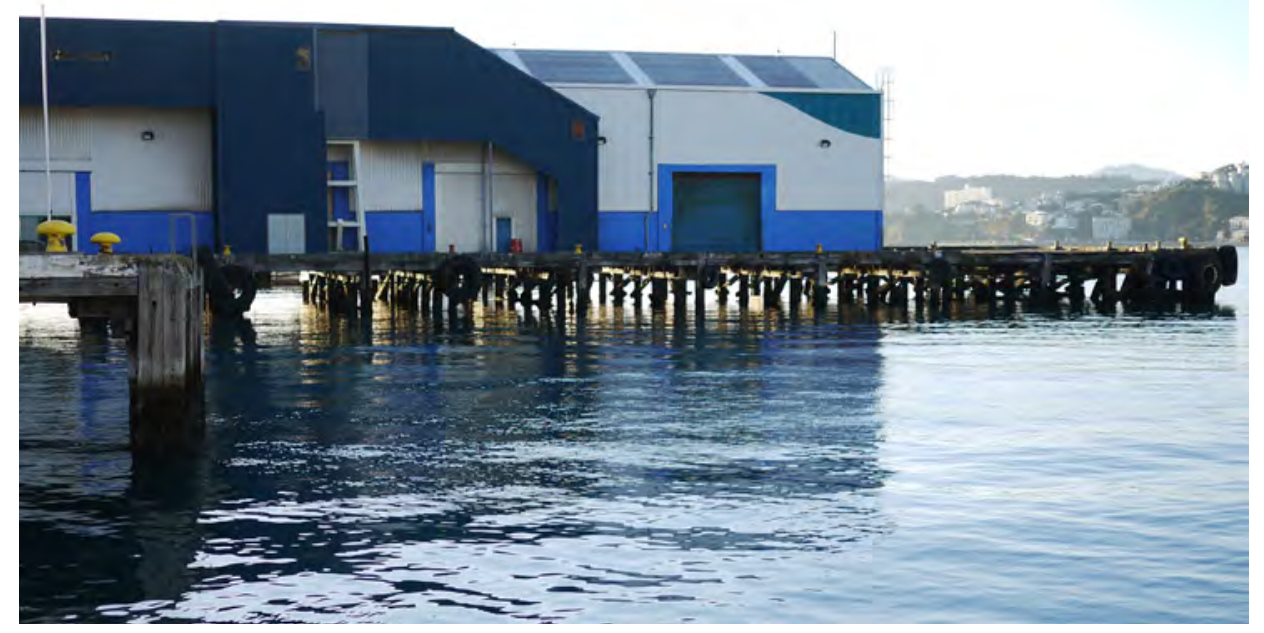

Fig. 41 - The finger wharves are a defining characteristic of the area. 


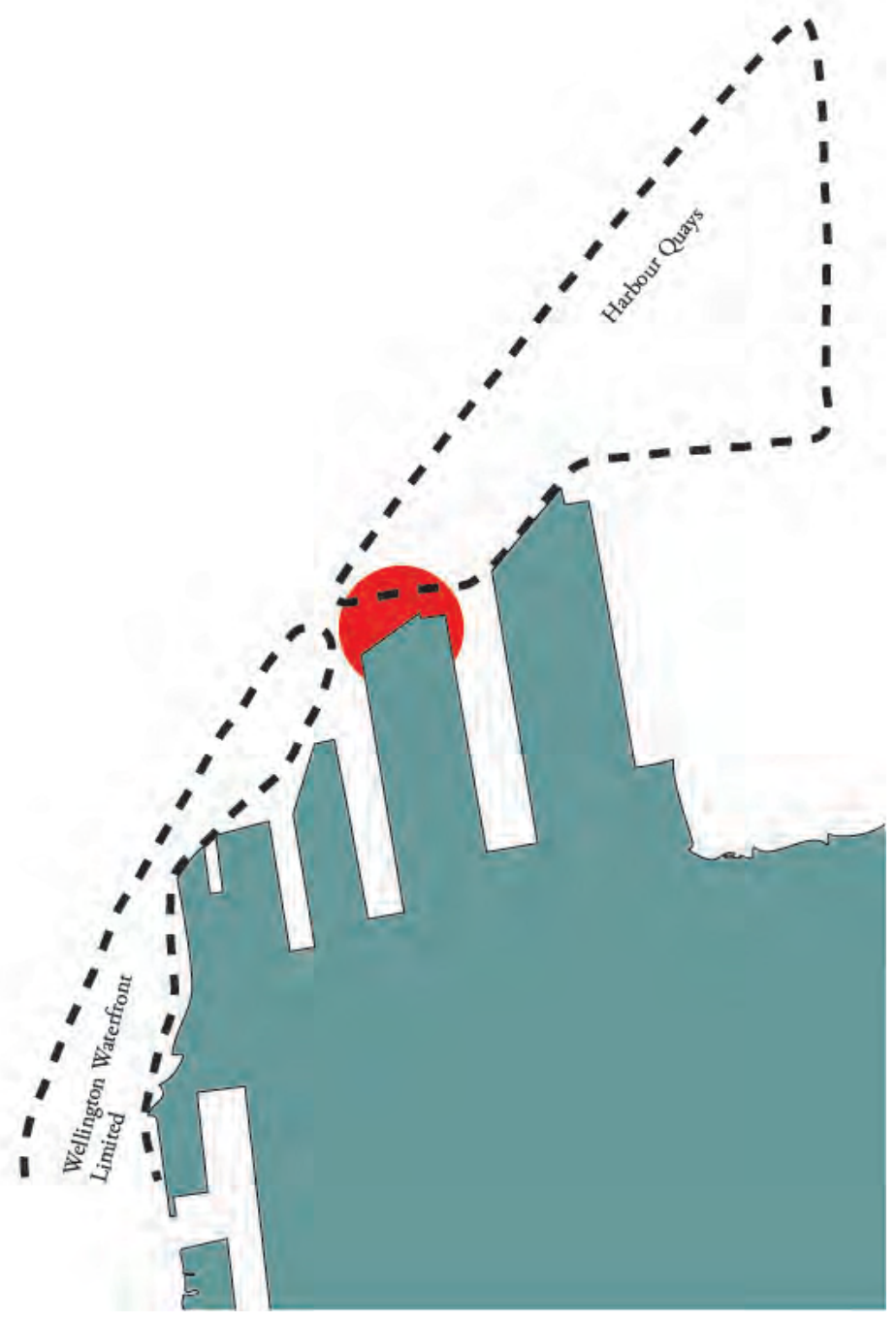

Fig. 42 - Approximate development jurisdiction boundaries within study area, with proposed harbour ferry terminal site shown in red. 


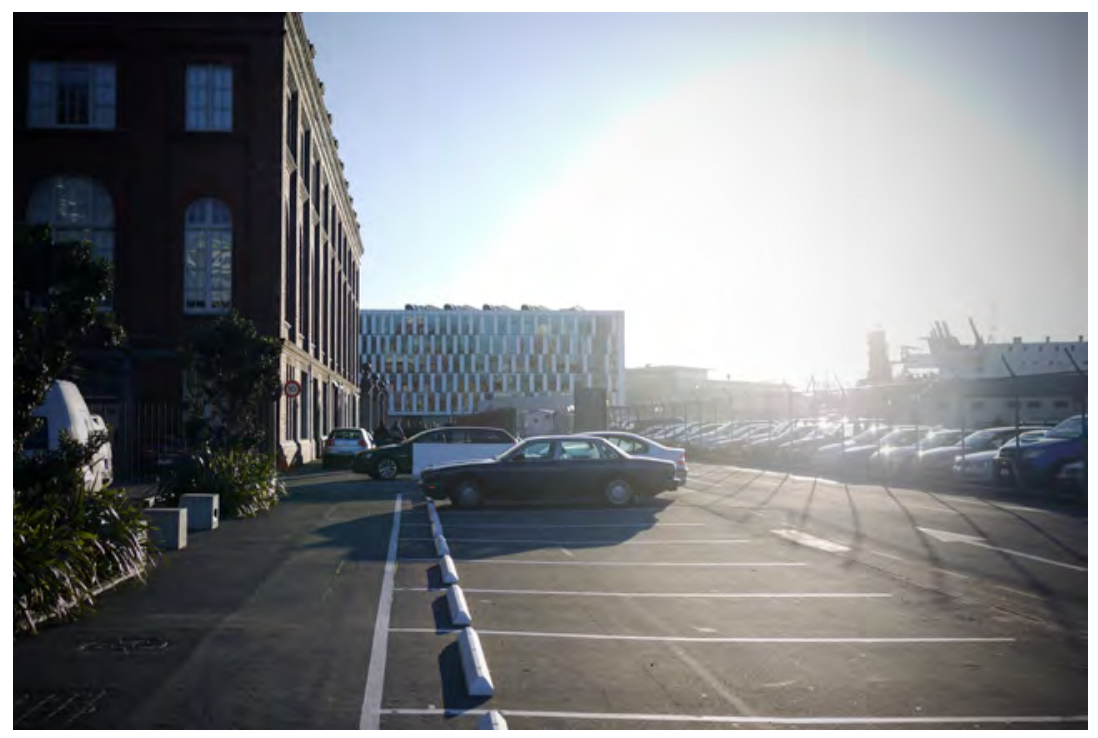

Fig. 43 - Looking northeast at Shed 21, the waterfront promenade degenerates into car parking.

\footnotetext{
A s the mapping on page 85 and the WCC urban development strategy show, the city is spreading north into previously industrial areas. One major development that exemplifies this impetus is Harbour Quays, on former CentrePort land, which lies immediately to the north of the site proposed for intervention.

Immediately to the south is the northern tip of Wellington Waterfront Ltd. (WWL) area. The proposed intervention must then function as a continuation of the waterfront promenade developed by WWL, and a connector to the commercial developments to the north. At present the Bluebridge car park (figures 37, 43) marks an end to the promenade and a barrier to pedestrian flow continuing northeast.
} 


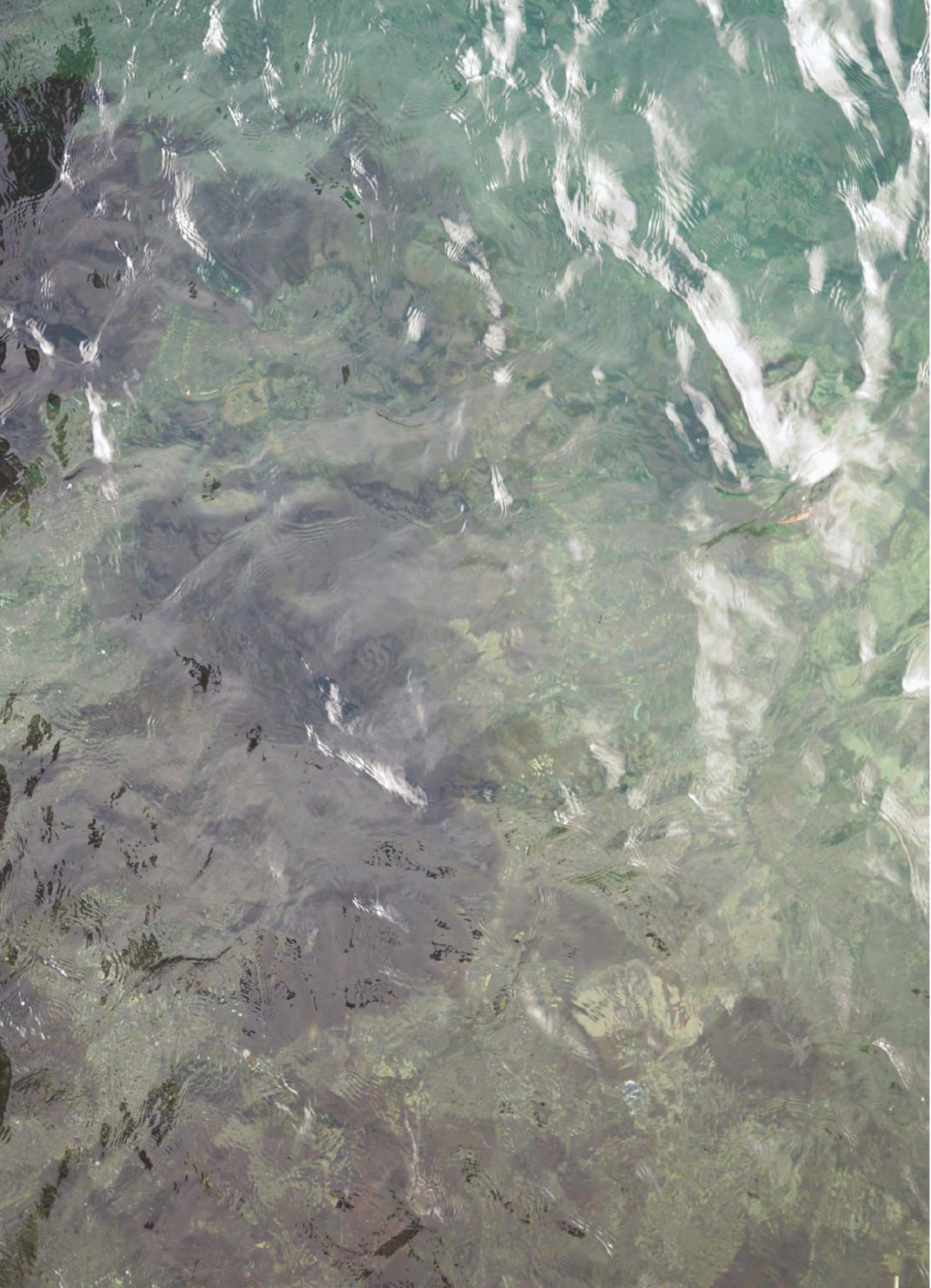




\section{SITE MATERIALITY}

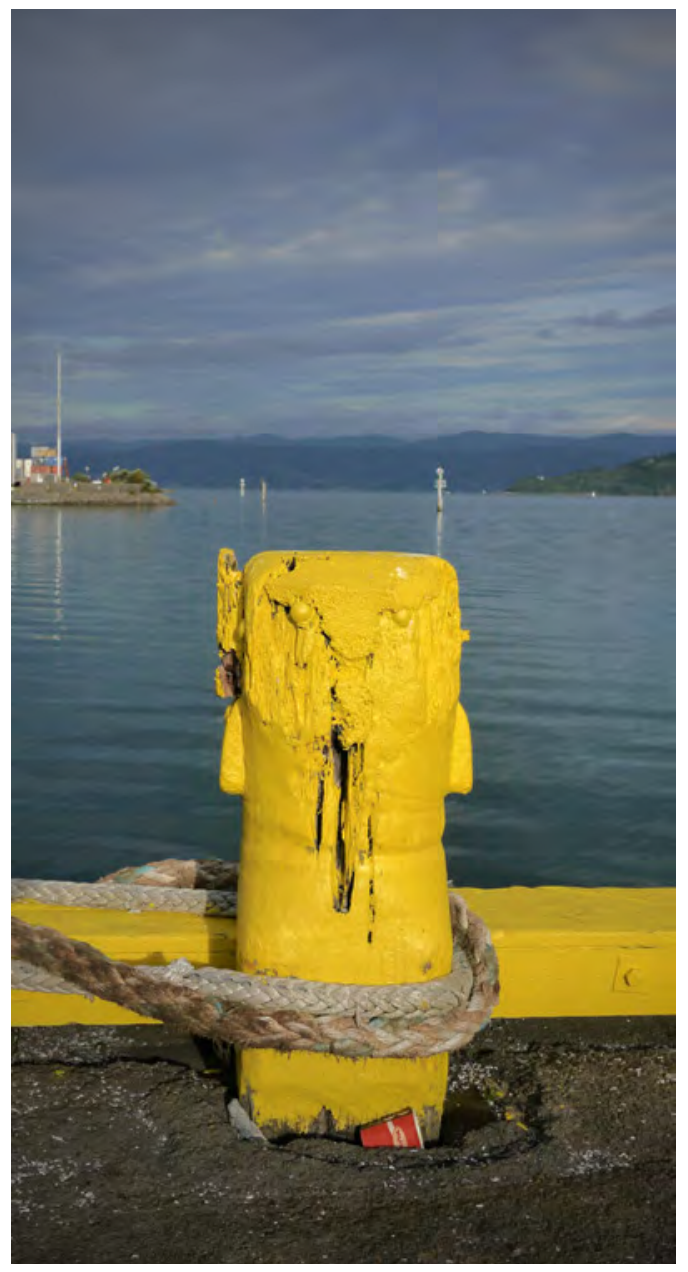

$A_{\text {s discussed earlier in the section }}$ on mnemonic (page 61), and illustrated by the Docks de Paris case study (page 62 ), materiality has the potential to play a central role in ritual architecture, particularly in the adaptive reuse of industrial land.

Timber and water are the two strong material elements at the site, along with corroded steel, concrete, and asphalt, as the photography in this section shows.

Fig. 44 - The finger wharves were constructed with extensive use of massive ironbark timber members, connected with steel bolts, and topped with asphalt. 


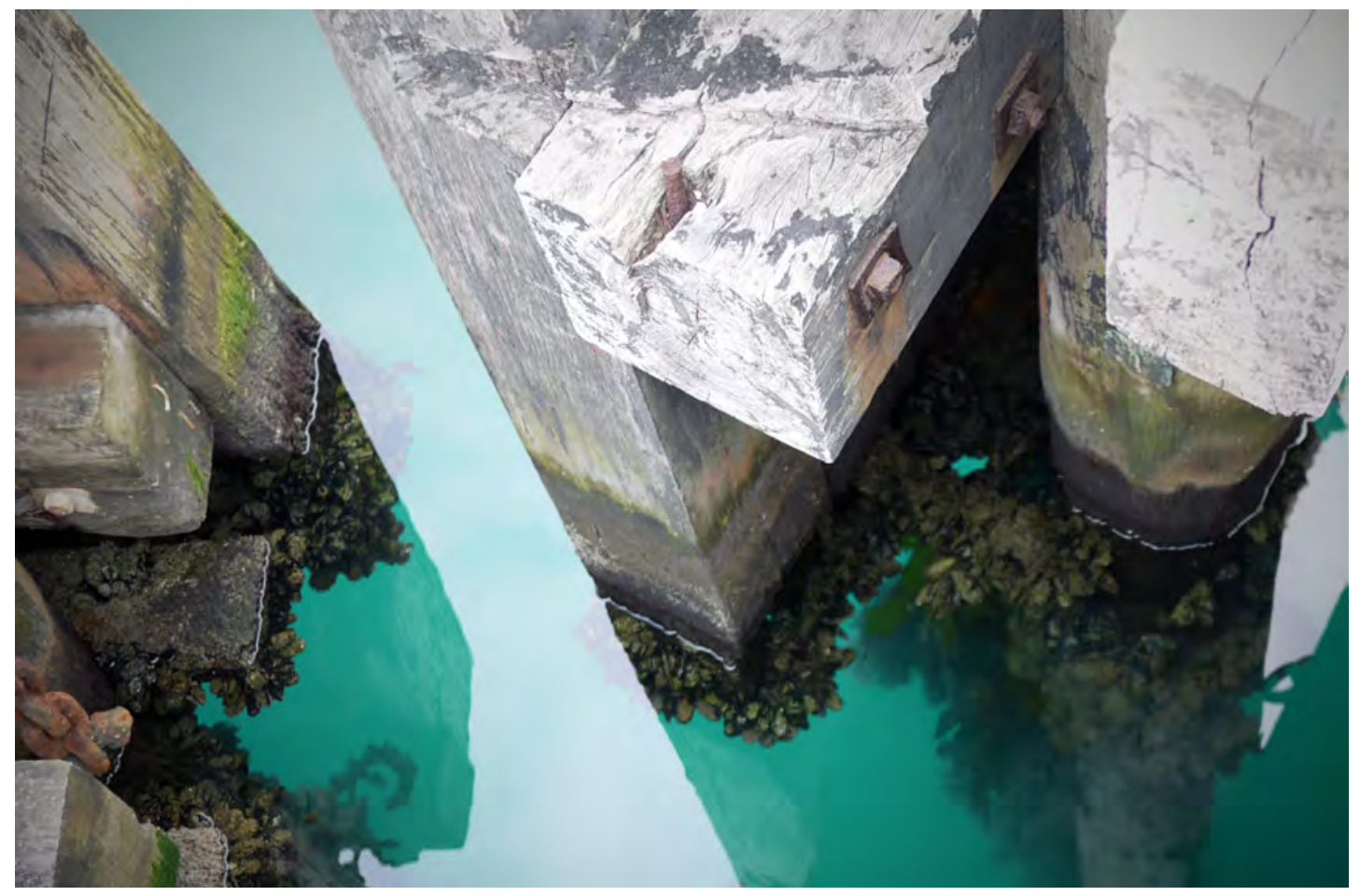

Fig. 45 - The harbour experiences a tidal range of approximately one metre. Next page, Fig. 46 - The harbour wharves - timber plunging into water. 


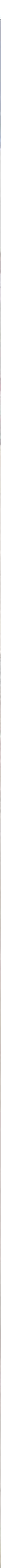




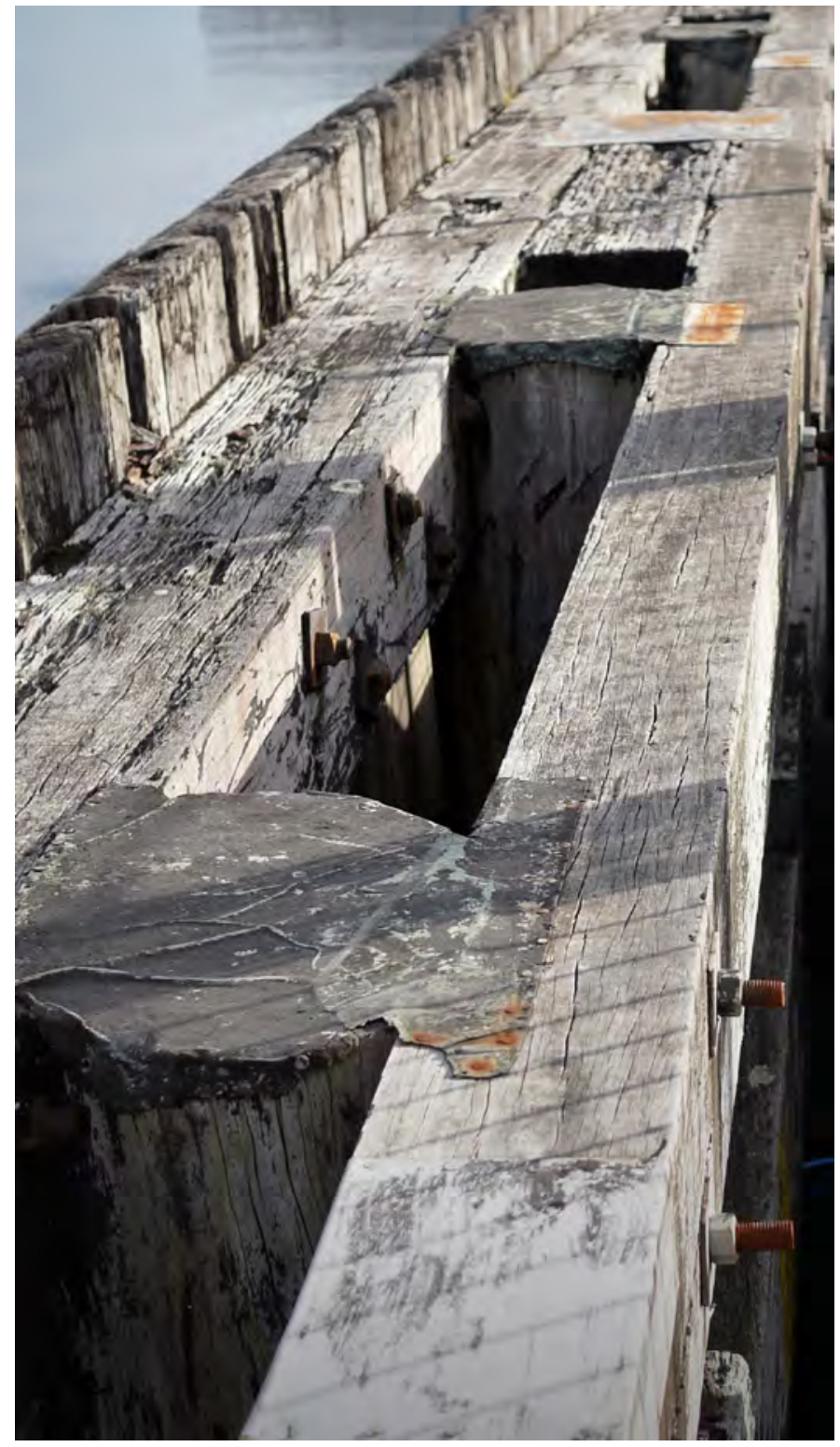

Fig. 47 - Timber end grains are capped with metal, or bull-nosed to prevent water pooling. 




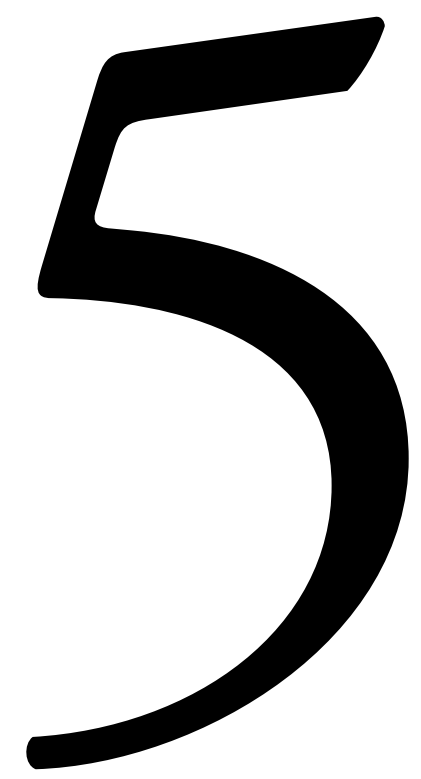

INTERVENTION 


\section{INTRODUCTION}

$\mathrm{T}$

he commute can reasonably be described as a ritual. Ritual, as we have seen, is a valid and active phenomenon in contemporary life, far from the somewhat flippant use of the word that is common in a secular setting. Framing the commute as a quotidian, secular ritual suggests design criteria for transport infrastructure derived from ritual's key components (action and symbol), and their functions (discussed in this research as liminality and mnemonic).

These criteria can be summarised as:

\section{Action}

As explained by the theory of performativity, bodily movement possesses an agentic quality in relation to culture. The key spatial consideration of this is accommodating movement in a way that facilitates viewing and interpretation by agents (commuters, in this case).

\section{Liminality}

Ritual has a transformative effect that is explained by the concept of liminality. This is interpreted to infer a particular spatial quality that references bounding states, but is distinct from both. 
Liminality also suggests a spatial implication of ritual action through discussion of its sequential, processional nature.

\section{Symbol}

Ritual communicates meaning through symbols; the ritual action occurs in relation to the symbolic. The symbolic is evident in transport, but plays no explicit role in the current conceptual framework for transport infrastructure. Under a ritual framework, the symbolic potential of a piece of transport infrastructure, and its associated buildings, is central.

\section{Mnemonic}

Ritual has a mnemonic quality that is related to the symbolic - the symbol embodies a group's common history, values, and aspirations, promoting continuity through reminding members of these.

A mnemonic imperative in the architecture of transport infrastructure suggests a particular method of deploying symbol, drawing on to the broad sociocultural remit of transport infrastructure. While this is a subtle concept, the spatial implications are potentially profound when considering application across a number of scales. 
These criteria are addressed in a number of ways through the design of the proposed harbour ferry terminal, including the larger scale ramifications of such a proposal, while the pragmatic requirements of a transport terminal and urban design issues are satisfied.

Under Jon Lang's definition of urban design works, the proposed terminal operates as a piece of 'plug in urban design'. Lang describes such works as that which "...focuses on the strategic building of infrastructure components of a city" (Lang 2005: 318), and goes on to describe how "[t] he goal of infrastructure projects if to have a catalytic effect on their surroundings - social and physical." (ibid: 356 ). The catalytic effect of the proposed intervention is discussed at the regional, urban, and local scales.

More directly relevant to the program and site of the proposed intervention is Rinio Brutomesso's view that in approaching waterfront urban design works, waterborne transport must be considered. Brutomesso argues that waterborne transport should be addressed in the following way:

"Upgrading waterborne transport needs to be effective in two ways, The first, a "rediscovery" of this system of transport by the public, entails relaunching urban mobility through a full exploration of the potential of waterborne means, and both relieves pressure on the city roads and makes transfers from one part of the city to another more pleasant, avoiding crossing the central zones. The second way is that of encouraging and improving modal interchanges between the different systems of land and water..." (Marshall 2001: 46) 


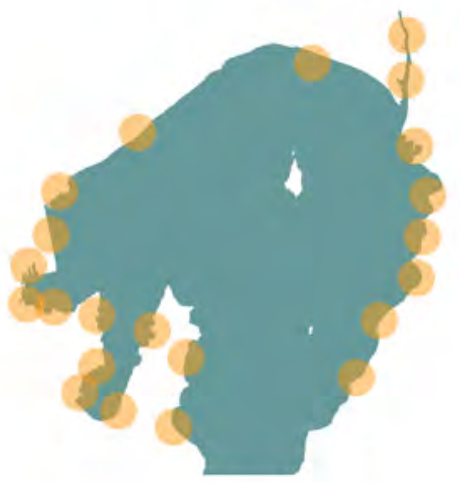

Fig. 48 - Nodes of density ring the harbour in the proposed ferry-oriented development, placing the harbour at the centre of an inhabitation strategy

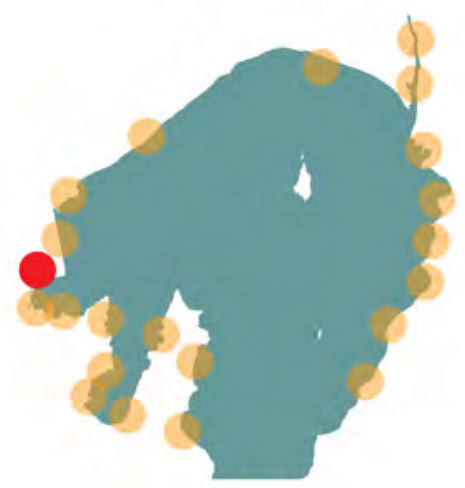

Fig. 49 - A catalytic node at the hub leverages increasing popularity of ferry patronage and effectively ties waterborne transport into land based transport at the point of greatest activity in the network

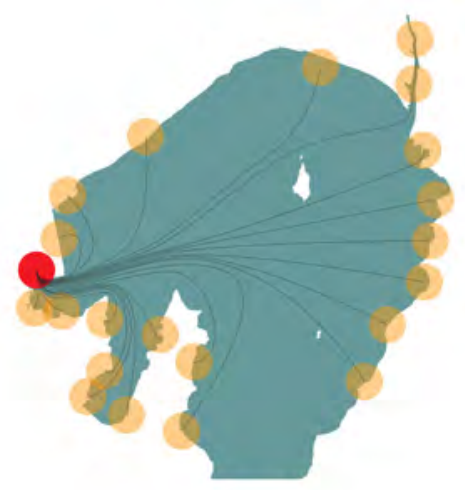

Fig. 50 - The catalytic node services high amenity harbour side commuter inhabitations, connecting directly to local, regional, and national transport networks

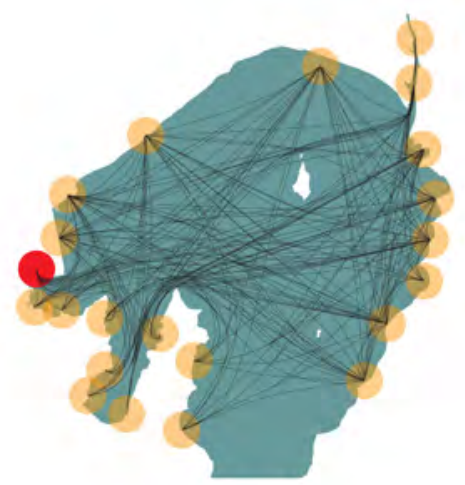

Fig. 51 - Ultimately, a FOD offers a high degree of connectivity within the region 


\section{REGIONAL CONTEXT}

\footnotetext{
$\mathrm{T}_{1}$ he regional context for this design intervention takes the form of a ferry-oriented development (FOD) for Wellington. At this scale the harbour itself acts as a threshold, a liminal zone between the two states of home and work. Traversing the harbour also has a mnemonic potential, referencing a common cultural history of the ocean voyage (as described on page 69).
}

As the images to the left indicate, the proposed FOD consists of dense nodes of inhabitation clustered around ferry terminals along the harbour rim. This positions the harbour at the literal and symbolic centre of an inhabitation model and commuter transport network. A node at the point of greatest activity in the public transport network, Wellington City's transport hub, is proposed as a catalyst for this FOD model. 


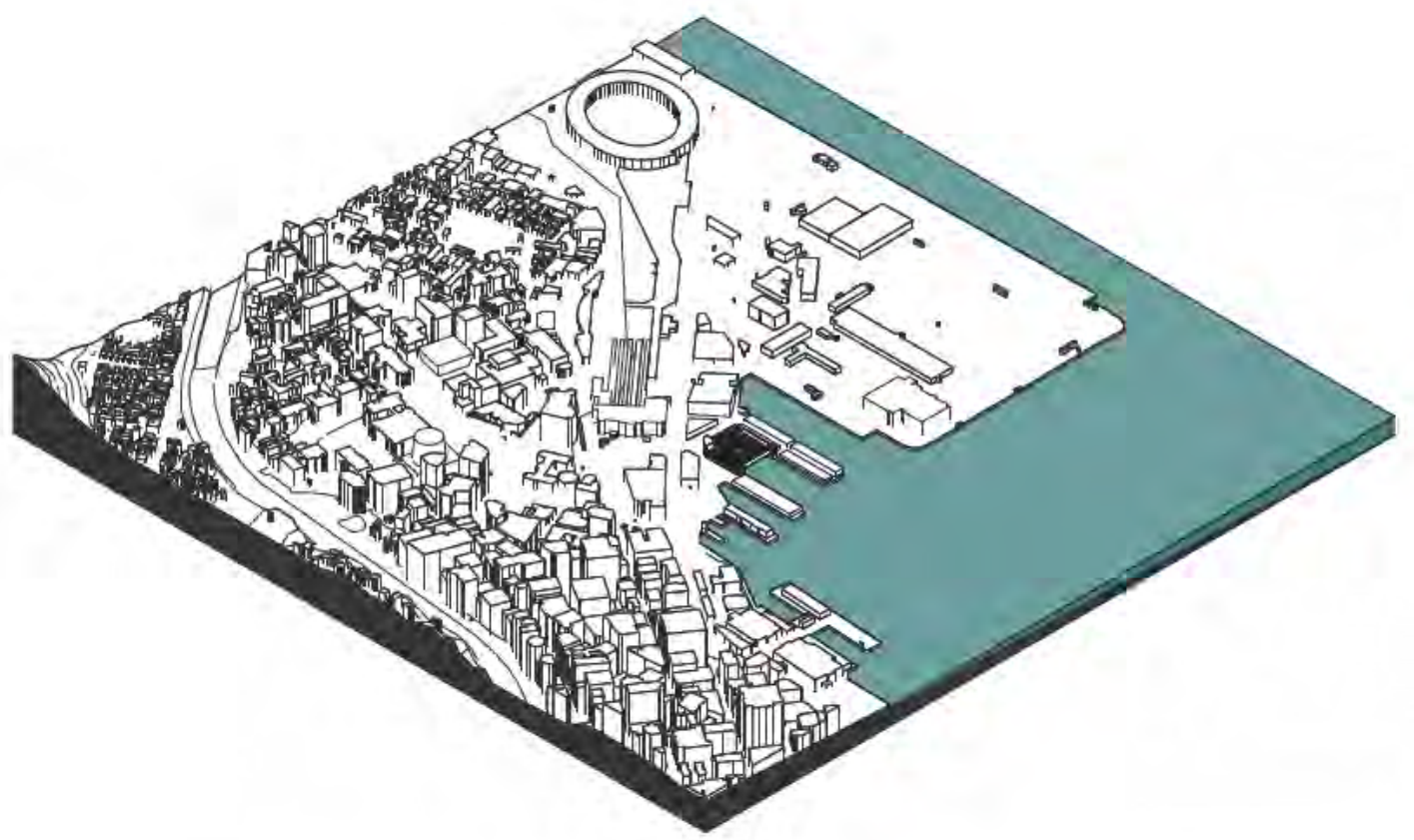

Fig. 52 - Isometric of study area showing intervention in place between Glasgow and Interisland Wharves 


\section{URBAN CONTEXT}

$\mathrm{T}$

he urban context for this design intervention necessarily engages with many factors; adaptive reuse of industrial land, the relationship between the city and the harbour, building in the parliament precinct, to name a few. As indicated in the previous chapter, the proposed terminal is situated at the water's edge between Glasgow and Interisland Wharves.

Repositioning waterborne commuter transport as a credible and valuable player in the mix of modes that make up Wellington's public transport infrastructure network presents an opportunity to critically engage with the arrangement of the 'hub'. The proposal of a harbour ferry terminal then also takes the opportunity to suggest a rationalisation of the hub, thus providing better connectivity between the three primary modes of public transport in Wellington.

Wellington's public transport hub is currently poorly legible. Positioning the proposed terminal between Glasgow and Interisland Wharves suggests that the current Railway Station forecourt could be reconceptualised as Wellington's 'hub' area. 


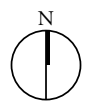

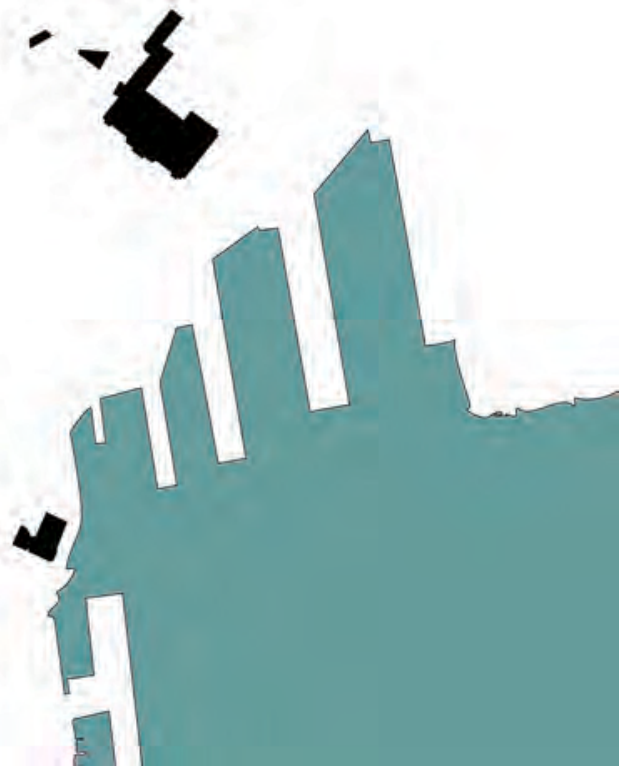

Fig. 53 - Current arrangement of the three primary public transport commuter modes

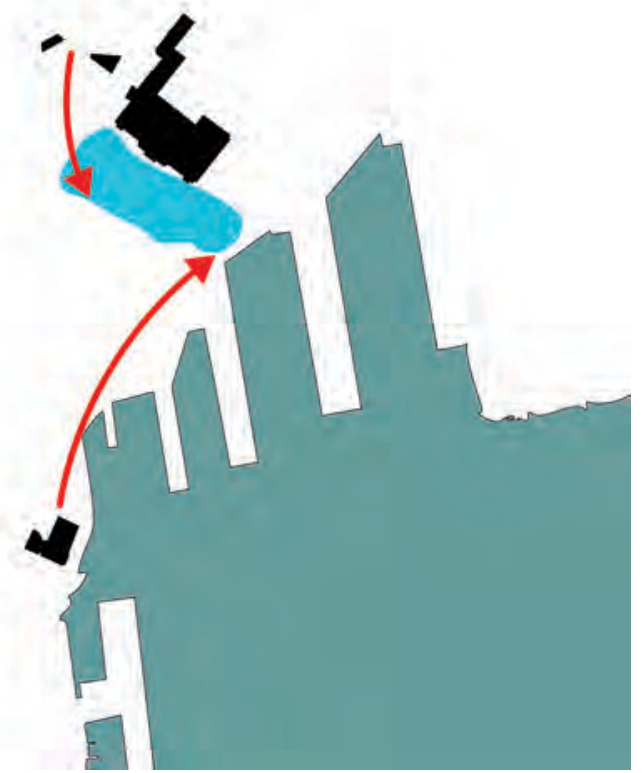

Fig. 54 - Suggested re-arrangement, framing the Railway Station forecourt as the hub area 


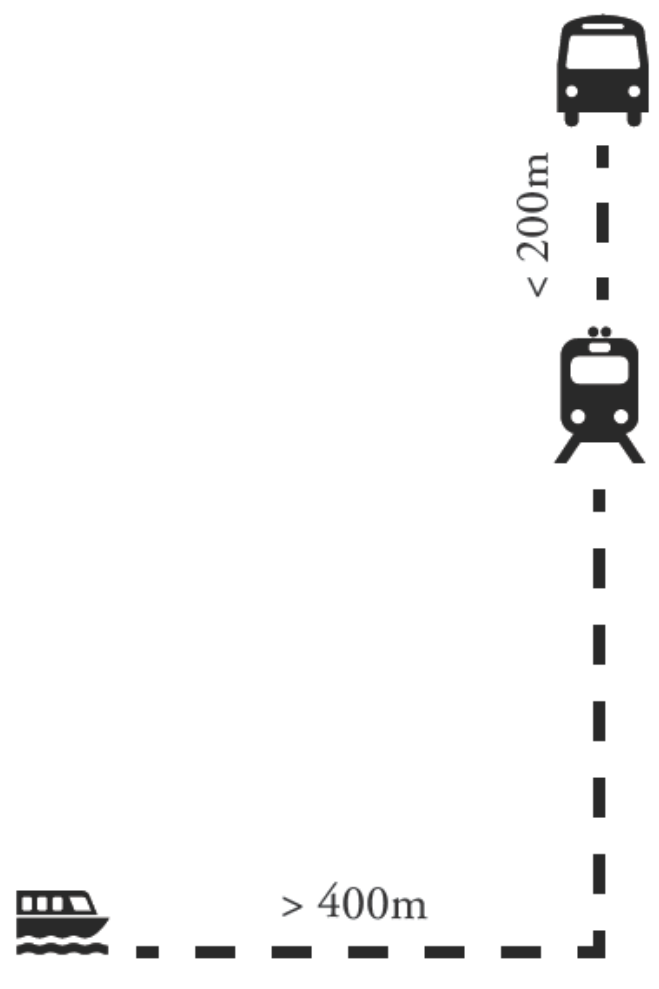

Fig. 55 - Diagrammatic representation of current modal arrangement, indicating relative proximities. Dashed line indicates lack of visual connection

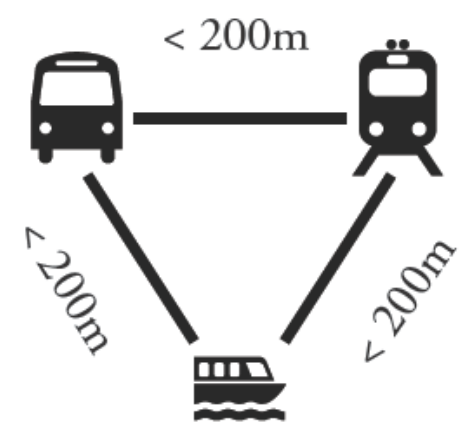

Fig. 56 - Diagram of suggested spatial arrangement, solid line indicates visual connection 


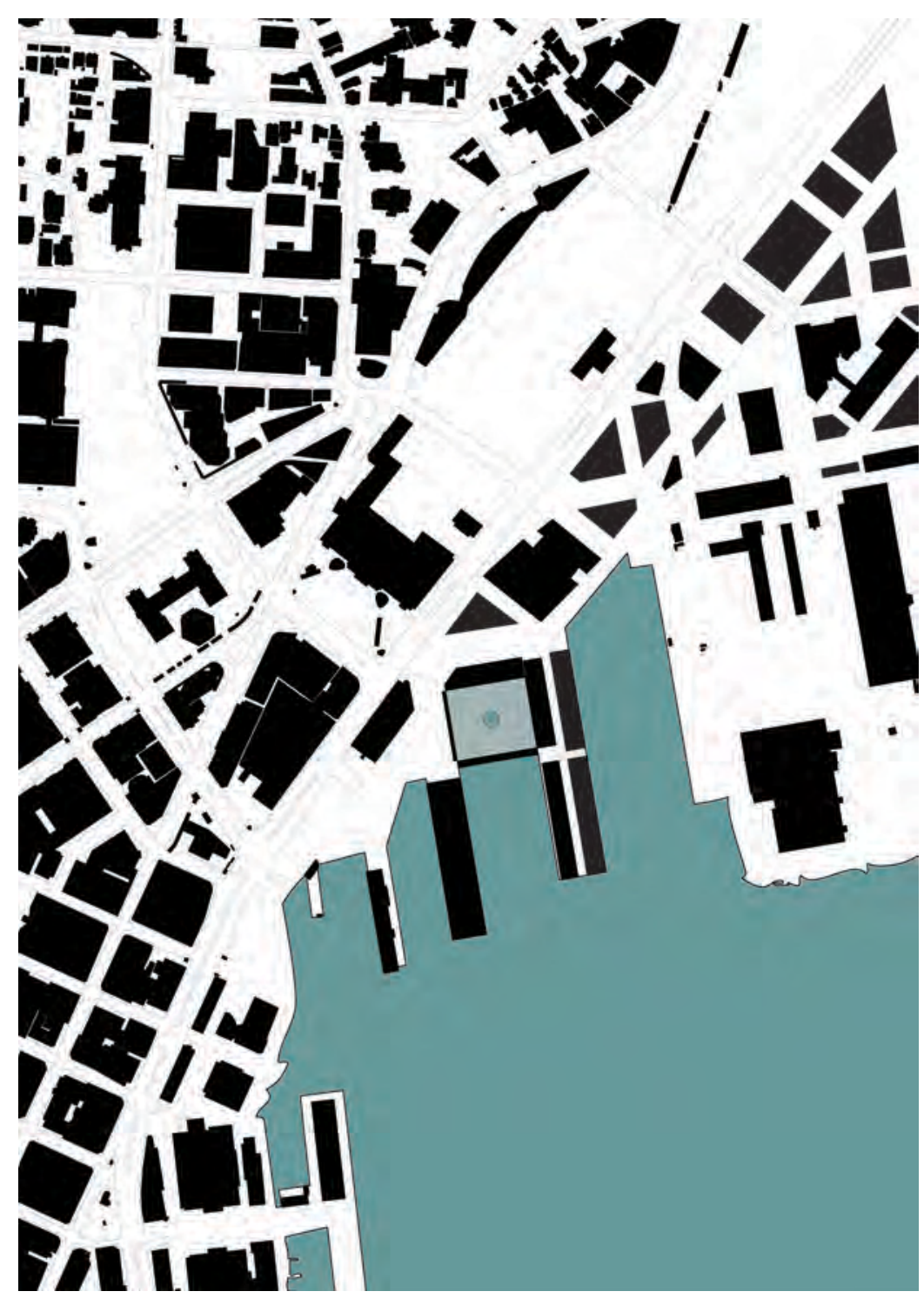

Fig. 57 - Proposed figure ground showing interventions in place, preliminary roads for former rail yard development, and restoration of street edge at former bus terminal. 1:10,000 (see figure 33, on page 87 for comparison) 


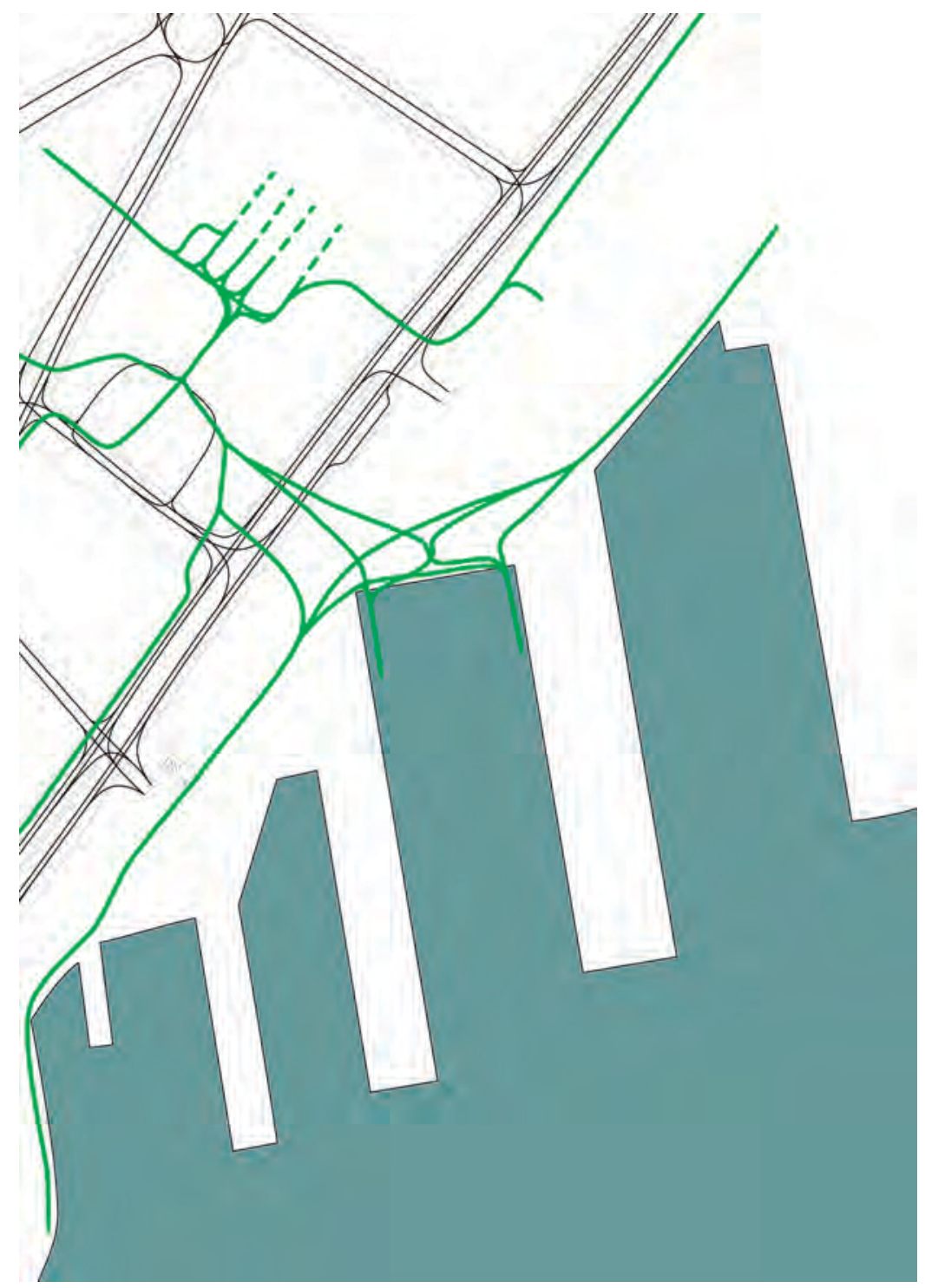

Fig. 58 - Proposed vectors showing continuation of waterfront promenade and increased pedestrian connectivity across Waterloo Quay. 1:4,000 (see figure 35 , on page 89 for comparison) 


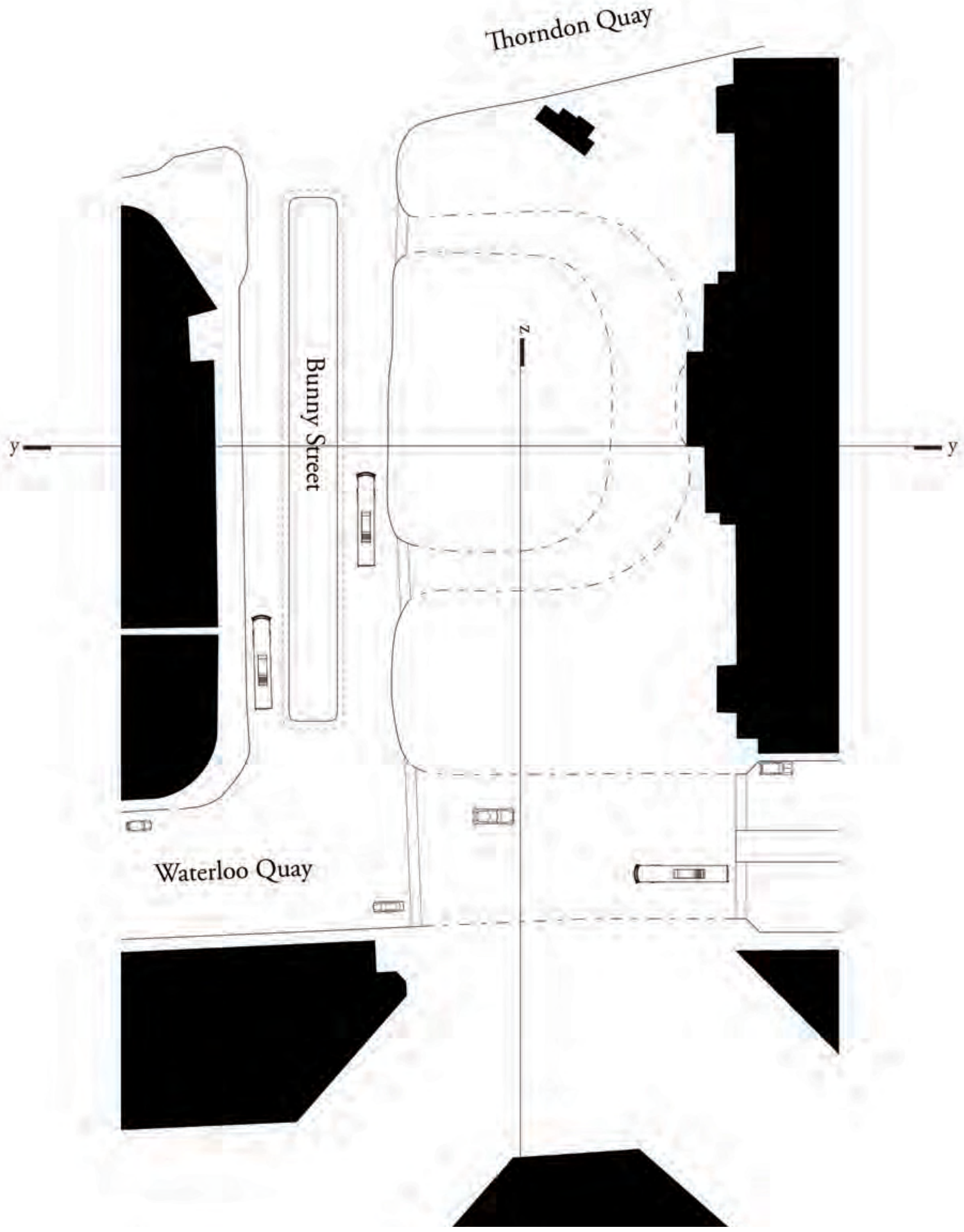

Fig. 59 - Sketch design of proposed central hub area, showing Bunny Street as bus station, and corner of the ferry terminal at bottom of the diagram. 1:1000 


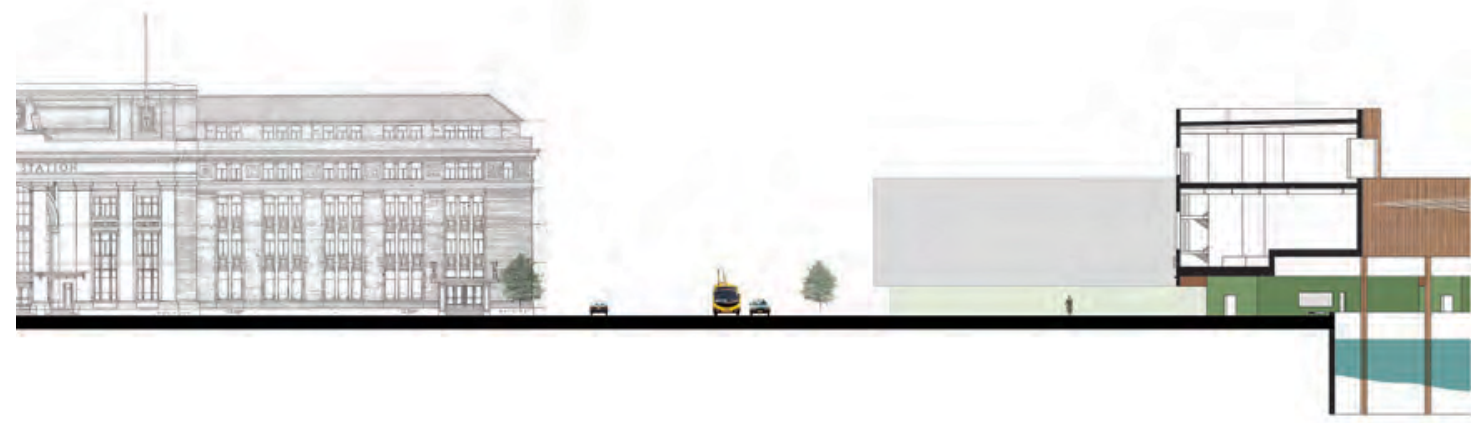

Fig. 60 - Section z-z 1:1000 showing relationship of proposed ferry terminal to Wellington Railway Station.

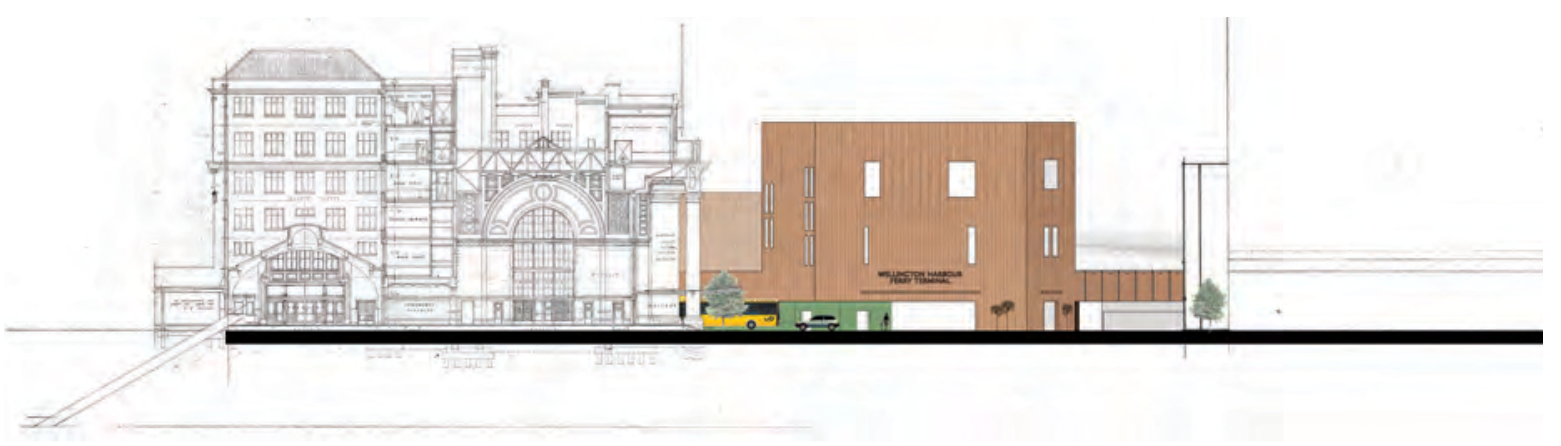

Fig. 61 - Section y-y 1:1000 showing relationship of proposed ferry terminal to Wellington Railway Station. Note the escalators from the underground rail.

Part of this vision for the public transport hub is the tunnelling of rail underground from the northern tip of the city, freeing up urban land for development in an area identified for intensification (see WCC urban development strategy on page 79). In this scenario, the bus depot takes over the land that currently holds railway platforms, allowing the area of Lambton Quay where the bus terminal currently is to become a street again, connecting through to Thorndon Quay.

The former railway platform area would in this scenario accommodate a reconfigured national bus station and a local bus depot servicing the terminal on Bunny Street. Running bus services from Bunny Street would aid legibility of the hub. The harbour ferry terminal frames the hub from the south. 
(1)

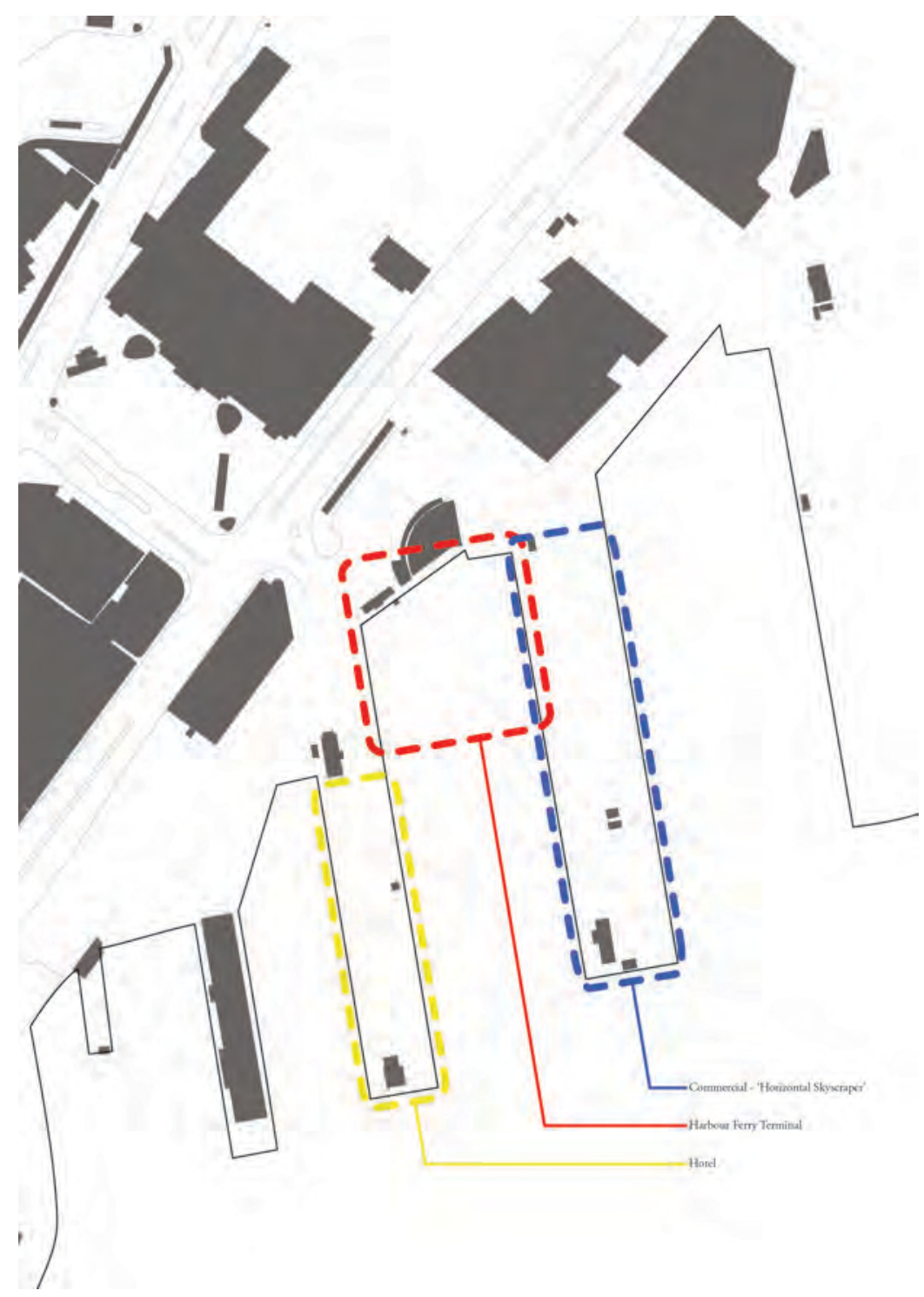

Fig. 62 - Site schematic showing primary development zones and programs. 


\title{
TERMINAL PRECINCT
}

\author{
- Proposed works -
}

$\mathrm{T}_{\mathrm{k}}$ he terminal precinct is a proposed urban development, centred around a harbour ferry terminal, that links the Wellington Waterfront promenade with Harbour Quays developments, and is instrumental in rationalising the public transport commuter hub.

The three primary development zones are shown in figure 62. While program and massing consideration have been addressed for all three zones, the harbour ferry terminal is the focus of this design work.

Characterised by an intimate relationship between built fabric and the harbour, the area differentiates itself from the more open, and exposed, public areas to the south. This is symbolic of the work of the terminal in bringing the harbour into a more immediate relationship with our inhabitations. 


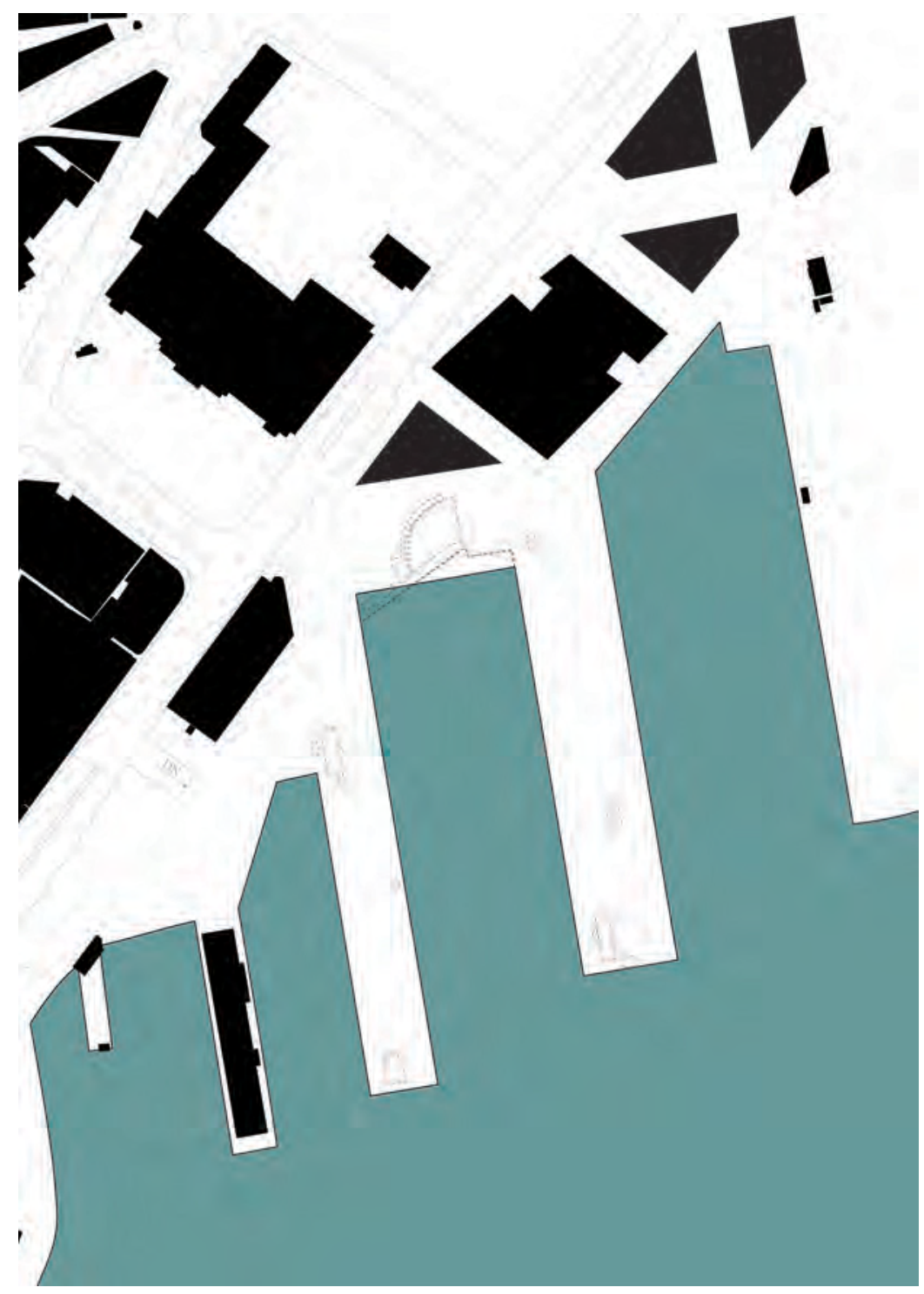

Fig. 63 - Preliminary Site Works 1:4000. Harbour Quays is shown complete. Dashed line indicates demolition.

Fig. 64 - Site Plan 1:2000 
$0^{N}$

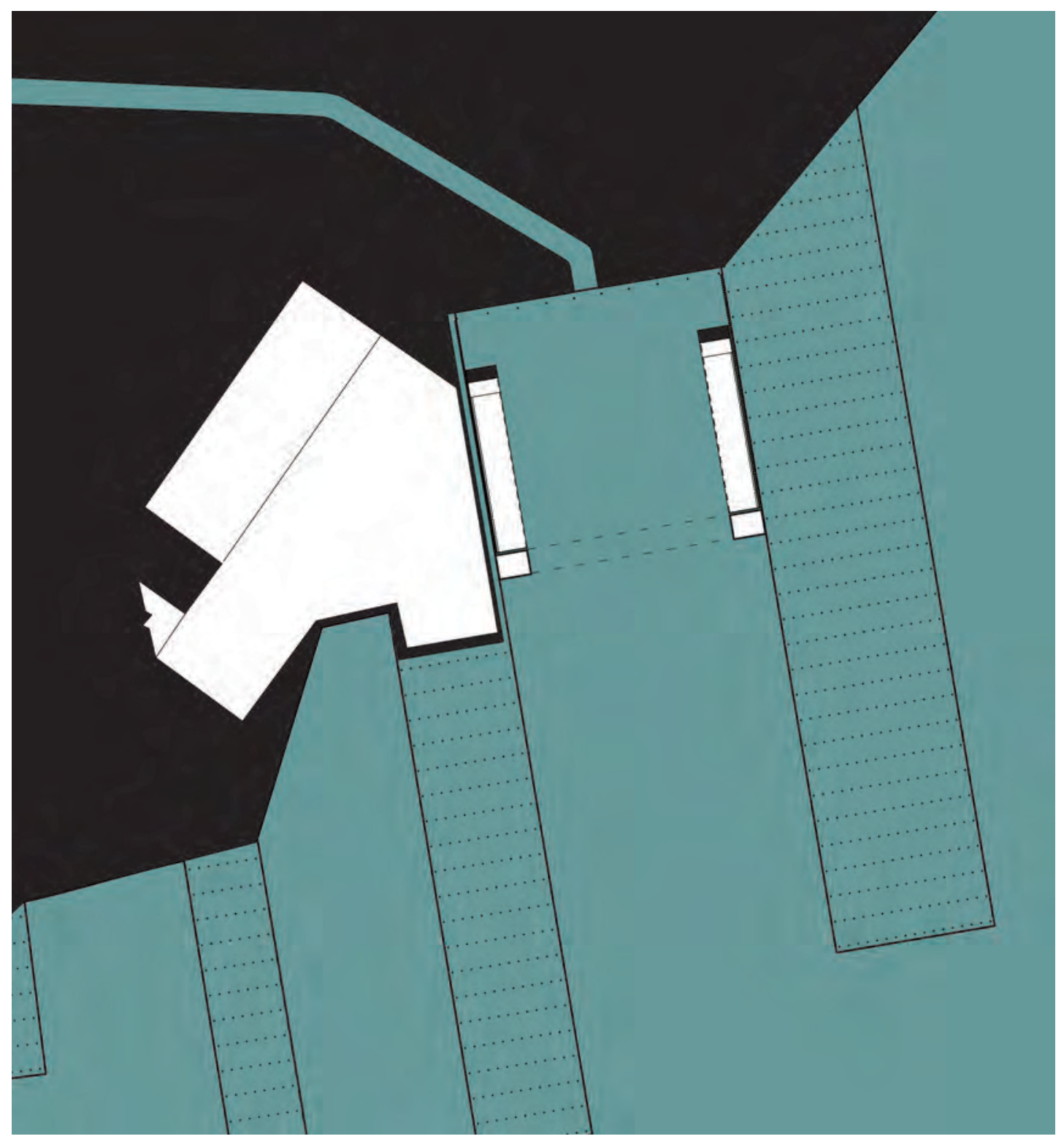

Fig. 65 - Sub-floor plan showing underground parking for hotel and apartments, and Waipuri Stream culvert. 1:2000 


\section{MASTER PLAN}

$\mathrm{T}$ he proposed harbour ferry terminal is situated between Glasgow and Interisland Wharves - these finger wharves remain intact in the proposal, with minor alteration of the seawall and re-routing of the Waipuri Stream culvert (see figure 65) accounting for the bulk of site alterations associated directly with the terminal. Underground car parking for the hotel and apartments at Shed 21 is accessed from Waterloo Quay at the south end of Shed 21.

The triangular building to the north of the proposed ferry terminal is taken from the Harbour Quays master plan, which does not indicate a program, merely the footprint. This thesis proposes that the building house Metlink (Wellington's public transport provider) on the upper levels, with the ground floor occupied by a public bicycle rank ${ }^{17}$ (see page 168).

Glasgow Wharf is reconceptualised as a horizontal skyscraper (see page 172), with commercial activity at the land-side 'base' graduating into private offices and conference facilities at the seaward 'base'.

Interisland Wharf is the proposed site for a new five-star hotel (see page 171).

${ }^{17}$ Wellington City was gifted 100 bicycles by the Mayor of Beijing in July 2011 


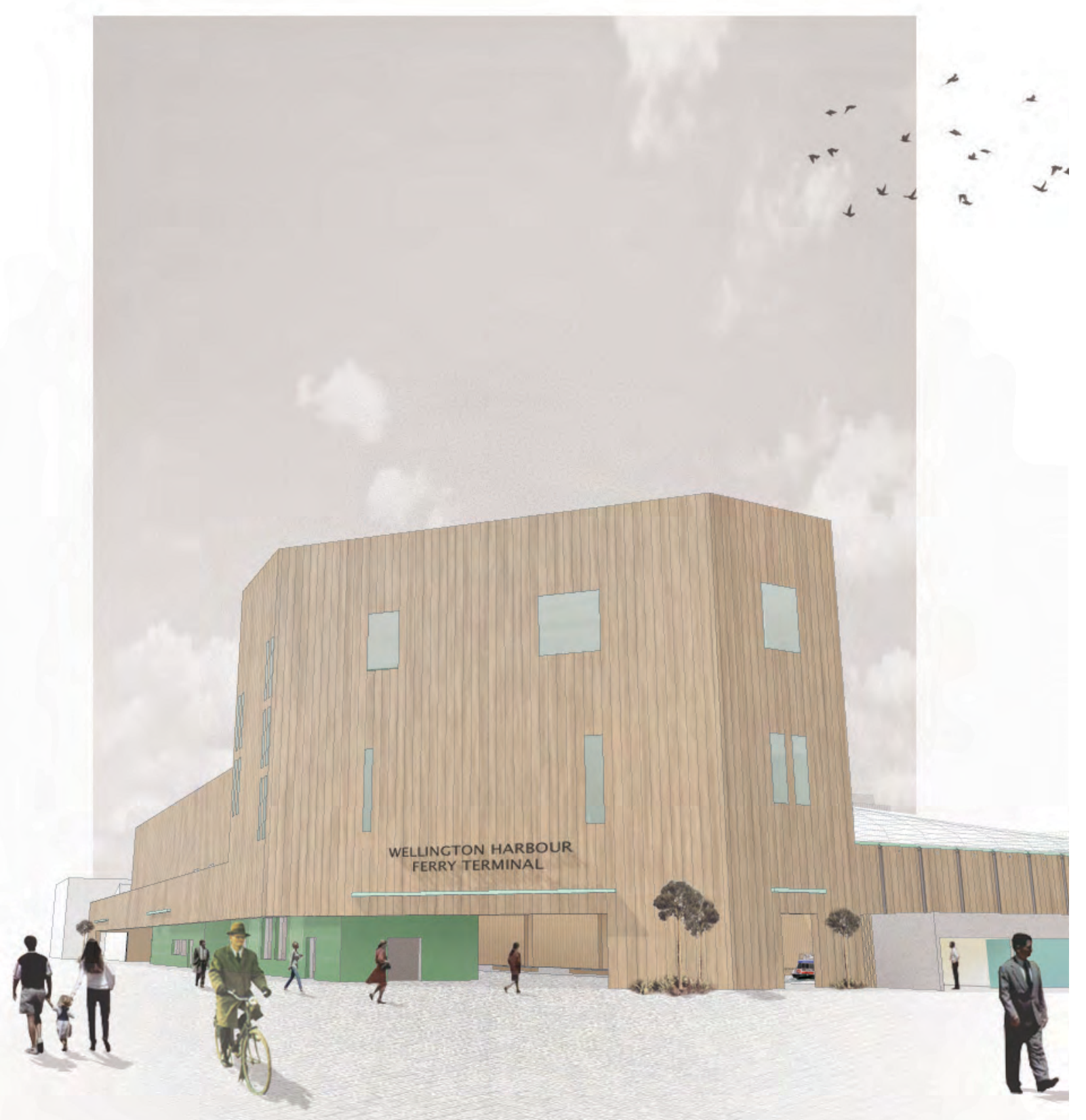




\section{WELLINGTON HARBOUR FERRY TERMINAL}

\footnotetext{
$\mathrm{T}$ his section outlays the design of the harbour ferry terminal - the keystone in the terminal precinct proposal. Initially discussed in terms of the over-all layout and generic qualities of the building, the terminal is then broken down into discrete parts for discussion.
}

The proposed harbour ferry terminal layout sets up a strong north - south axis derived from the existing finger wharf layout, giving direction to the processional route. This is further embellished by the layout of water elements through the building - the large oculus in the centre of the canopy admitting rain into the centre of the main hall, the Waipuri Stream culvert outlet centred on the sea wall, and in front of the building a bore brings water from the aquifer below Wellington Harbour to the surface.

Drawing on the materiality of the site, as identified in the previous chapter, massive timber members form the basic building element of the design. Timber is an apt material for the site, and also as a mnemonic driver. The timber (Ironbark, a Eucalyptus used extensively in the construction of the finger wharves) is used both as a structural material and cladding, finished with oil to allow the timber to be seen.

Fig. 66 - Perspective of the proposed harbour ferry terminal from the north-eastern end of Shed 21. 


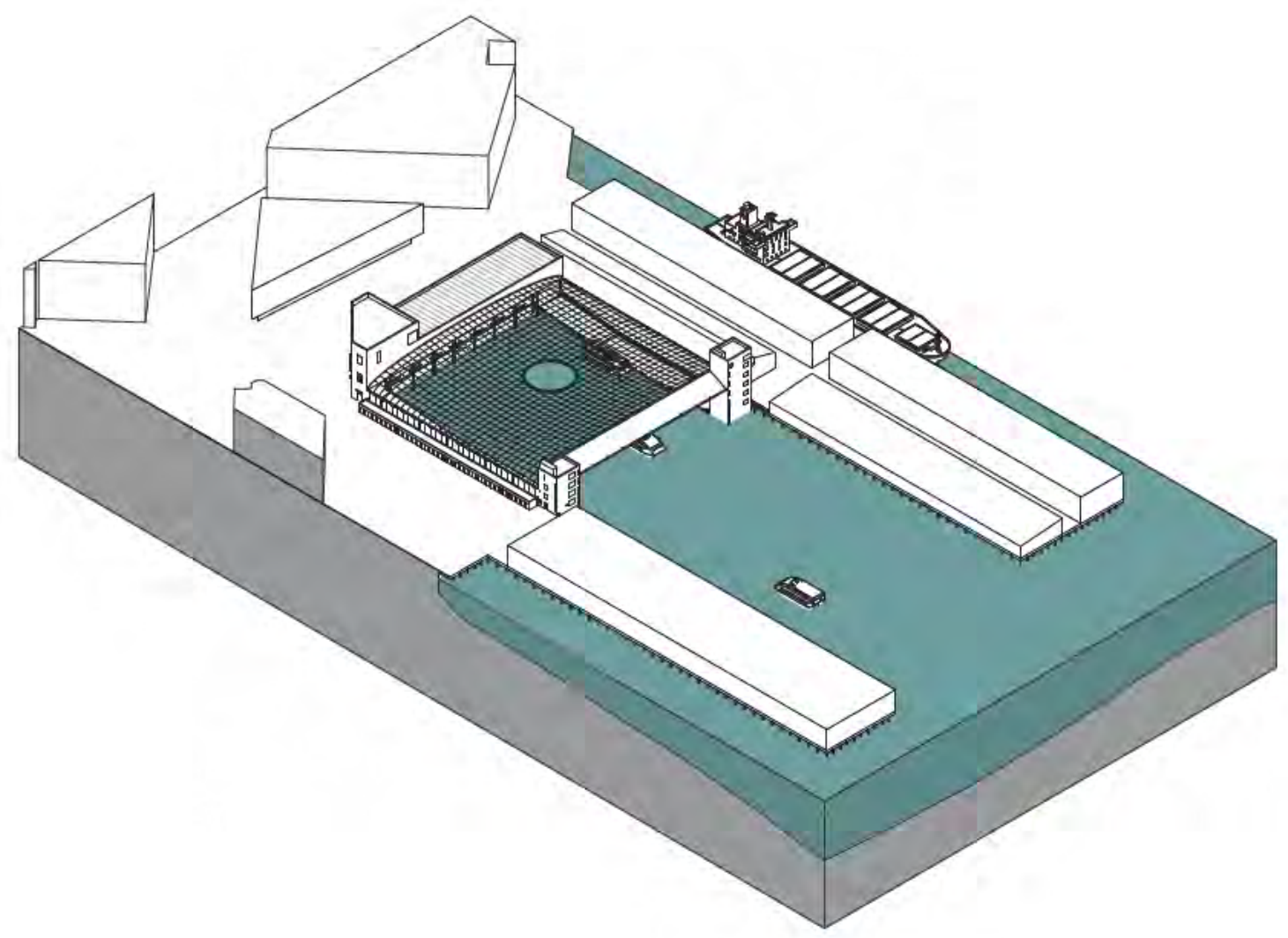

Fig. 67 - Isometric of proposed harbour ferry terminal in context 1:6000

Fig. 68 - Terminal ground floor plan 1:1000 
(1)
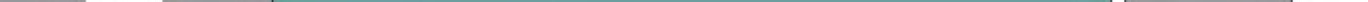


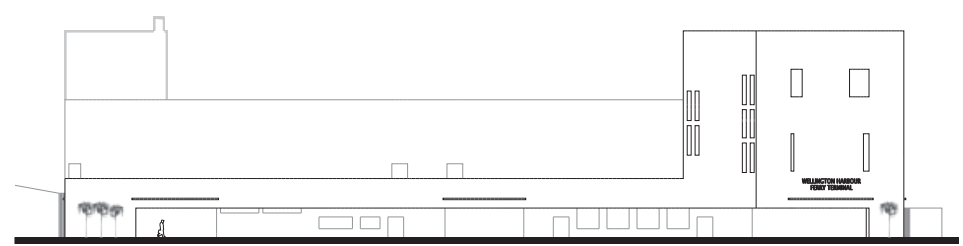

Fig. 69 - North elevation 1:1000

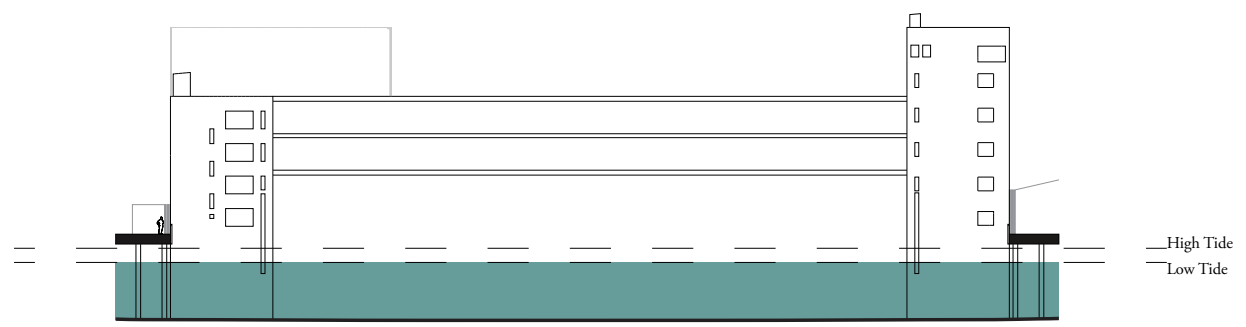

Fig. 70 - South elevation 1:1000

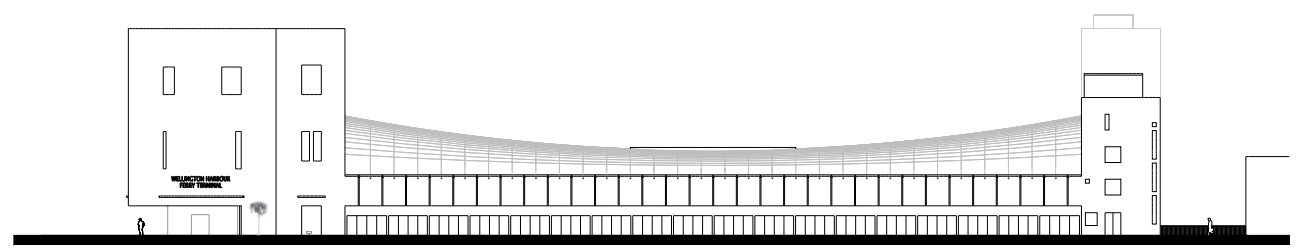

Fig. 71 - West elevation 1:1000

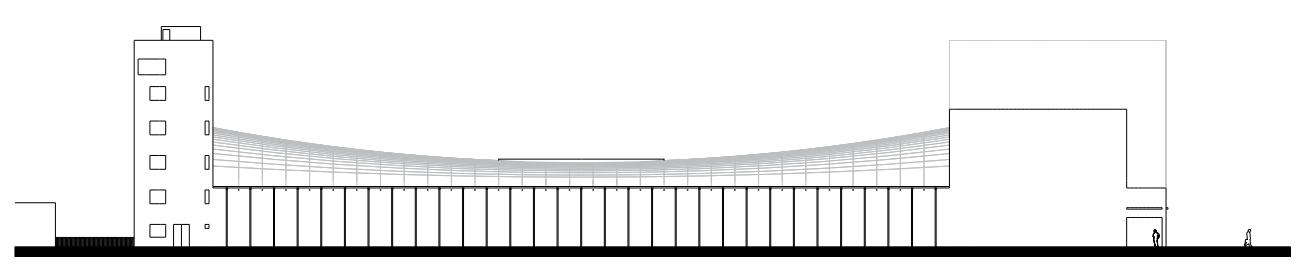

Fig. 72 - East elevation 1:1000 


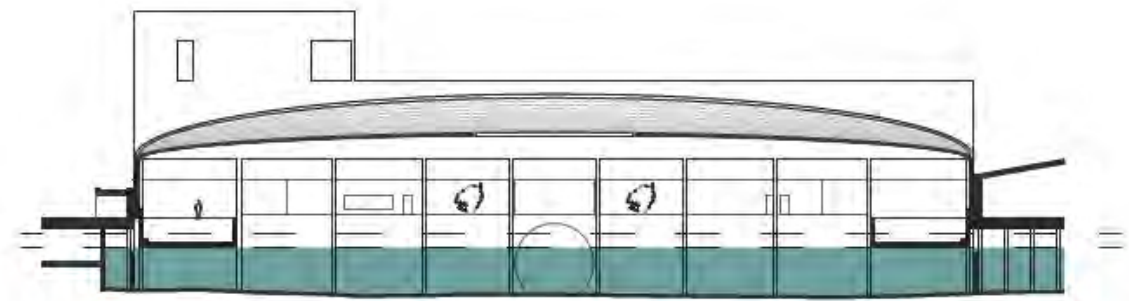

Fig. 73 - Section a-a 1:1000

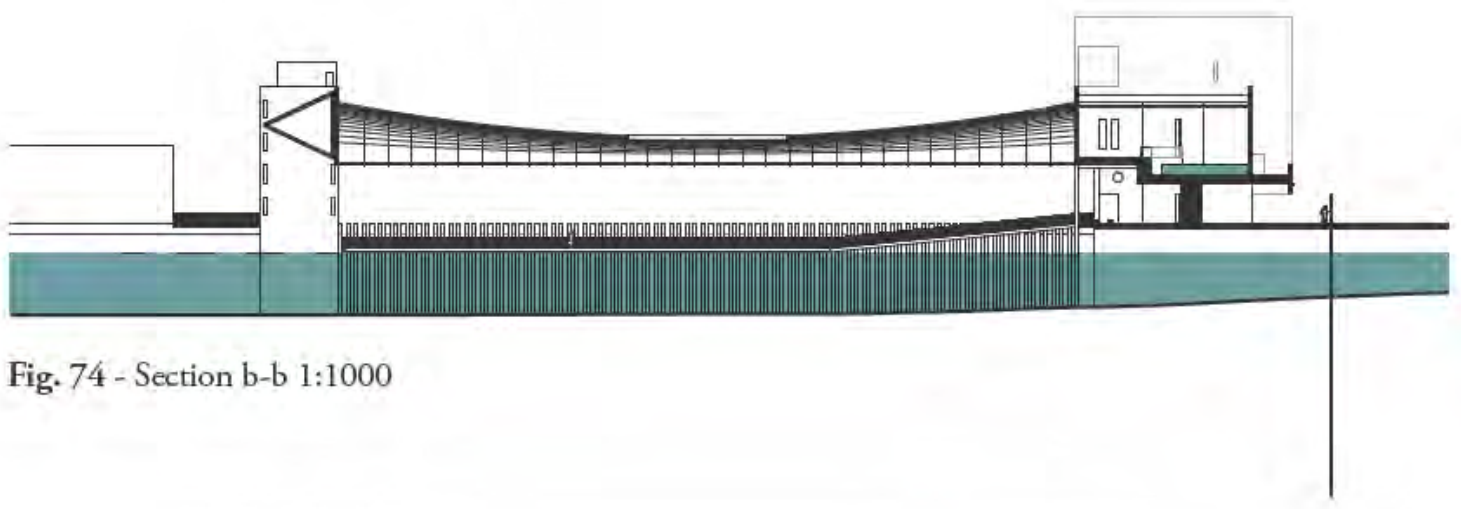




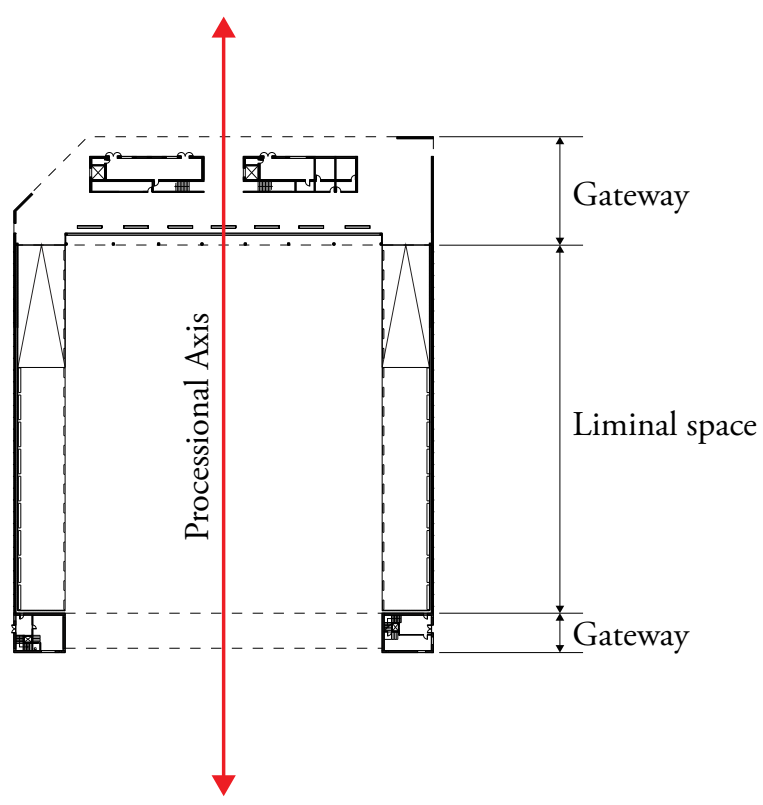

Fig. 75 - Schematic diagram of terminal procession. NTS

Schematically, the ferry terminal building is conceptualised as a liminal zone framed by a pair of gates, signifying thresholds. This spatialises, in a basic manner, the process of ritual within a single building. As described on the previous page, water performs the primary symbolic role of the waterborne commute ritual, thus a large portion of the main hall of the terminal (the liminal zone) is given over to water. This functions as a symbolic gesture, but also operationally, allowing plenty of room for ferries to manoeuvre.

Programmatically, the towers of the harbour gate house offices for the relocated tugboat operators and harbour master (the large truss that connects these towers to form the gate is uninhabited). The liminal zone is the main hall of the terminal, where passengers embark and disembark from ferries. The city gate houses a ticketing and information office, a fish monger, a café and toilets on the ground floor. On the first floor is a prototype urban eel farm, with associated offices on the third. An eel farm offers an apt analogy for the building and the ferry commuters, which straddle land and sea, crossing the threshold of the shoreline as eels do. 


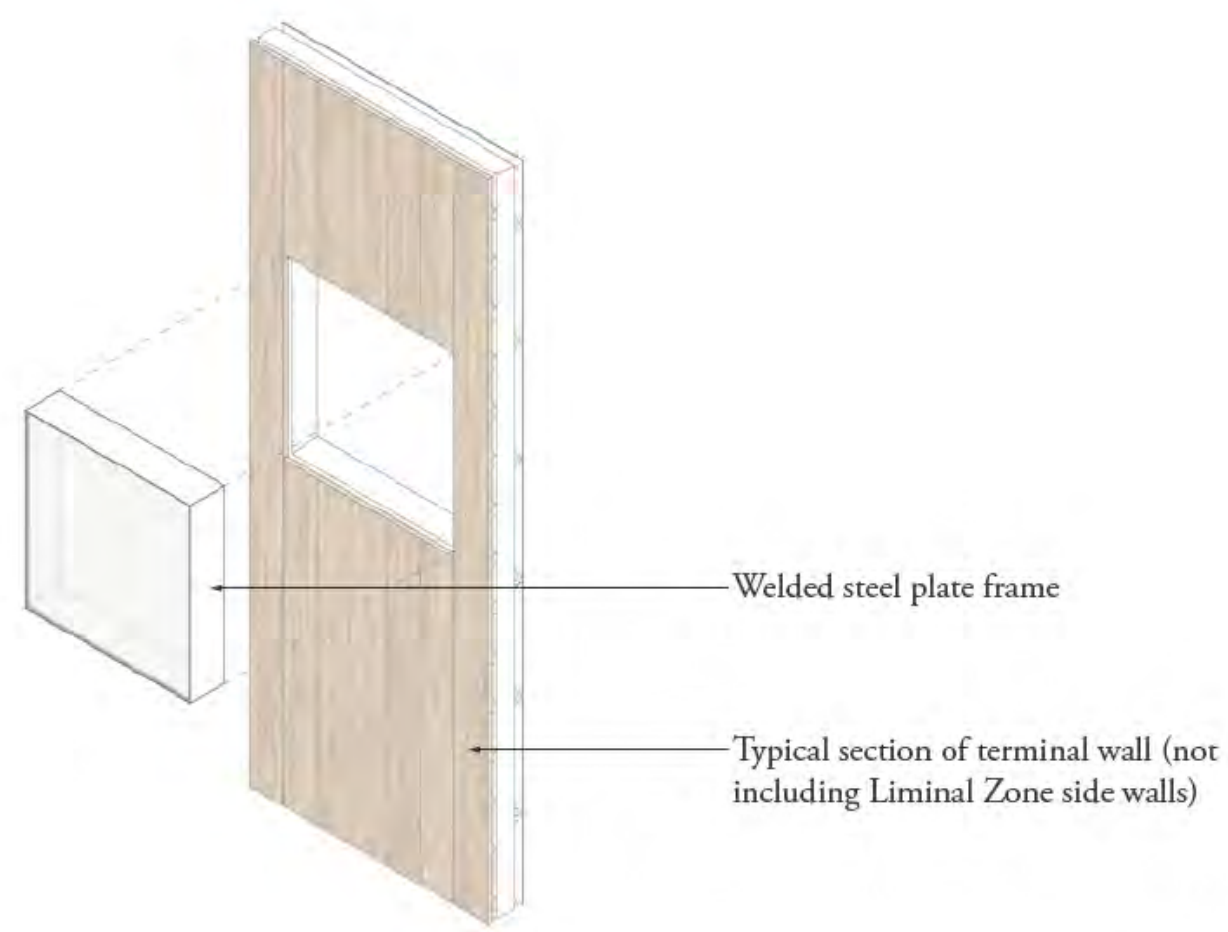

Fig. 76 - Exploded isometric of typical window and wall construction 1:100. Window frame is constructed from welded solid steel plates, creating a thin profile.

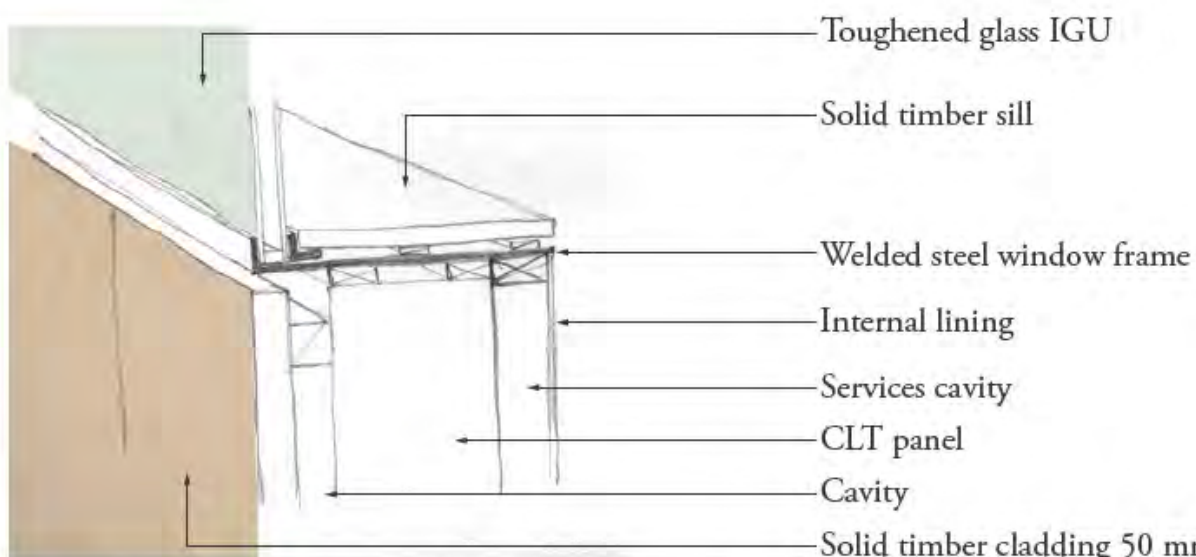

Solid timber cladding $50 \mathrm{~mm}$ thick

Fig. 77 - Sketch detail of typical window jamb. NTS $400 \mathrm{~mm}$ wide panels fixed at $500 \mathrm{~mm}$ centres 


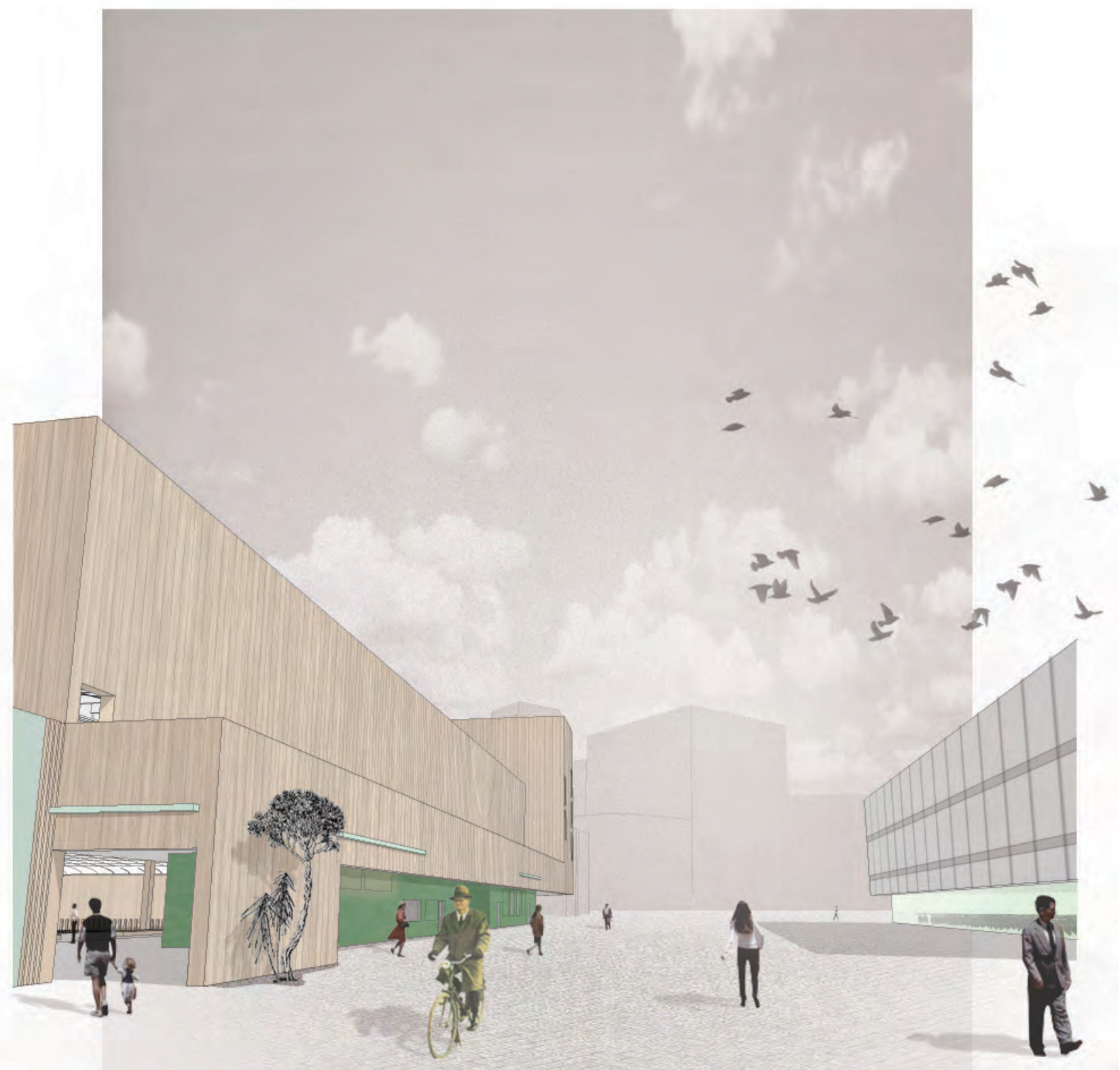




\section{CITY GATE}

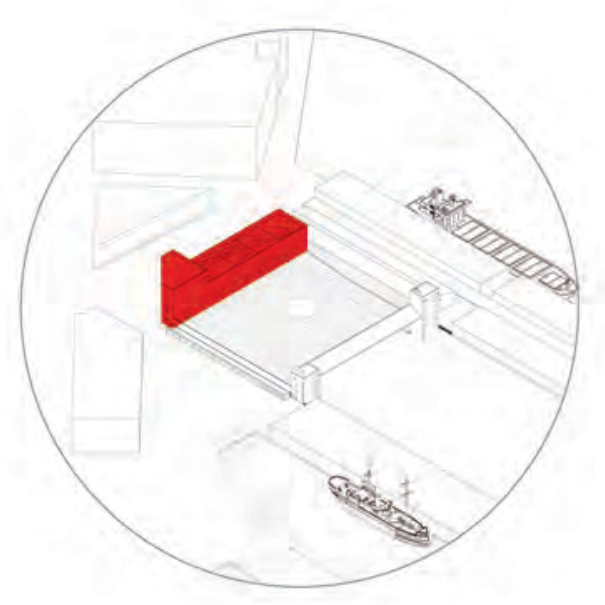

$\mathrm{T}$

he city gate is the northern component of the terminal building, functioning as the receiver of commuters leaving the city and the deliverer of those arriving. A large timber mass floats over a pair of volumes clad in stacked glass, giving the impression of a long horizontal opening with glimpses through to the main hall of the terminal. These are described as boulders, as they interrupt the flow of pedestrians through the gate, creating eddies of relative calm where appropriate programs are situated.

Copper gutters (shown here with a high degree of patina) mark and reduce dripping at the entrance points.

Fig. 78 - Looking west from the BNZ Building, the city gate of the terminal frames a new pedestrian space that acts as a continuation of the waterfront promenade. 


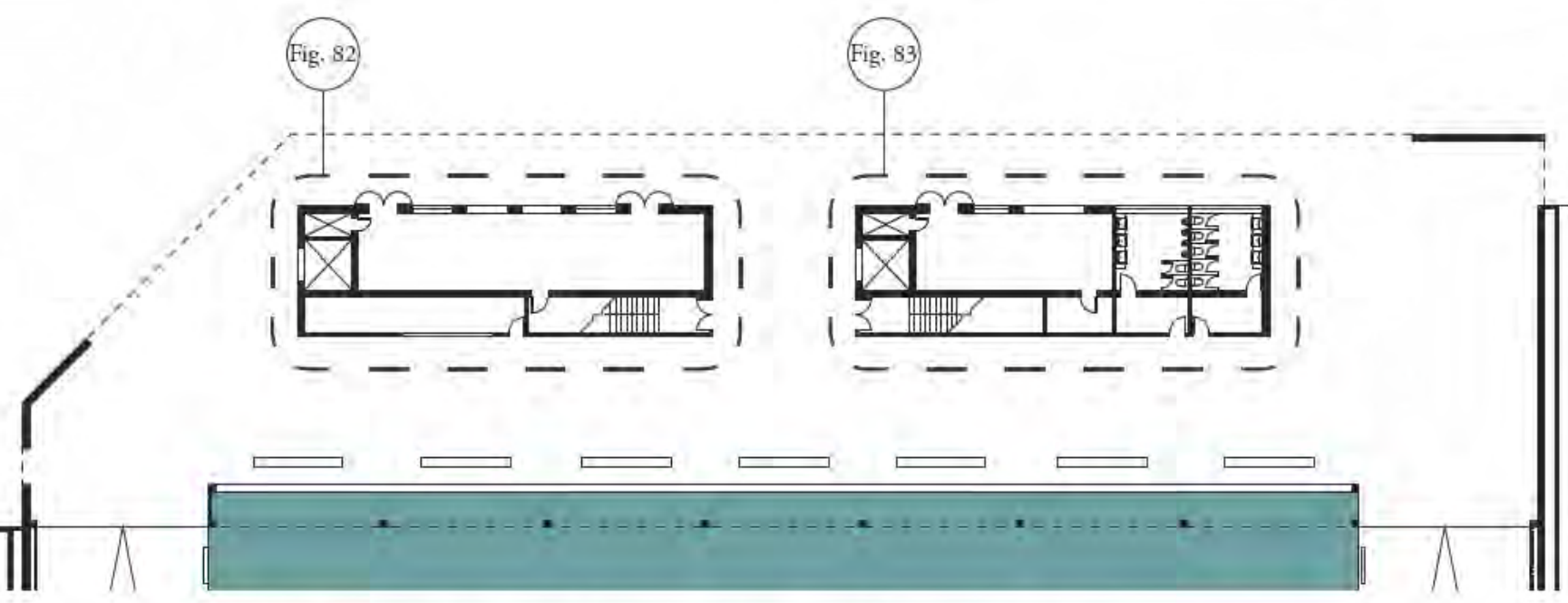

Fig. 79 - Ground Floor 1:500 (see call-outs over for detail of 'boulder' planning)

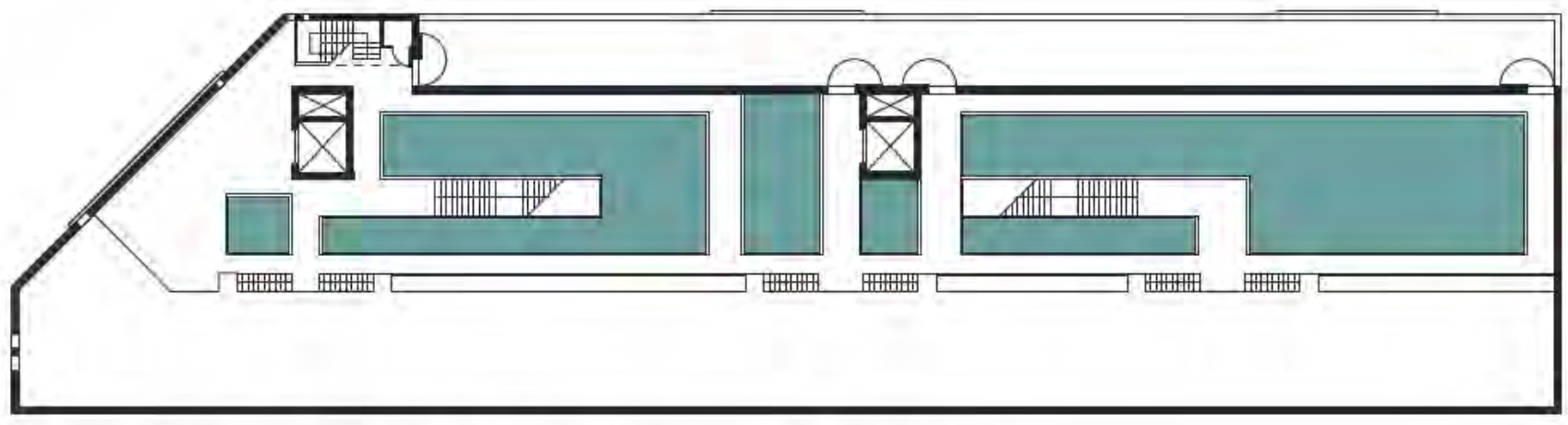

Fig. 80 - 1st Floor Plan (NIWA Eel Farm prototype facility) 1:500

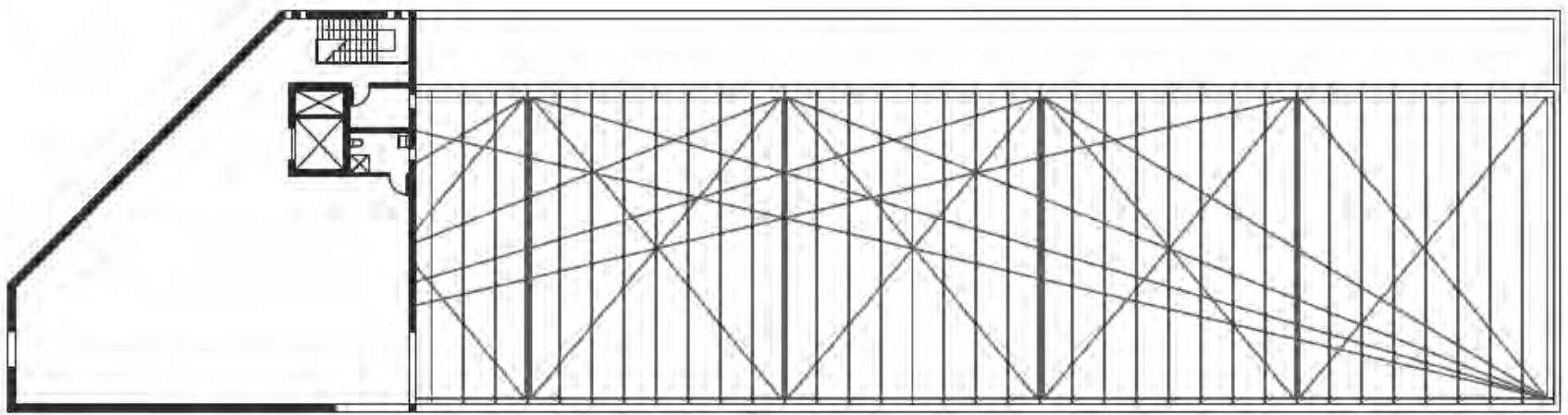

Fig. 81 - 2nd Floor Plan (NIWA Eel Farm prototype facility office), showing Bollman truss over the eel farm. 1:500 


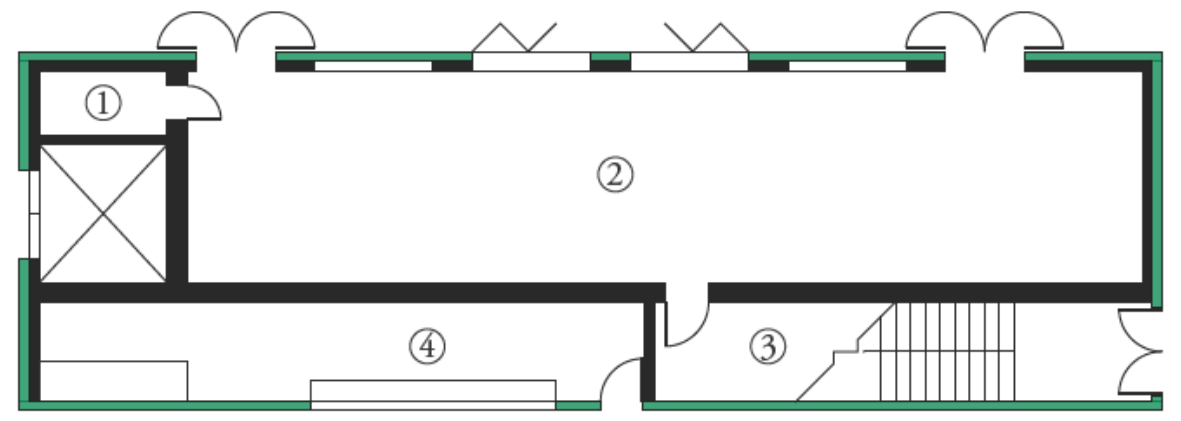

Fig. 82 - West Boulder plan 1:200.

1. Services core

2. Fish Monger

3. Storage

4. Ferry Information / Ticket Office

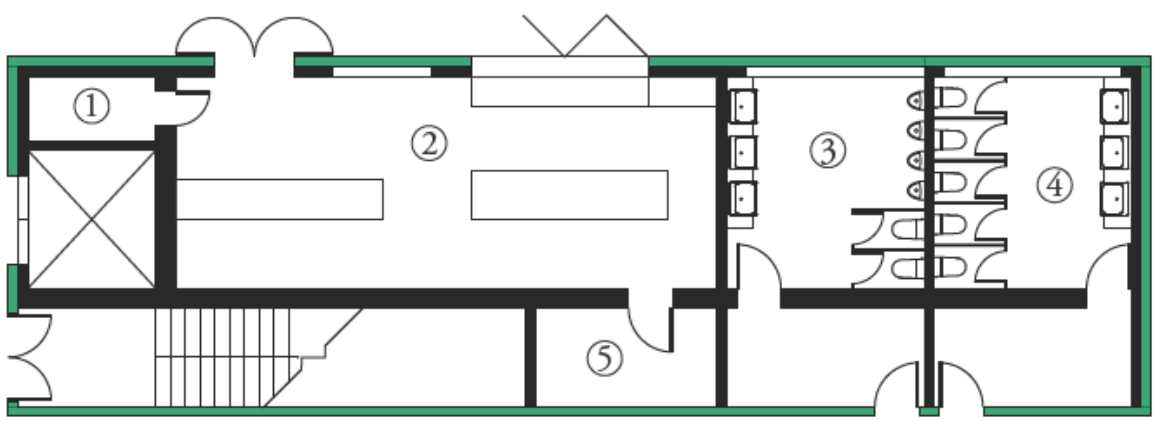

Fig. 83 - East Boulder plan 1:200.

1. Services core

2. Café

3. Male Toilets

4. Female Toilets

5. Storage 


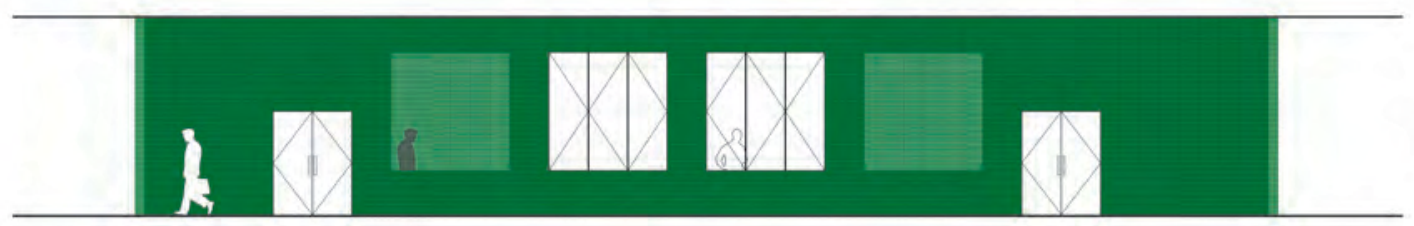

Fig. 84 - West Boulder north elevation 1:200

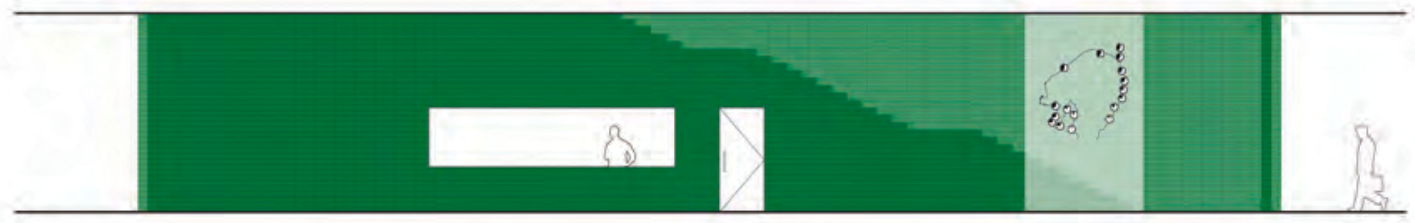

Fig. 85 - West Boulder south elevation 1:200, showing departure and arrival infographic

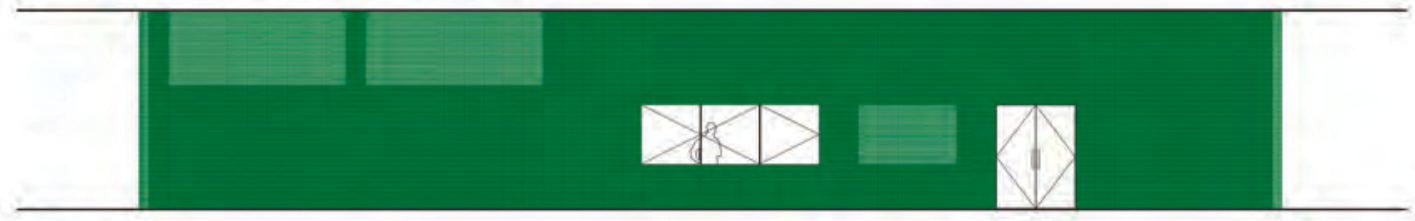

Fig. 86 - East Boulder north elevation 1:200

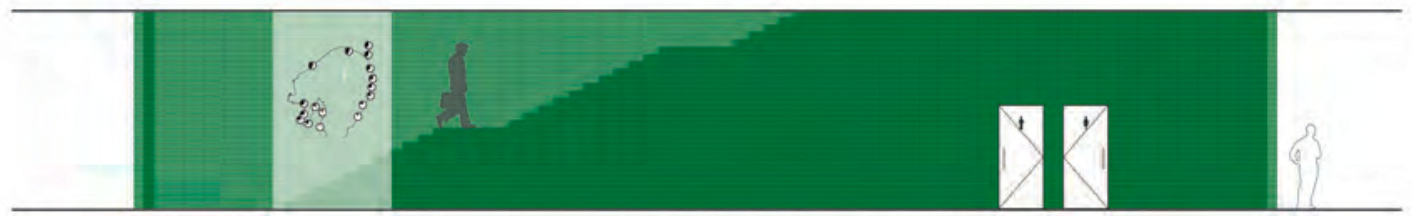

Fig. 87 - East Boulder south elevation 1:200, showing departure and arrival infographic 


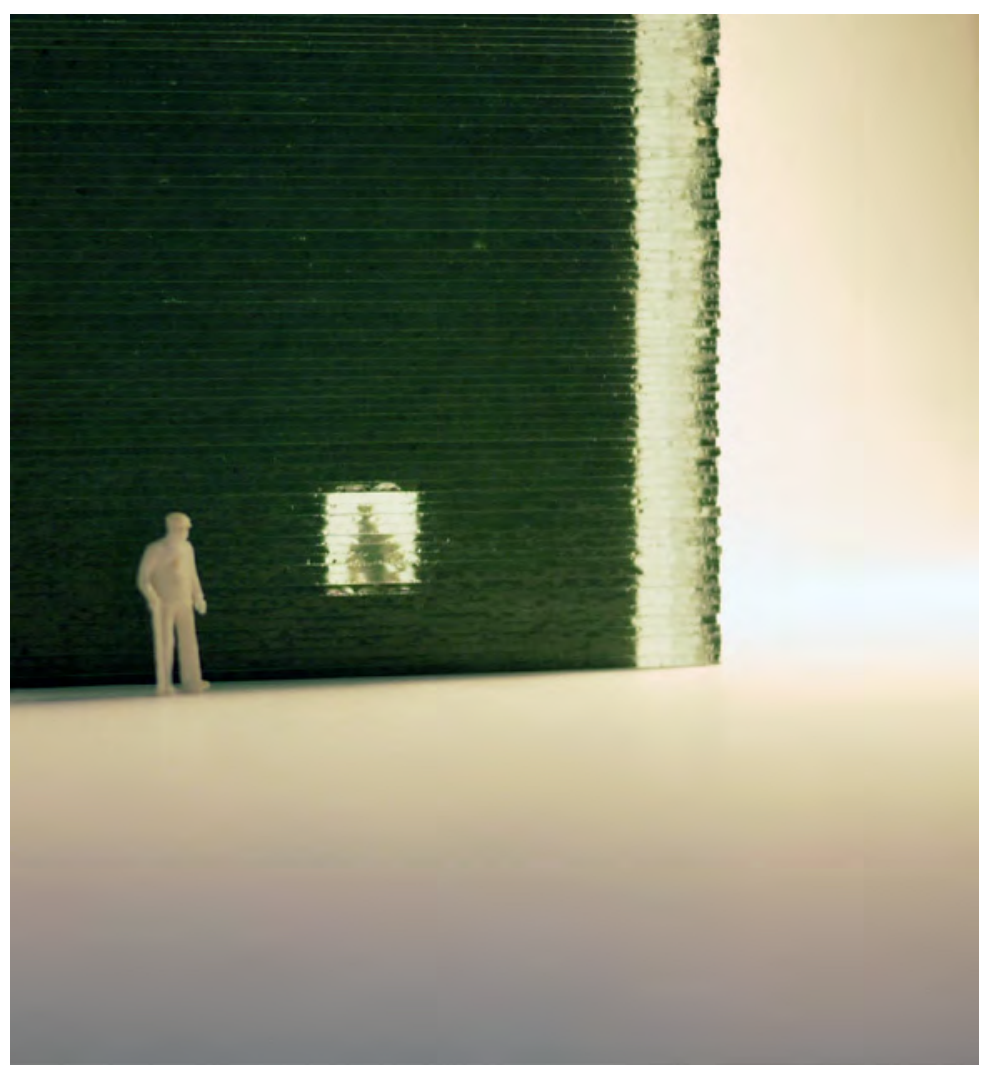

Fig. 88 - Materiality mock-up, testing lighting effects of stacked glass

The two rectangular volumes on the ground floor of the city gate are composed of stacked $200 \times 800 \mathrm{~mm}$ sheets of $20 \mathrm{~mm}$ thick glass, backed on to $200 \mathrm{~mm}$ thick reinforced concrete sheer walls. These sheer walls are cut in places to form door and window openings, some of which are covered in the stacked glass to create lighting effects reminiscent of water. The glass sheets are stacked in a stretcher bond creating a $400 \mathrm{~mm}$ horizontal rhythm that echoes the timber module used elsewhere in the terminal building. 


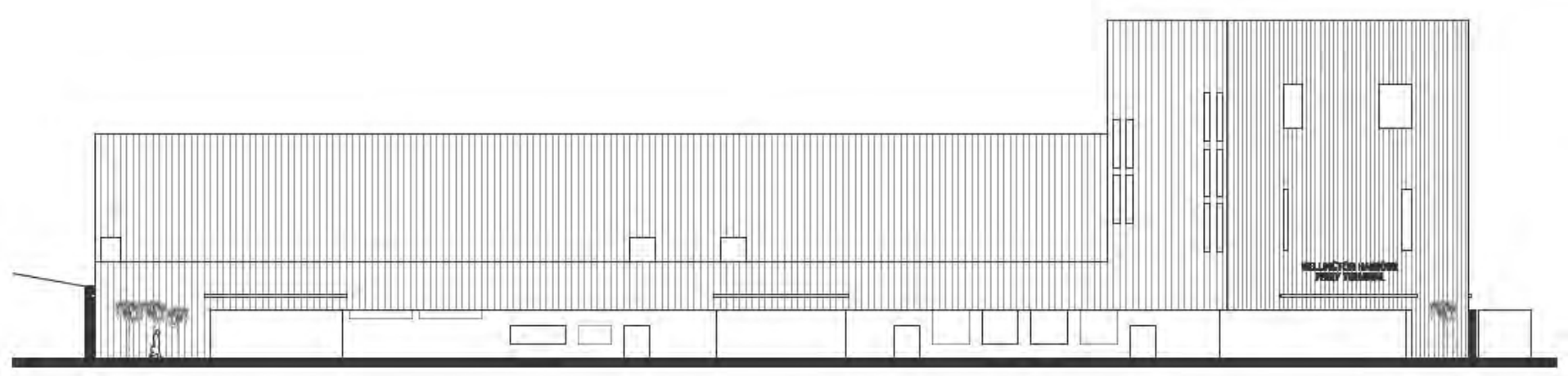

Fig. 89 - North elevation 1:500

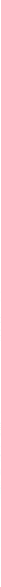

Fig. 90 - South elevation 1:500 


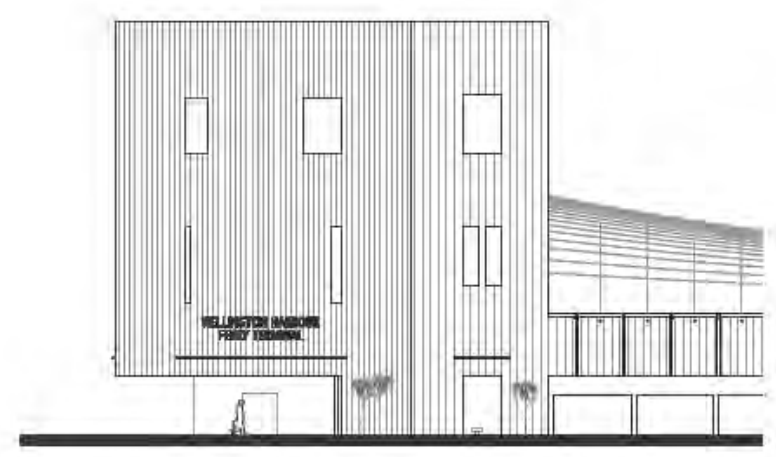

Fig. 91 - West elevation 1:500

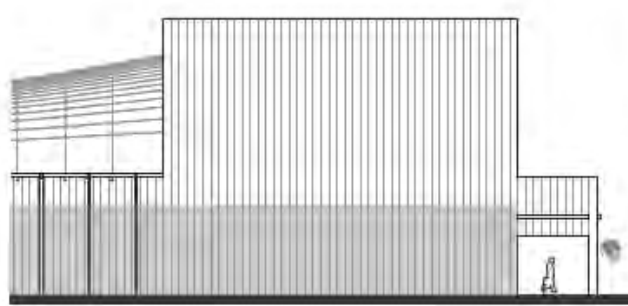

Fig. 92 - East elevation 1:500

The stacked glass is an abstraction of water, and the timber representative of land. In this way the north facade echoes the view beyond - receding layers of land over the water. From the interior the city gate references the finger wharves themselves, commuters passing under an abstracted wharf, hinting at the ambiguity suggested by liminality.

The lack of fenestration in the eel farm references the eel's natural habitat - as in streams and rivers, light comes from above. The large Bollman truss (figure 81) represents the branches of overhanging vegetation in the wild. 


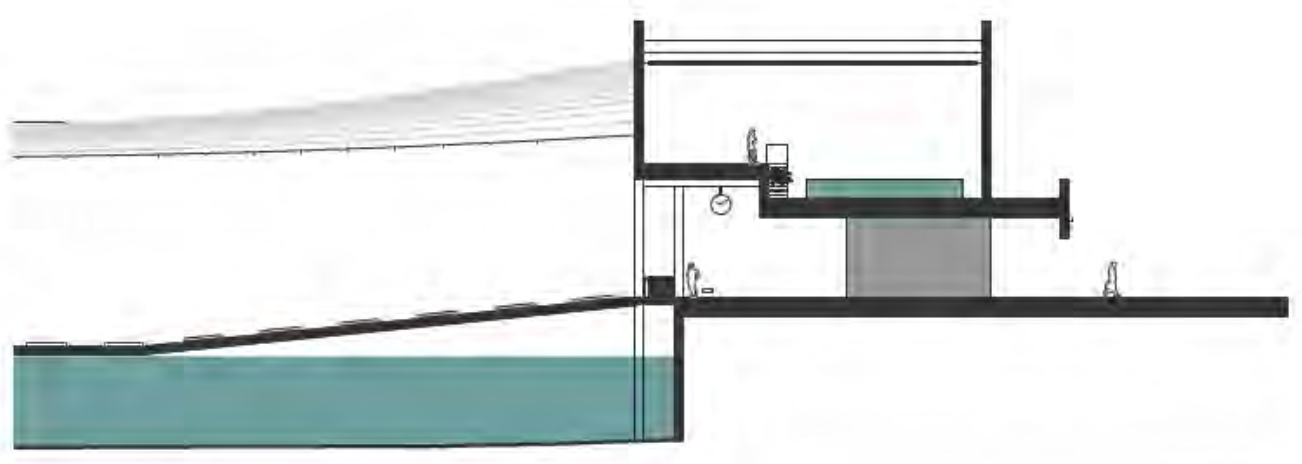

Fig. 93 - City gate cross section 1:500.

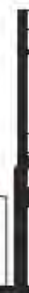

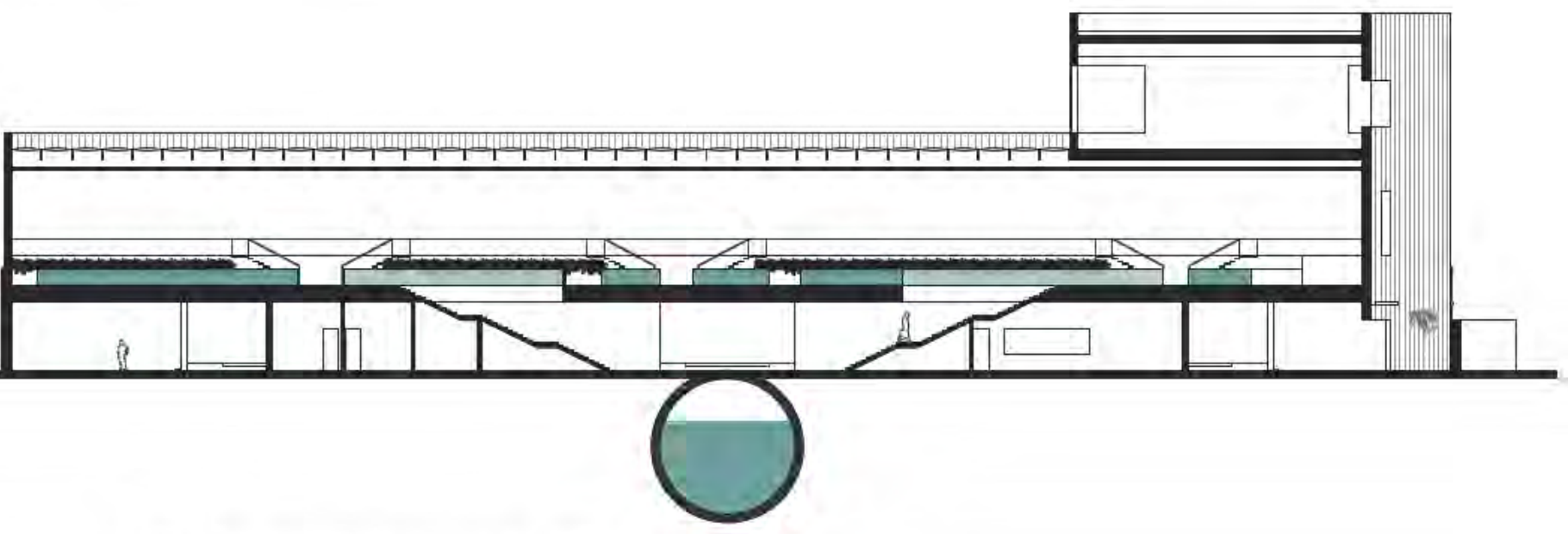

Fig. 94 - City gate long section 1:500. 
Evident in the long section of the city gate (figure 94) are the ETFE pillows supported by Glulam beams that form the roof of the eels farm, above the Bollman truss that distributes loads from the canopy in the main hall to shear walls at the east and west ends of the city gate. Planting along the mezzanine edge provides nutrients for the eel ponds.

The cross section of the city gate (figure 93) shows how spatial volume is modulated along the north - south axis, a technique that strengthens the processional nature of the route. Also explicit in this image is the balcony that runs along the facade of the terminal. The primary function of this feature is to act as a wind break, arresting the channelling of wind into the building from the face of the structure (the front facade faces directly into the prevailing wind). 


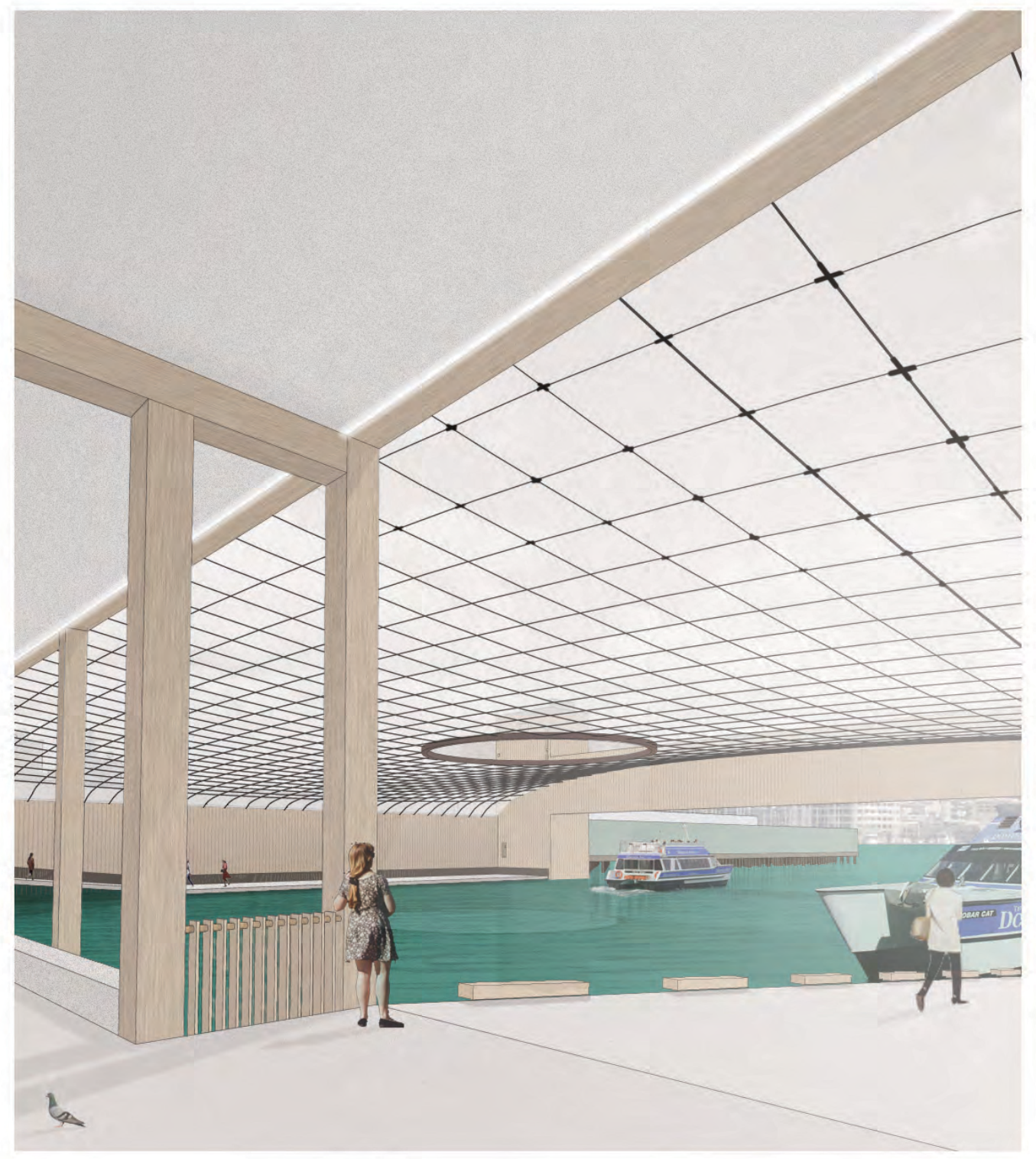




\section{LIMINAL ZONE}

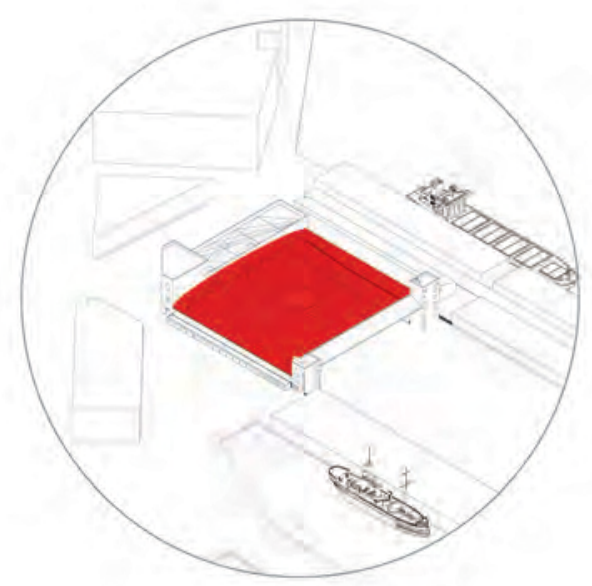

$\mathrm{T}_{\mathrm{k}}$

he 'liminal zone' of the proposed ferry terminal occupies the space between the thresholds of the City and Harbour gates. As an explicitly liminal space, it is designed to express qualities of the bounding states (harbour and city), while avoiding classification as distinctly either.

The large ETFE (Ethylene Tetraflouroethylene) canopy over the space is supported by carbon fibre cables - a technology borrowed from high performance yacht rigging. Carbon fibre is stronger and lighter than steel, allowing much thinner cable members. The cables running north - south are suspended between the harbour and city gates in a pure concave arch, while the east - west cables form a convex partial ellipse over the north - south cables. The anticlastic shape that results is inherently stable.

Fig. 95 - Looking southwest from under the City Gate into the Liminal Zone 
ETFE sheeting

Carbon fibre cables

Solid Ironbark timber posts 400 x $400 \mathrm{~mm}$

Existing finger wharf (Glasgow Wharf shown)

A single layer of ETFE sheeting is

High tide

stretched over these cables, sheltering the main hall of the terminal. The ETFE is specified at 30\% opacity, allowing daylight through but blurring the surrounding cityscape from the interior. Low tide ETFE sheeting, when used as a single layer (rather than the more common 'pillow' modules) requires fixings at approximately 2 metre intervals to remain rigid. The anticlastic curvature of the canopy adds some structural stability to the sheets, and so fixings are specified at slightly greater intervals.

Proprietary pontoon system, topped with asphalt and edged with solid timber

Existing boundary wharf pile cut and bolted to wave wall

Stainless steel reinforced concrete wave wall (footing is indicative only)

Seabed

\section{A large oculus of 16 metre diameter} has the dual purpose of reducing wind loading on the canopy and allowing rain to fall into the centre of the space.

Fig. 96 - Existing finger wharf / ferry terminal joint 1:100 


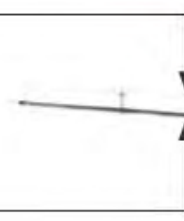

4

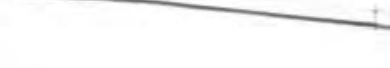

$$
\text { 4. }
$$

旦 H

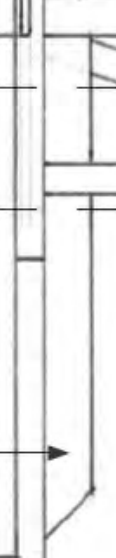

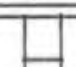
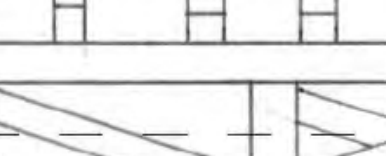
(1)

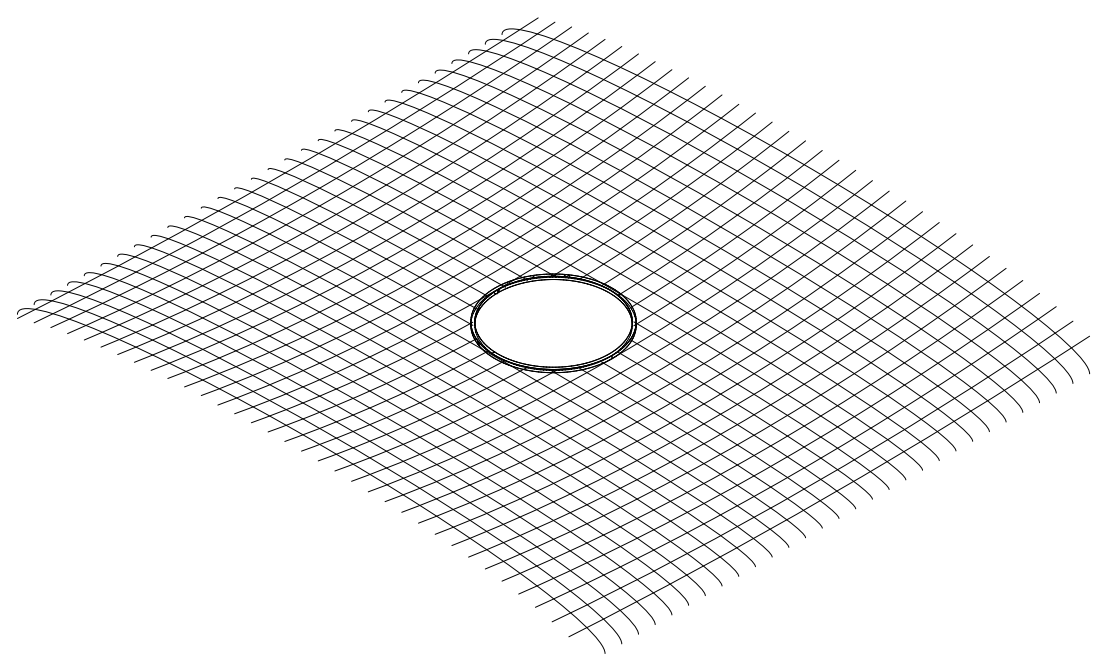

Fig. 97 - Isometric of canopy cable layout 1:1000

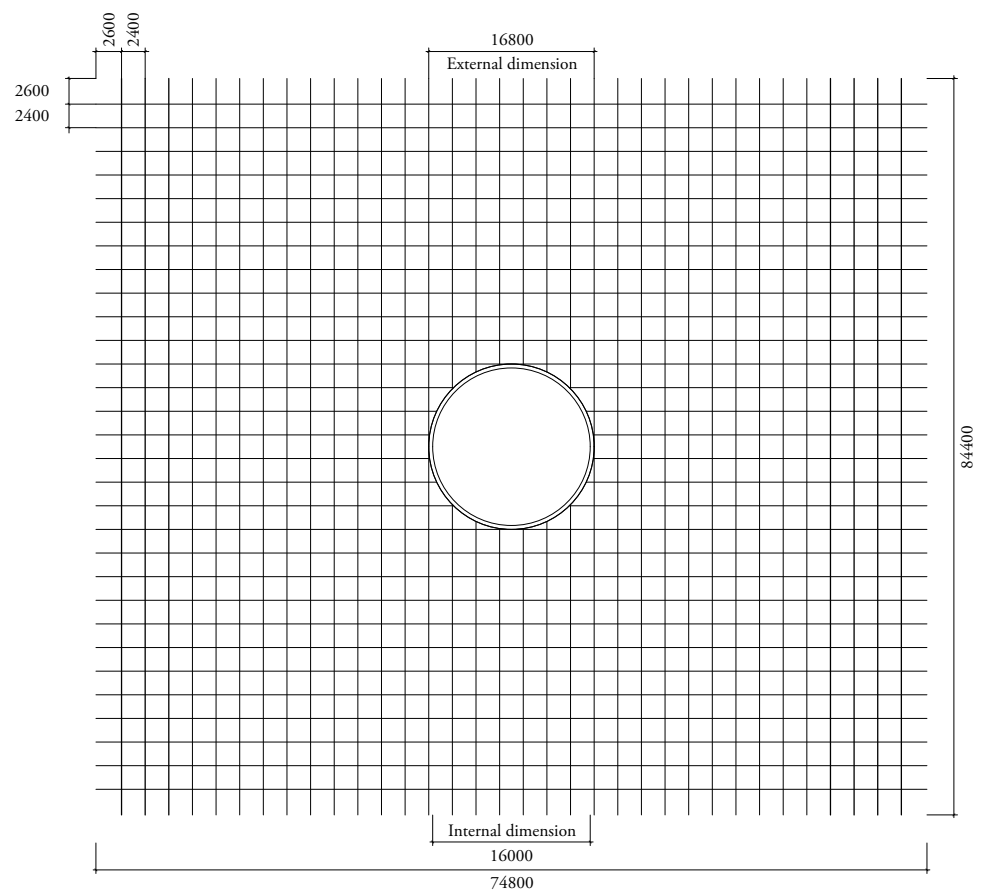

Fig. 98 - Layout of canopy cables. 1:1000 
Fig. 99 - West elevation of canopy cables showing convex pure arch in north south direction. 1:1000

Fig. 100 - South elevation of canopy cables showing concave partial ellipse in east west direction. 1:1000

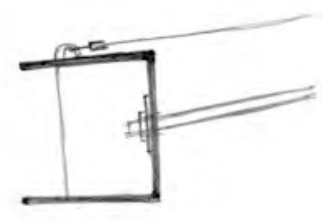

Fig. 101 - Oculus joint sketch, indicating method of connecting cables and ETFE sheeting to oculus ring. Carbon fibre channel with stainless steel clamps. NTS

Fig. 102 - Cable joint sketch, indicating method of connecting cables to each other, and ETFE to the cable structure. Cast brass, with stainless steel ETFE clamp. NTS 


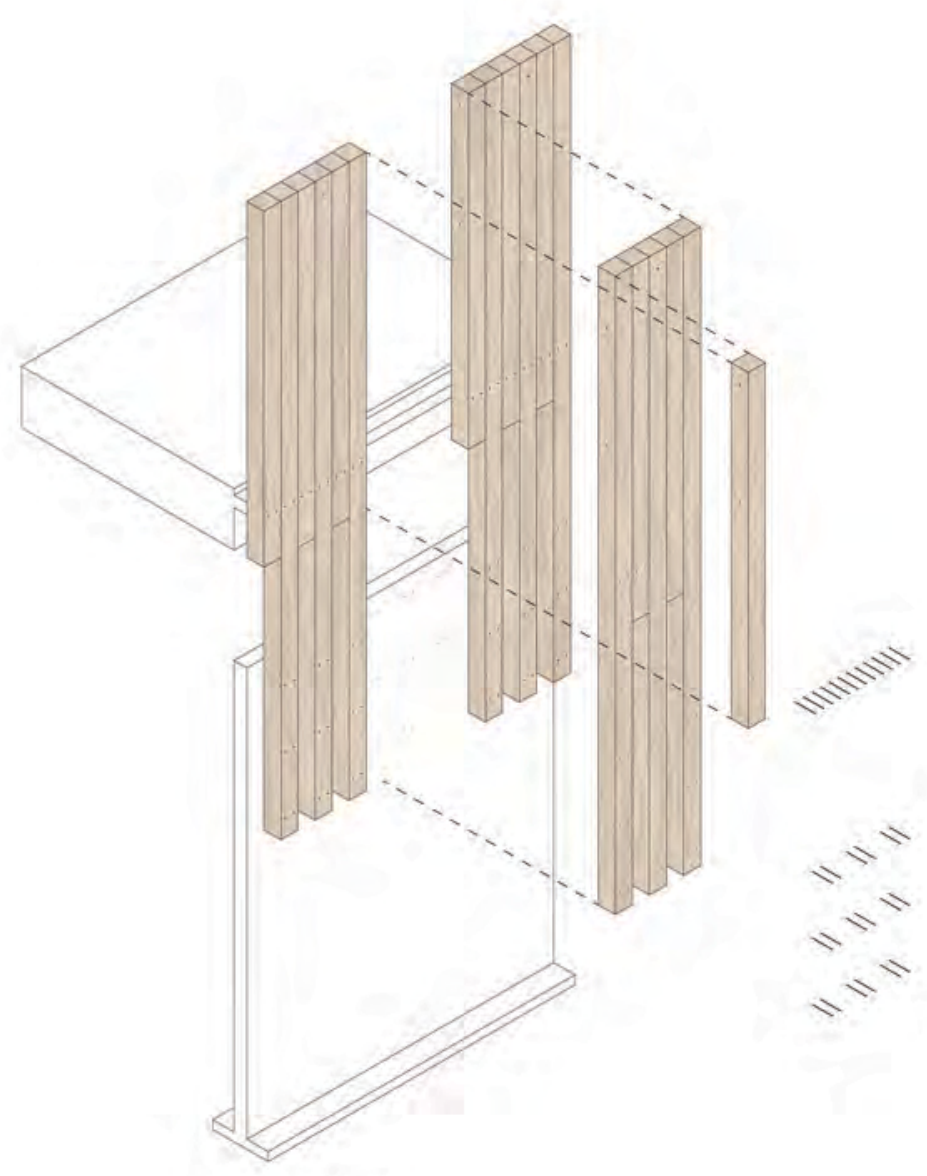

Fig. 103 - Exploded isometric of liminal zone wall, showing posts grouped into modules of 5 which are held together by two tension cables. The module is then bolted to the wave wall and wharf, and an intermediate post is installed. 


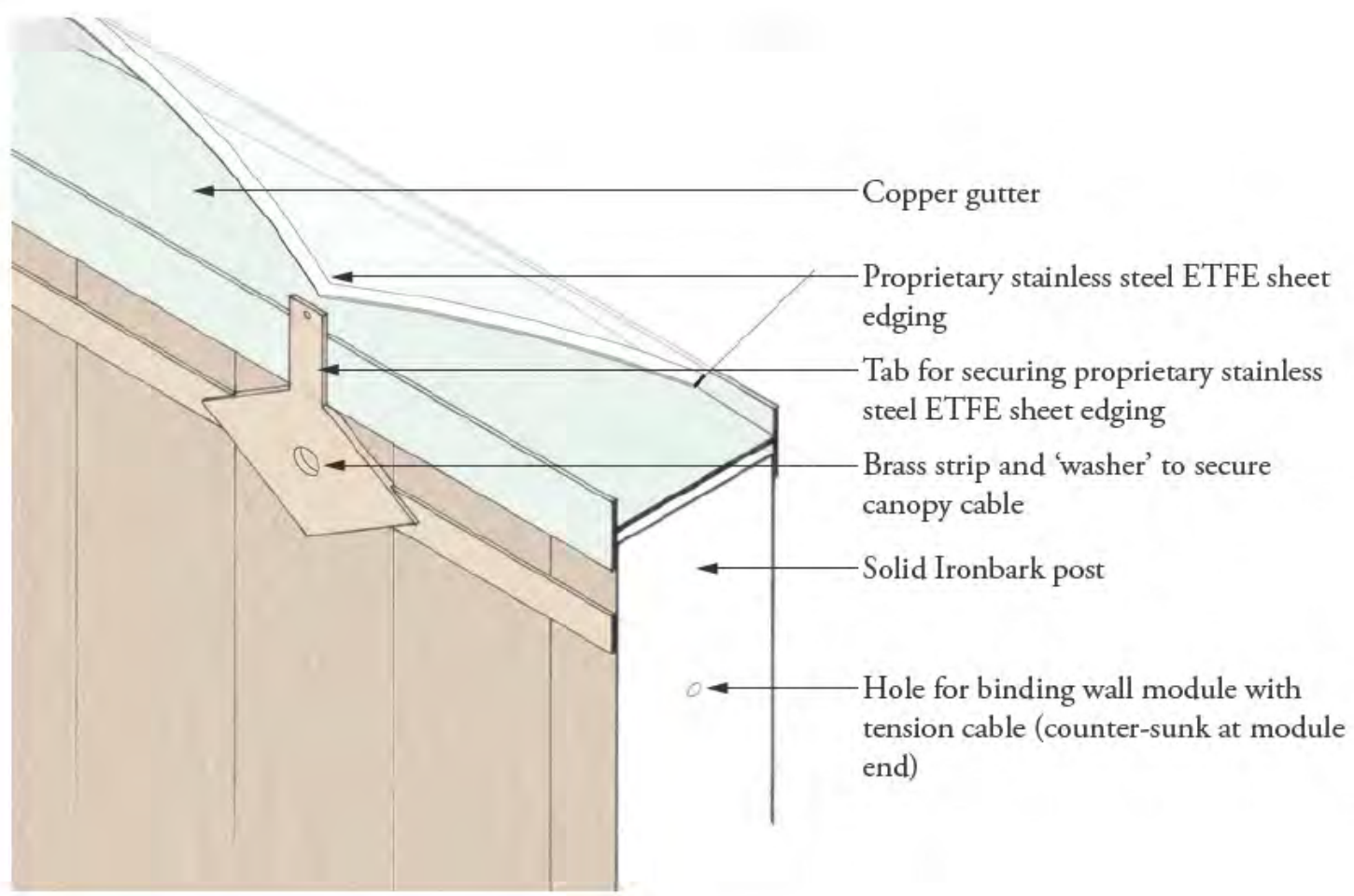

Fig. 104 - Liminal zone wall gutter detail isometric 1:20. The ETFE sheet is edged with a proprietary stainless steel clamping system which is attached to a cast brass 'washer' for the cable ends. 


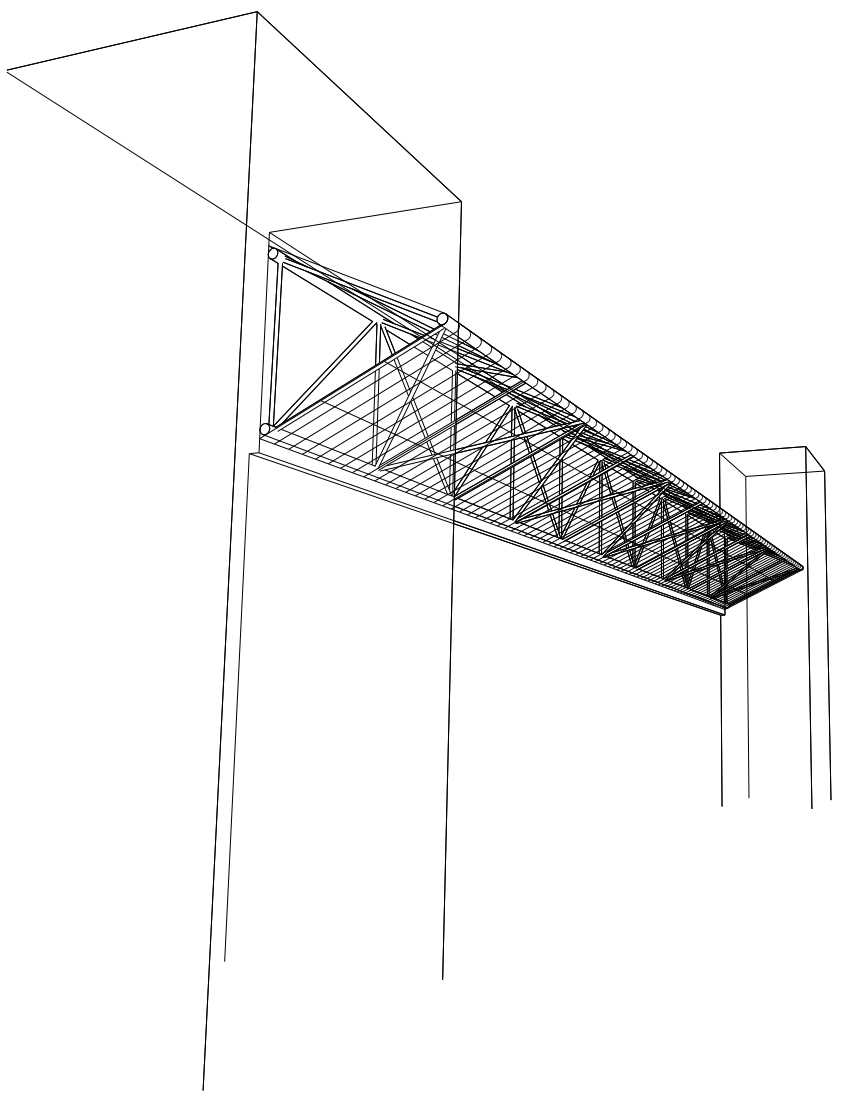

Fig. 105 - Wireframe image of the triangular truss that spans between the towers of the harbour gate, transferring loads from the liminal zone canopy to the towers. 


\section{THE HARBOUR GATE}

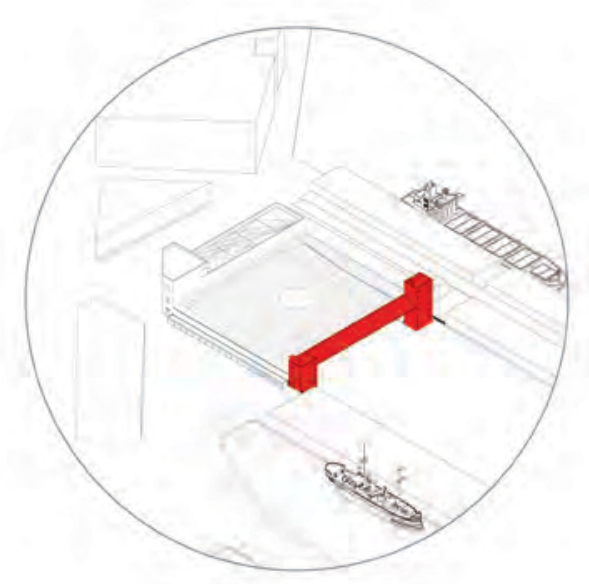

$\mathrm{T}_{\mathrm{b}}$ he harbour gate forms the water-side threshold of the terminal. Composed of two Ironbark clad towers, with a large triangular truss (figure 105) clad in copper sheeting spanning between these towers. The top surface of the truss is guttered to reduce the amount of dripping, or run-off water during rain. 


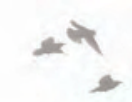

2
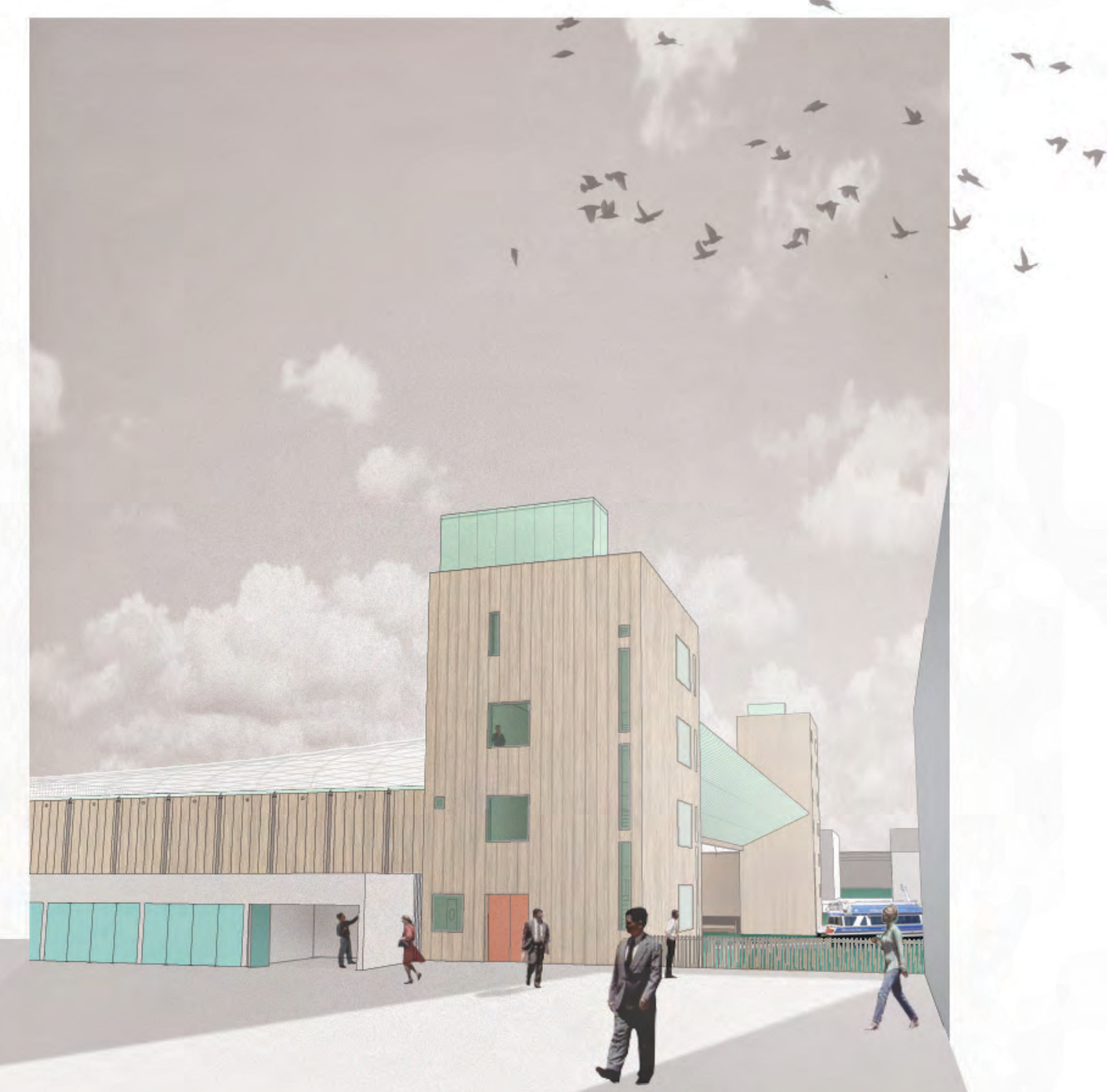


\section{THE HARBOUR GATE - West Tower -}

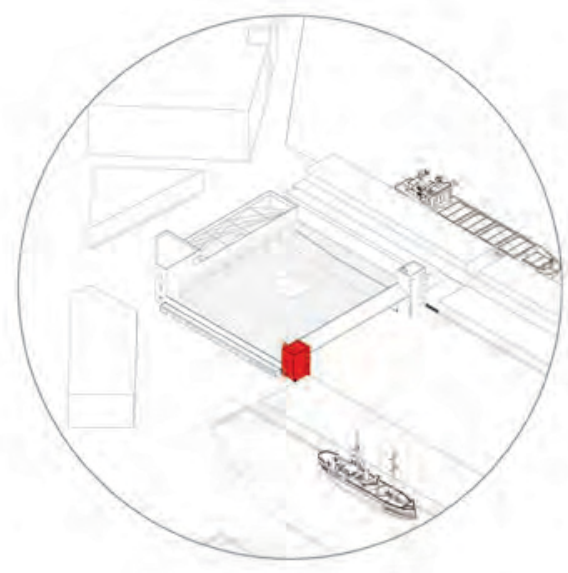

$\mathrm{T}$

he West Tower of the Harbour Gate is four levels high, each level housing a small office (approximately $42 \mathrm{~m}^{2}$ ), with roof access from the third floor (figure 109). The stair element is clad in copper (shown here with a high degree of patina, as would quickly occur in this location). The ground floor accommodates emergency egress via a ladder from the terminal (figures 107, 113).

Fenestration is designed to block views to the interior of the terminal, and restrict views to the gate threshold, promoting internalisation amongst commuters.

Fig. 106 - Looking east from the hotel entrance towards the Harbour Gate. The 'Artisan Sheds' (see page 170) are also captured in this view 
<smiles>C1CC2CCC1CC2</smiles>

The exterior walls of the tower are $400 \mathrm{~mm}$ thick, allowing room for structure to resist loads from the canopy to the north, and space to run services.

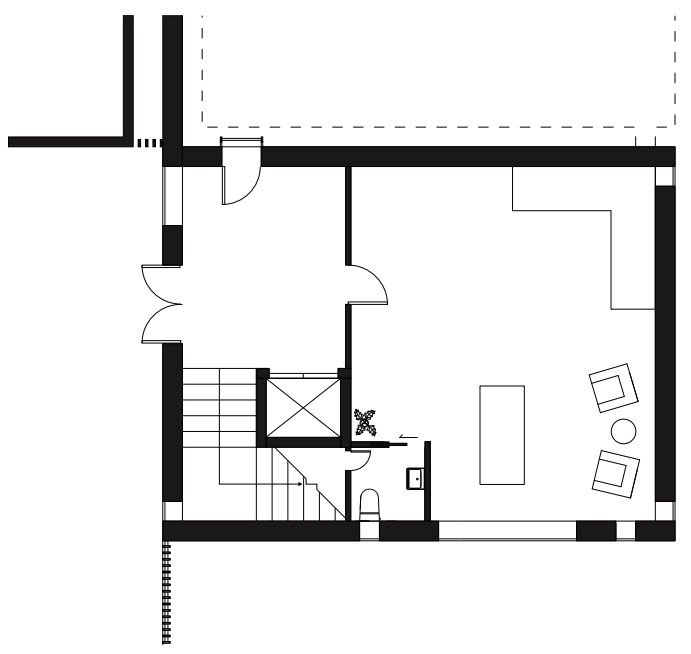

Fig. 107 - Ground Floor 1:200 


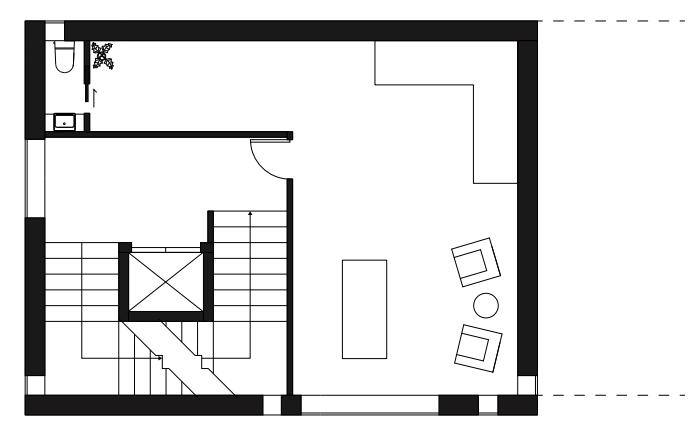

Fig. 108 - First \& Second Floors 1:200

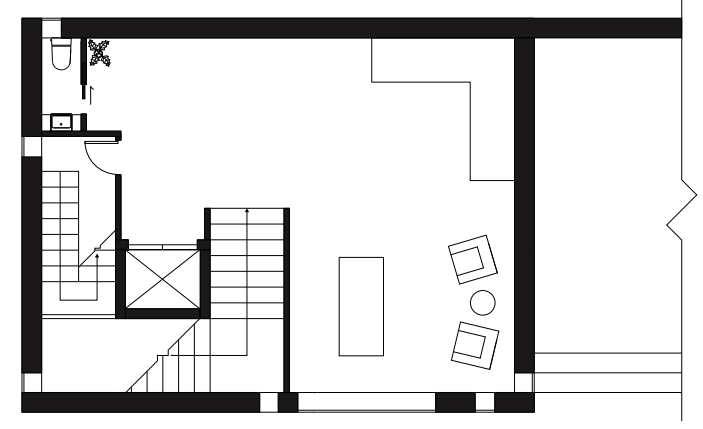

Fig. 109 - Third Floor 1:200 


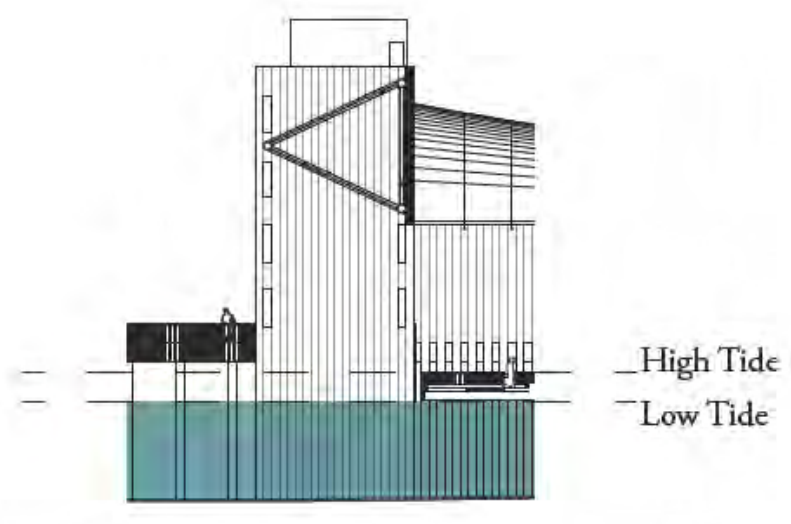

Fig. 110 - East elevation 1:500

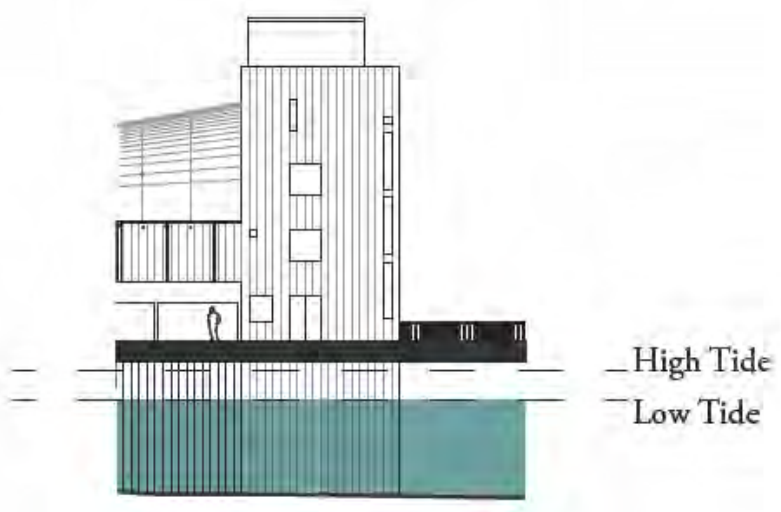

Fig. 111 - West elevation 1:500 


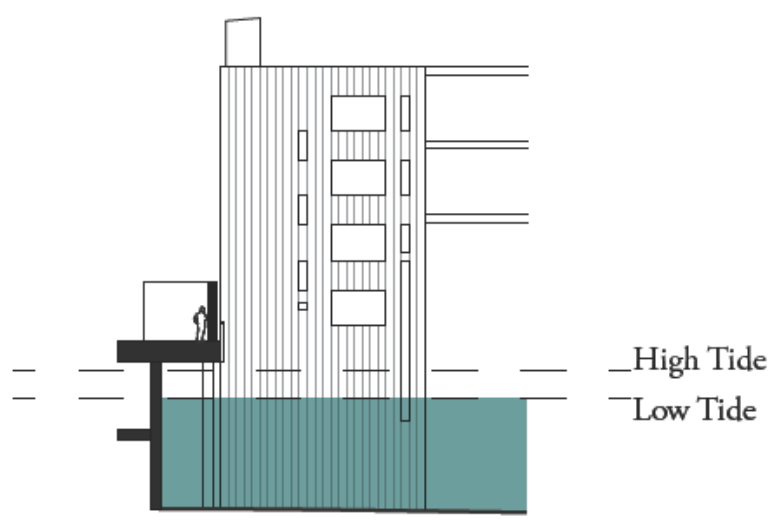

Fig. 112 - South elevation 1:500

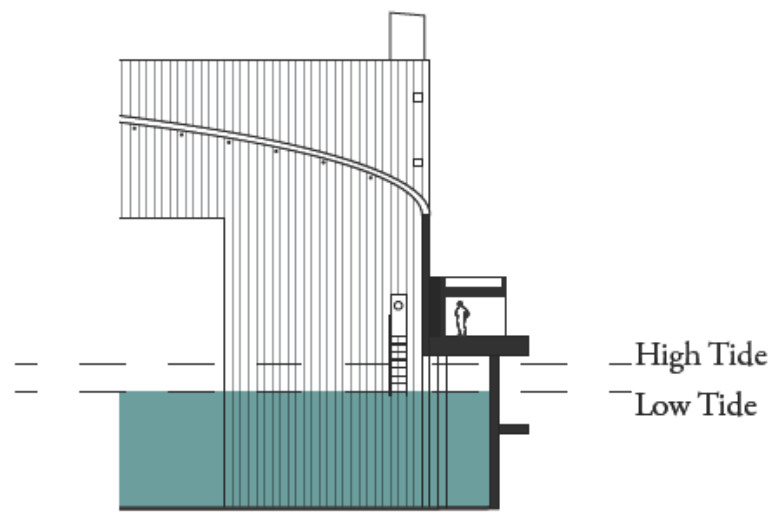

Fig. 113 - North elevation 1:500 


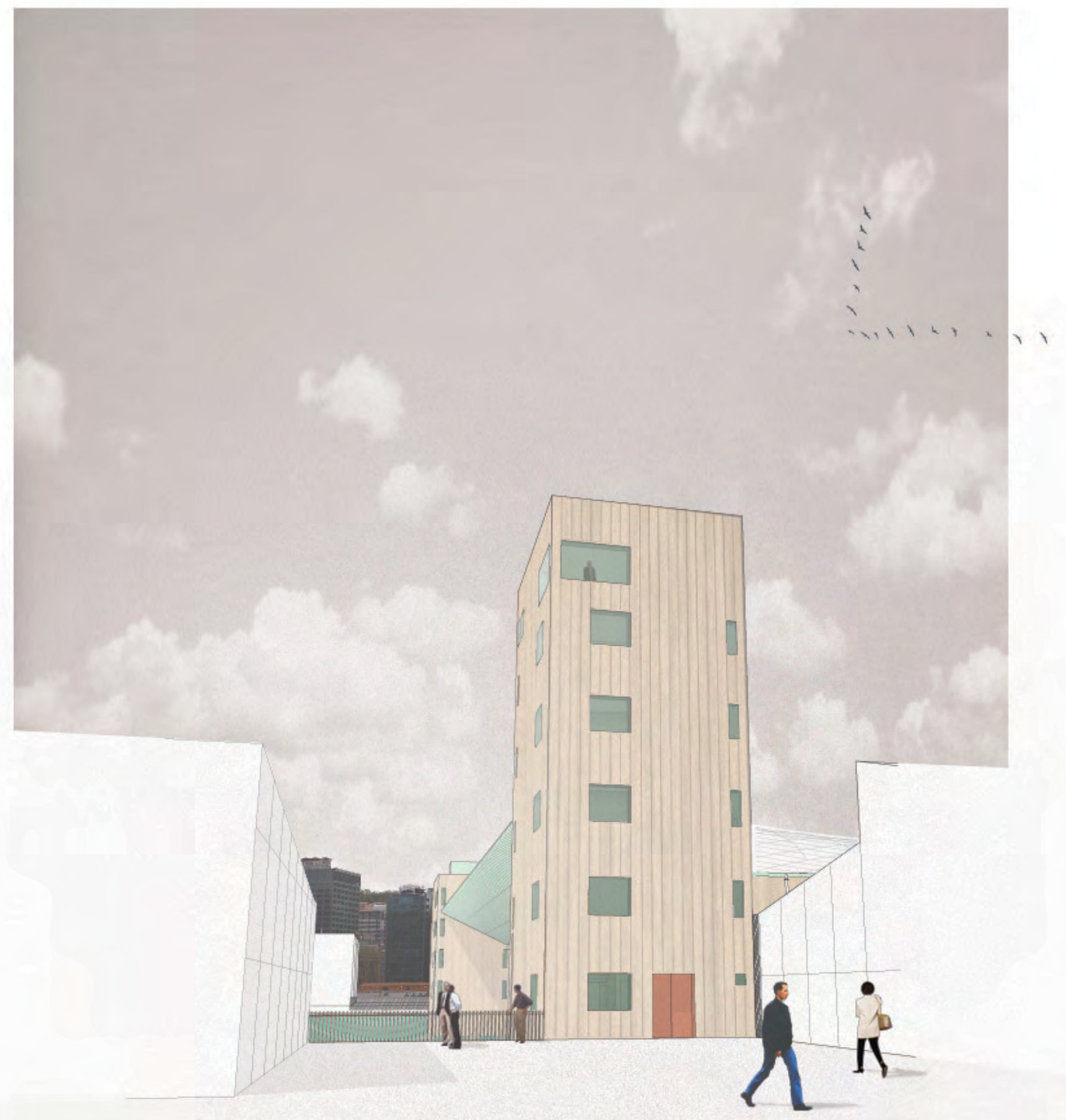




\section{THE HARBOUR GATE}

\section{- East Tower -}

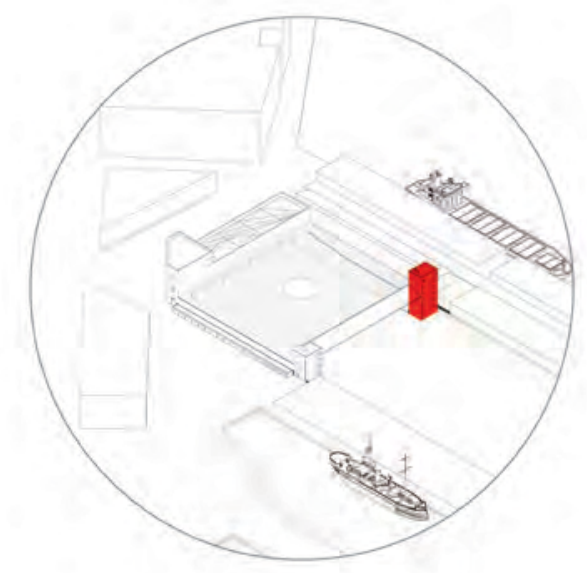

$\mathrm{T}$

he East Tower of the Harbour Gate functions programmatically, structurally, and conceptually in much the same way as the West Tower, but is differentiated by height. The additional two levels are designed as an apartment or home / office, with roof access. As with the West Tower, the ground floor also accommodates emergency egress via a ladder from the terminal (figures 115, 119).

Fig. 114 - Perspective looking west from Glasgow Wharf 


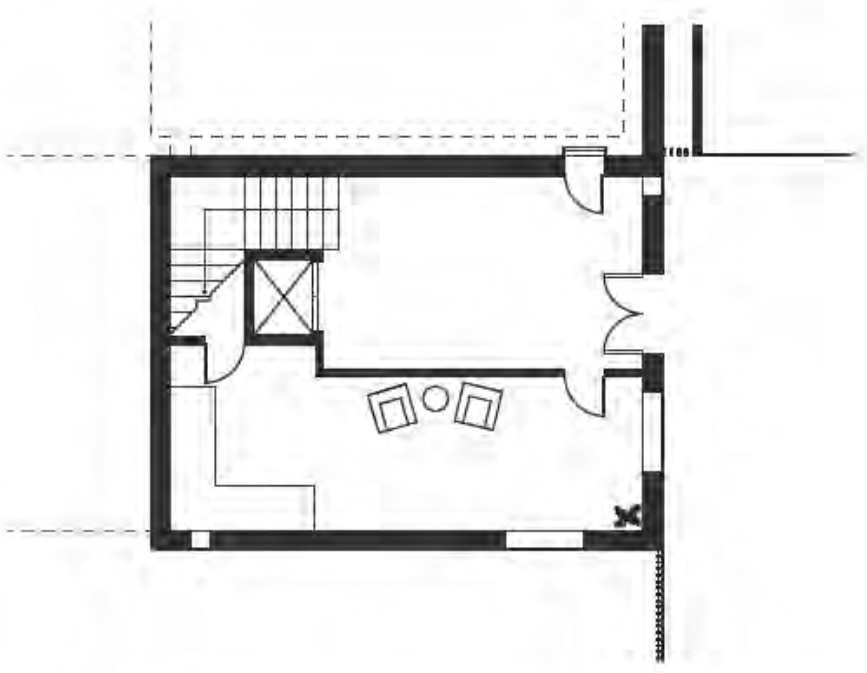

Fig. 115 - Ground Floor 1:200

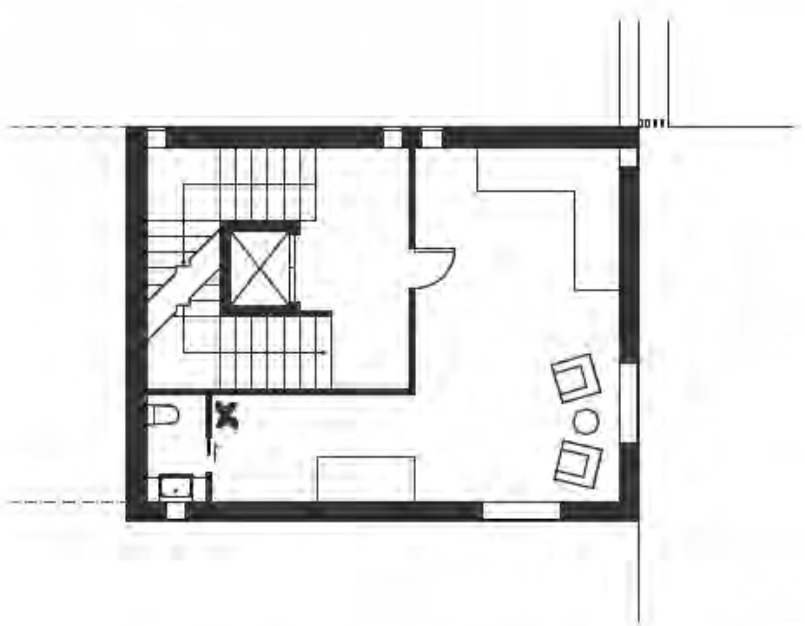

Fig. 116 - First, Second, \& Third Floors 1;200 


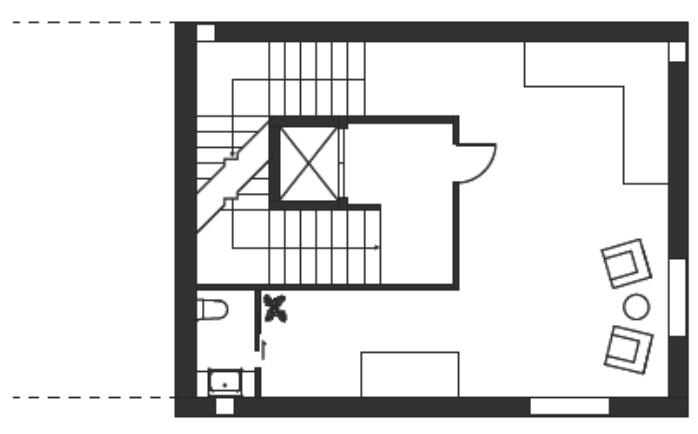

Fig. 117 - Fourth Floor 1:200

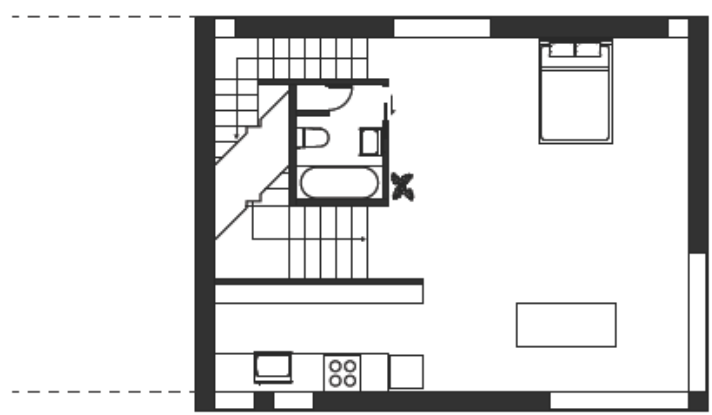

Fig. 118 - Fifth Floor 1:200 


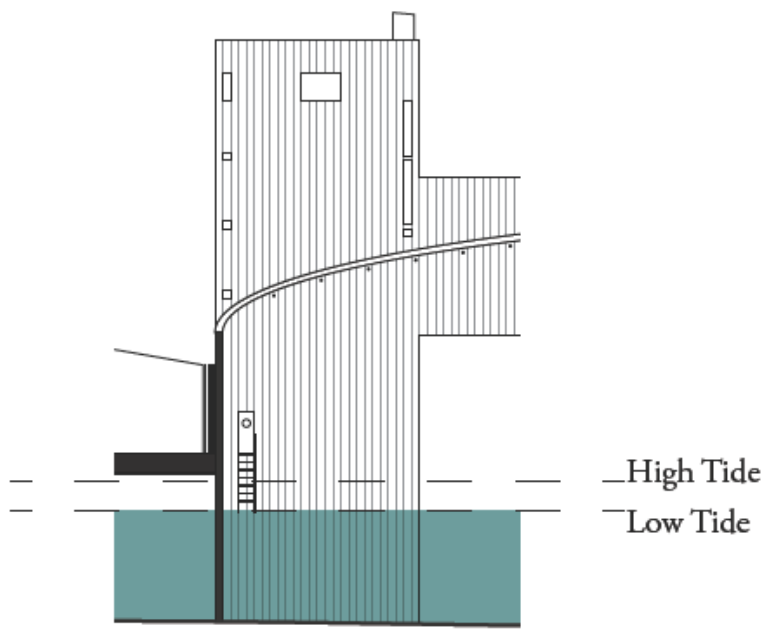

Fig. 119 - North elevation 1:500

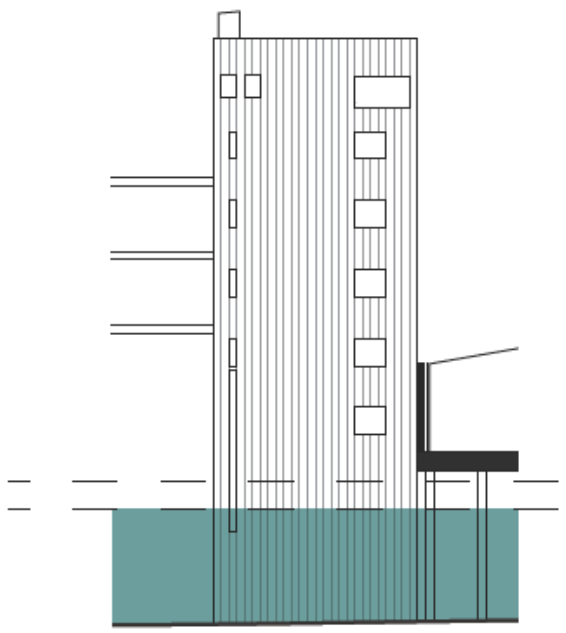

_High Tide

- Low Tide

Fig. 120 - South elevation 1:500 


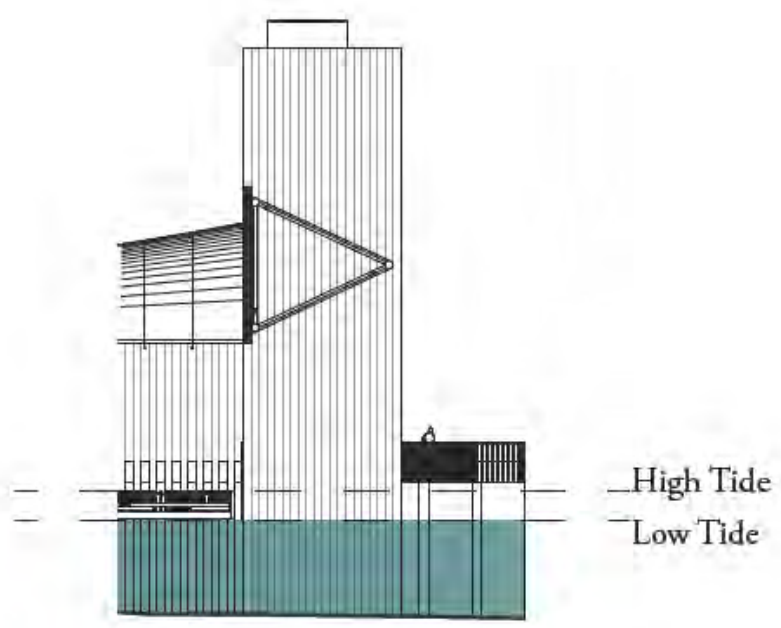

Fig. 121 - West elevation 1:500

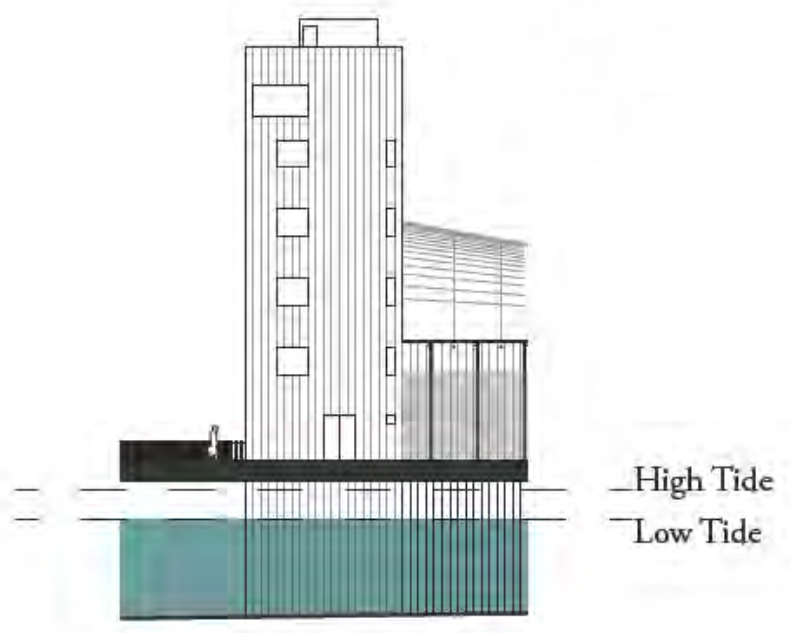

Fig. 122 - East elevation 1:500 


\section{THE ARRIVAL PROCESSION}

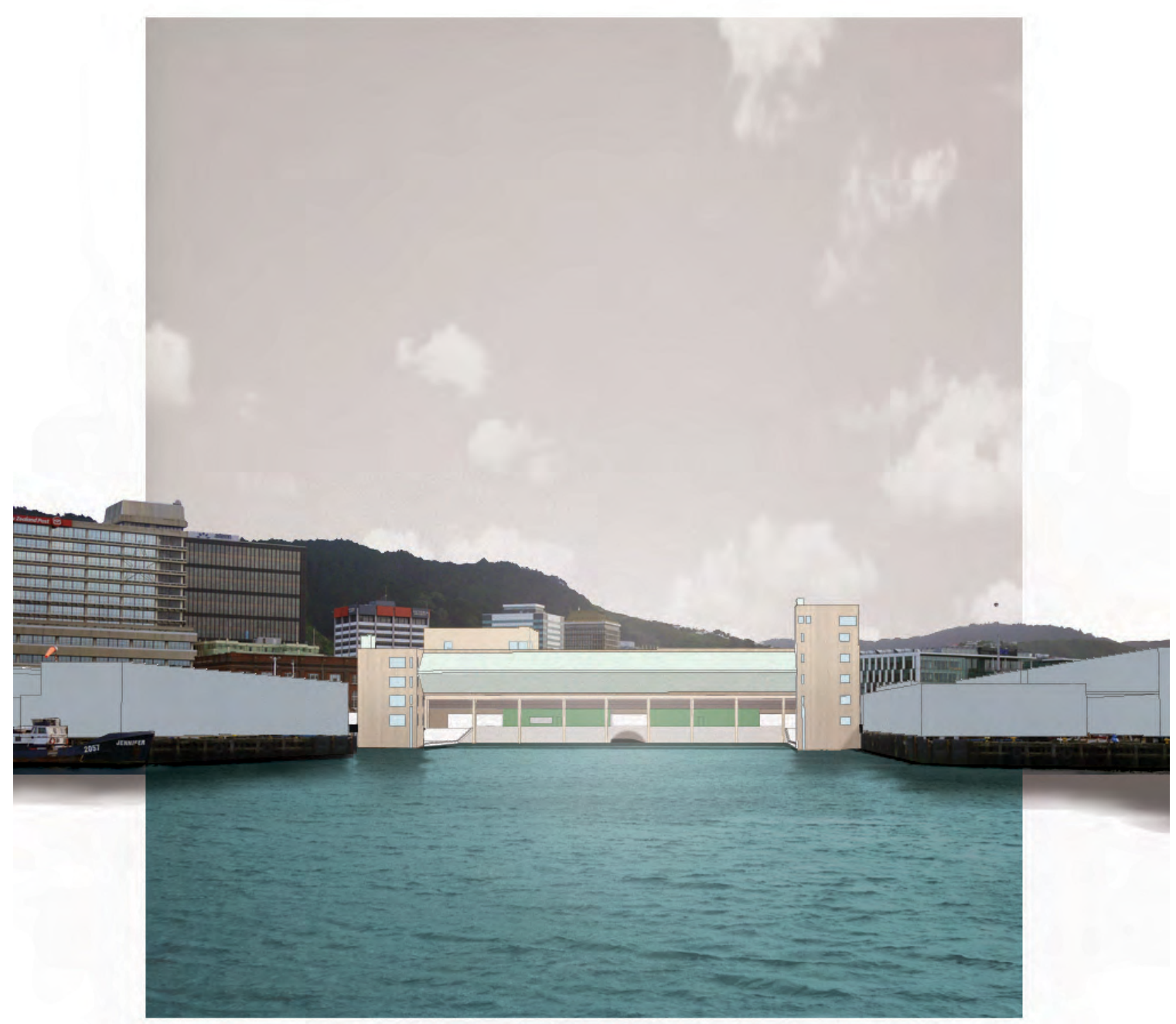

Fig. 123 - Approaching the wharves. 


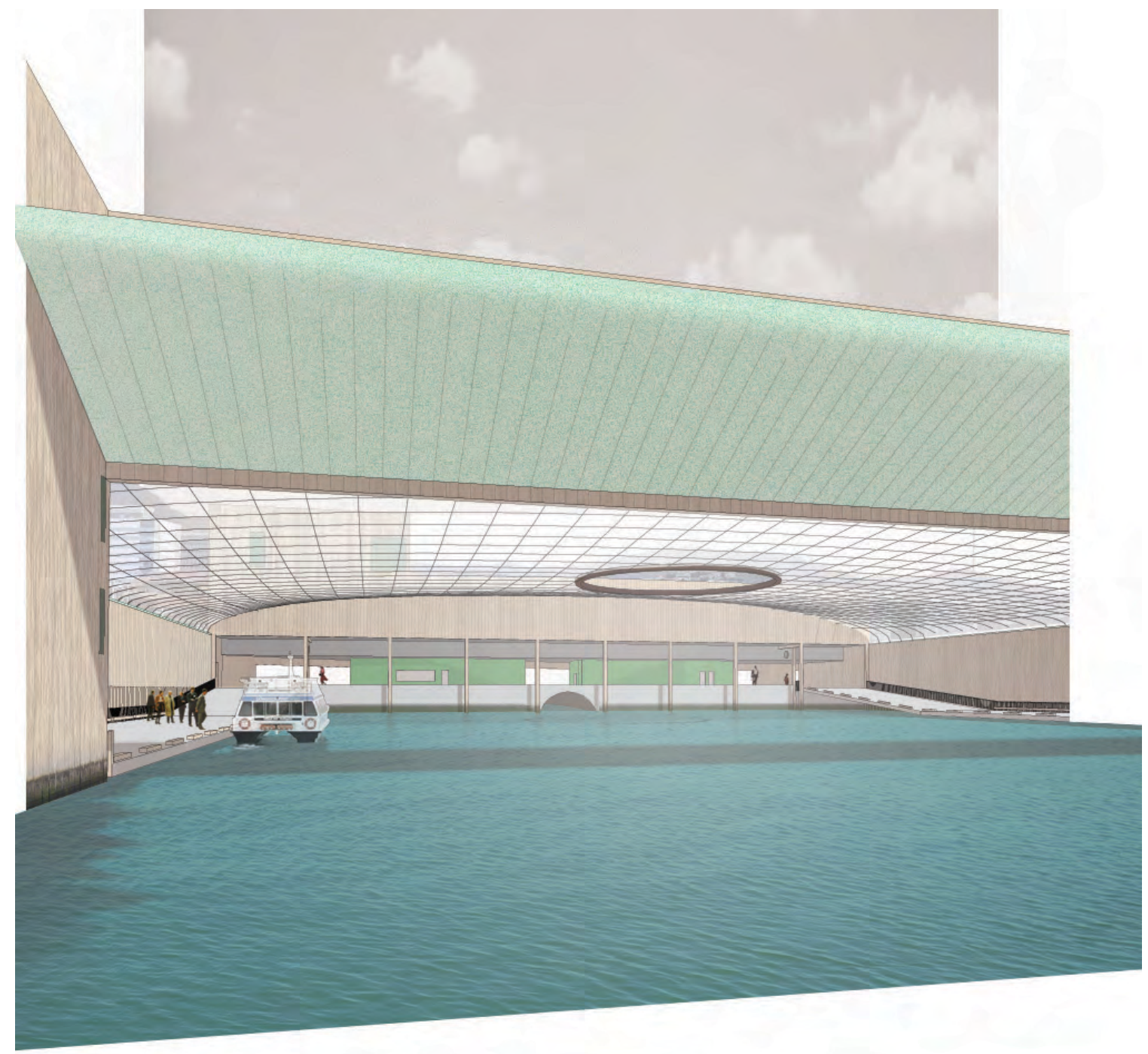

Fig. 124 - Passing under the first threshold - the Harbour Gate. 


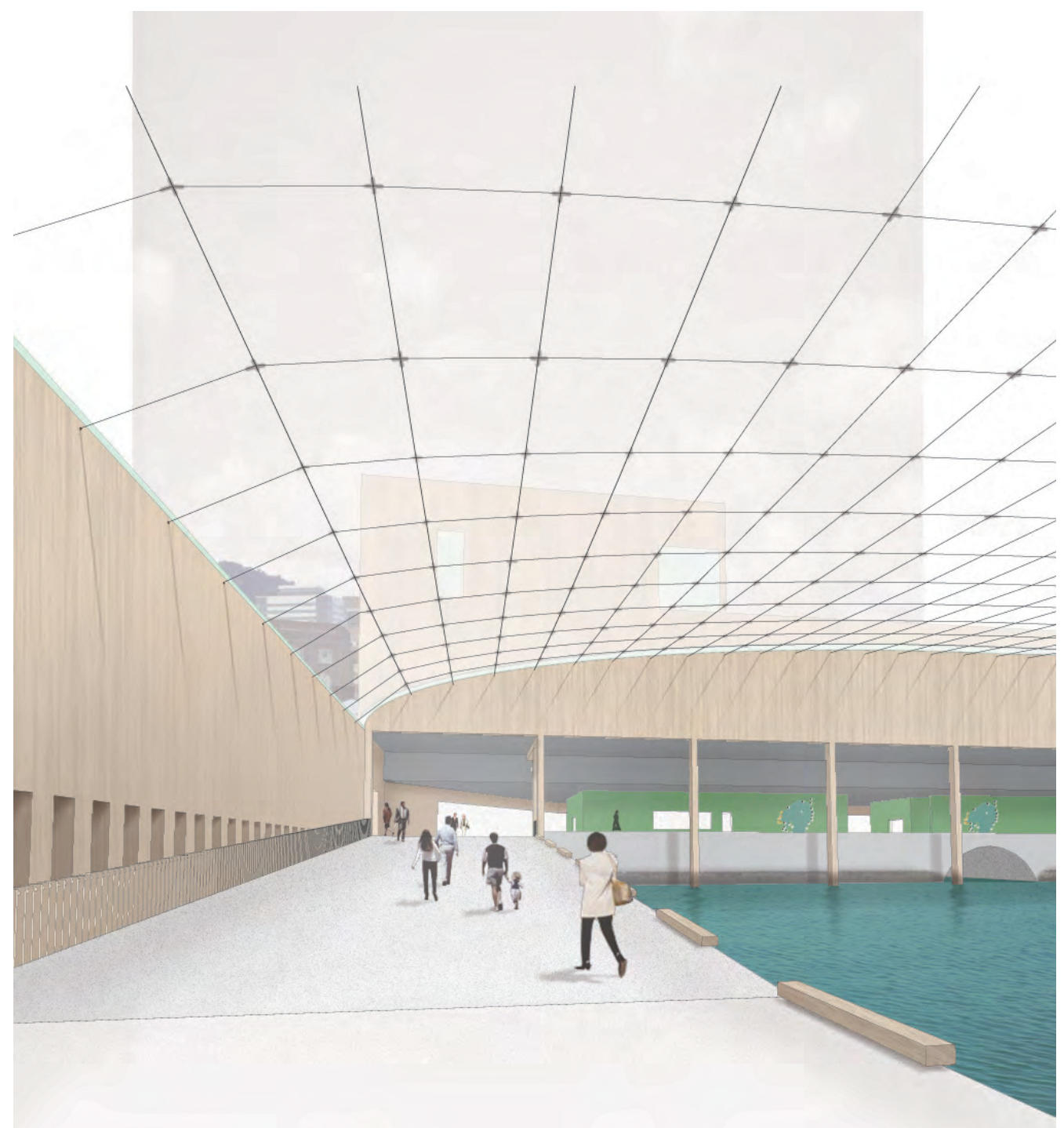

Fig. 125 - On the pontoon, in the Liminal Zone. 


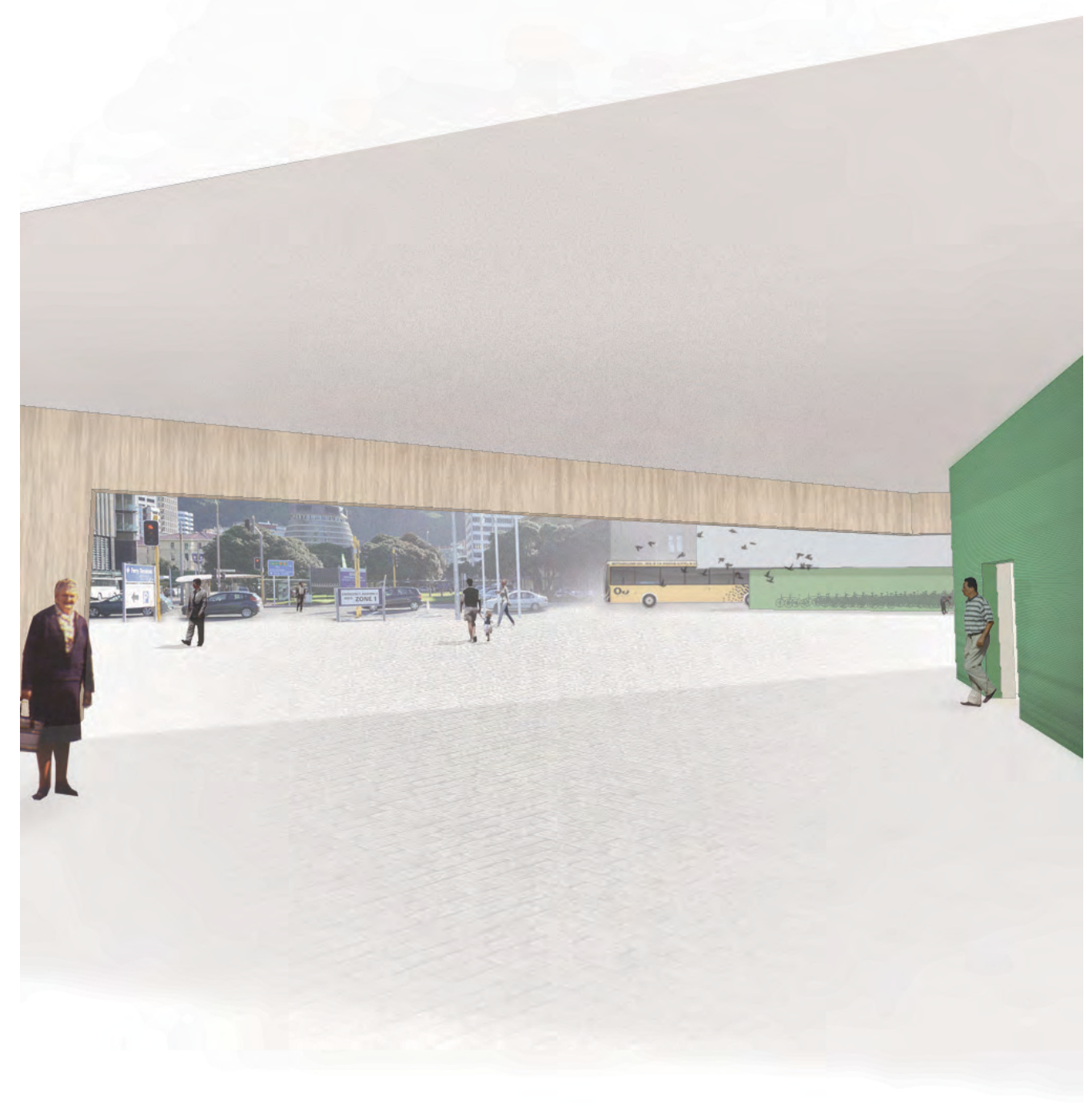

Fig. 126 - Passing under the second threshold - the City Gate - into the hub area with the Beehive in the background. 


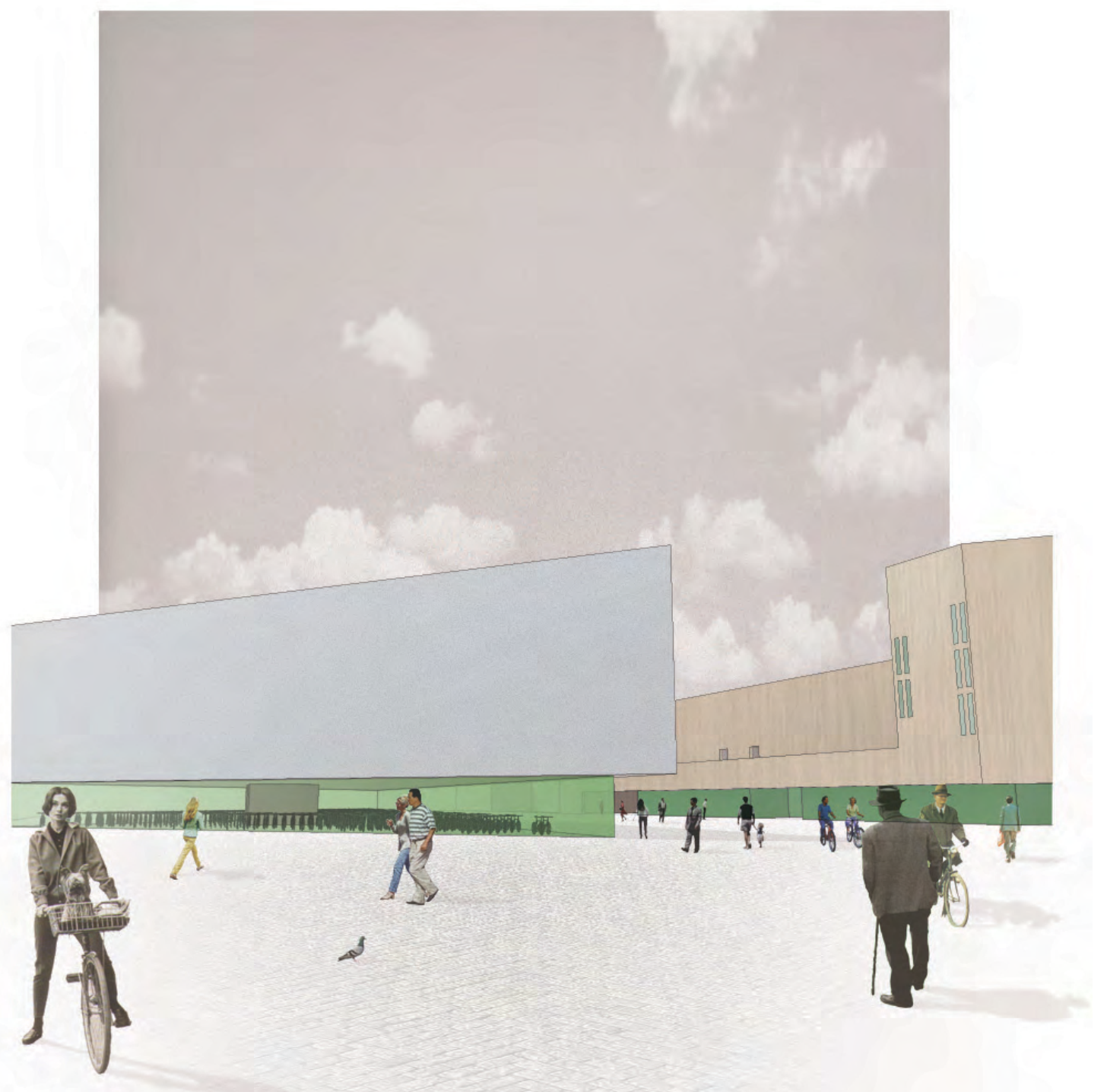




\section{TERMINAL PRECINCT}

\section{- Other buildings in master plan -}

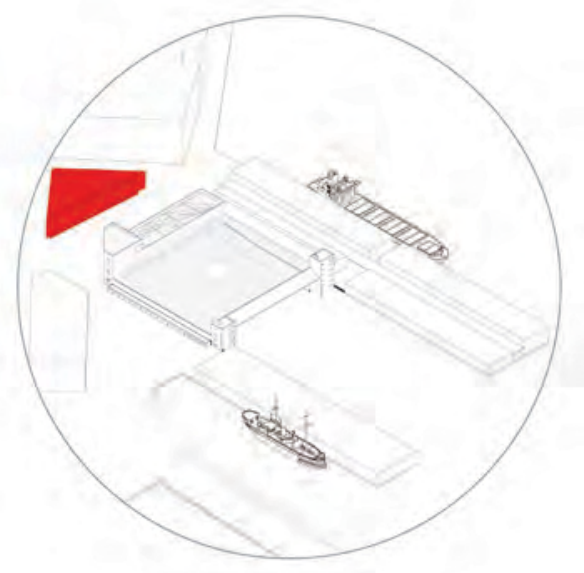

BICYCLE DEPOT / METLINK OFFICES

$\mathrm{T}$ he triangular building indicated on the Harbour Quays master plan to the North of the proposed harbour ferry terminal is adopted into this design proposal. The positioning of the building at the public transport hub, and on the harbour promenade, makes it apt for housing public bicycles. The ground floor is given over entirely to city bikes, while the upper floors are proposed offices for Metlink - Wellington's Public Transport service provider.

Fig. 127 - Looking towards the bicycle depot / Metlink offices, with the harbour ferry terminal in the background, from the corner of Bunny Street and Waterloo Quay. 


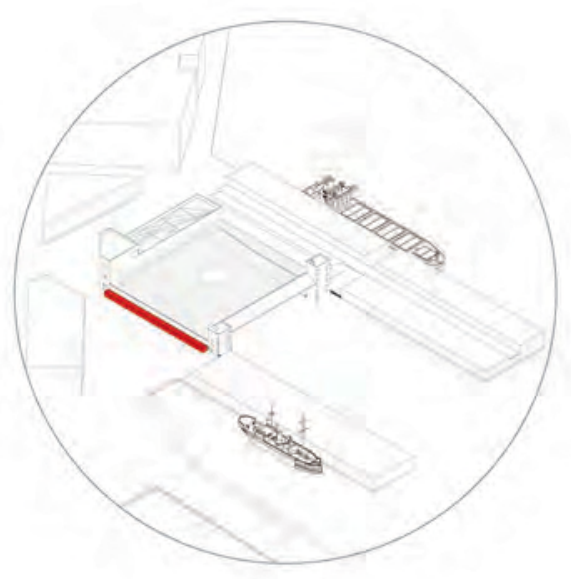

\section{ARTISAN SHEDS}

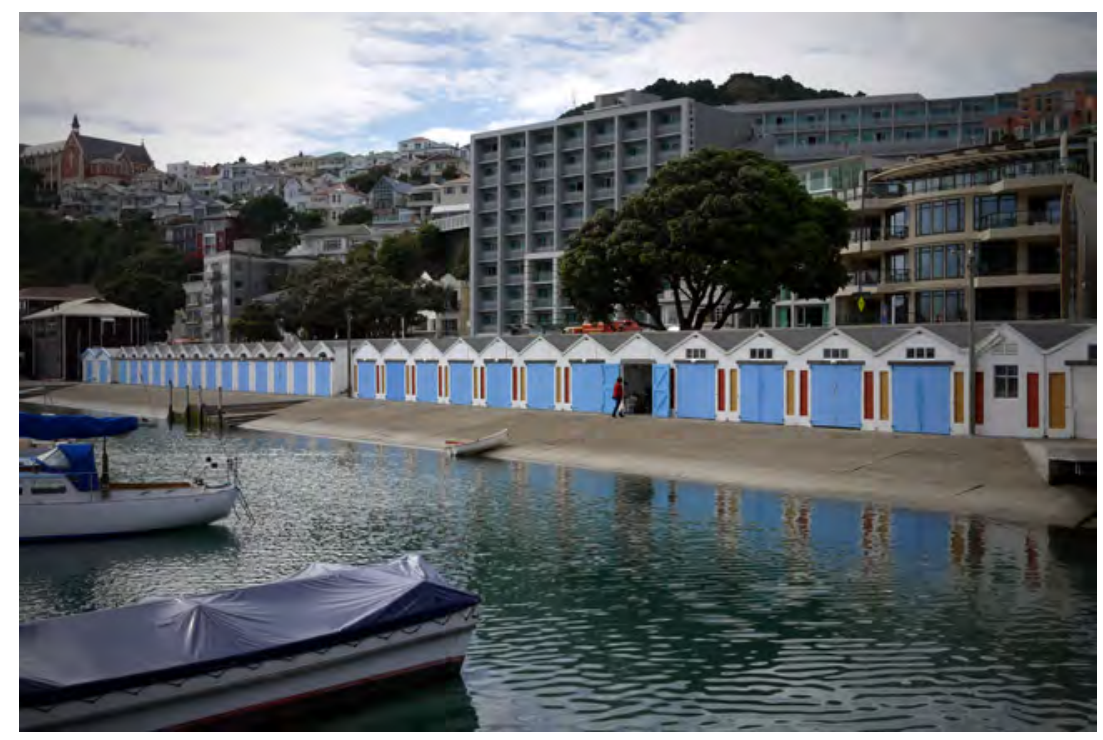

Fig. 128 - The boat sheds at Clyde Quay Marina - precedent for the terminal precinct sheds.

The western wall of the proposed ferry terminal is lined with a series of 18 small sheds designed to house workshops, artist's studios, or small scale commercial/retail activity. Modelled on the boat sheds that line Clyde Quay Marina, some of these could also feasibly be used for smoking eels from the farm next door. 


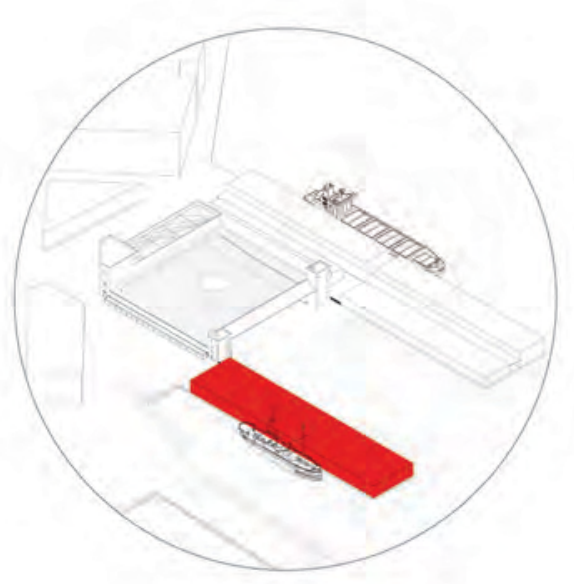

\section{HOTEL}

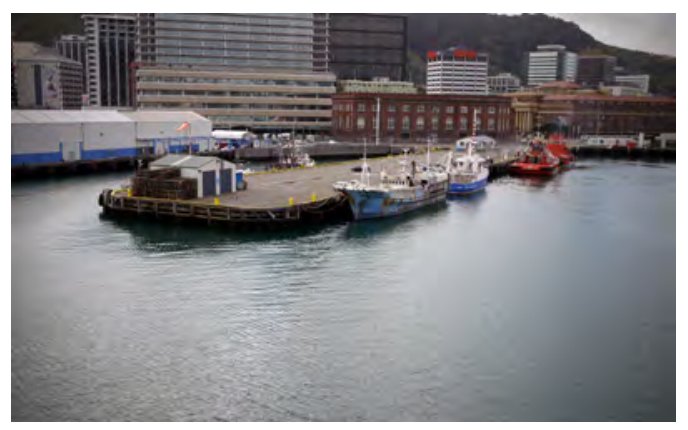

Fig. 129 - Interisland Wharf - currently a car park, commercial and tug boat berth.

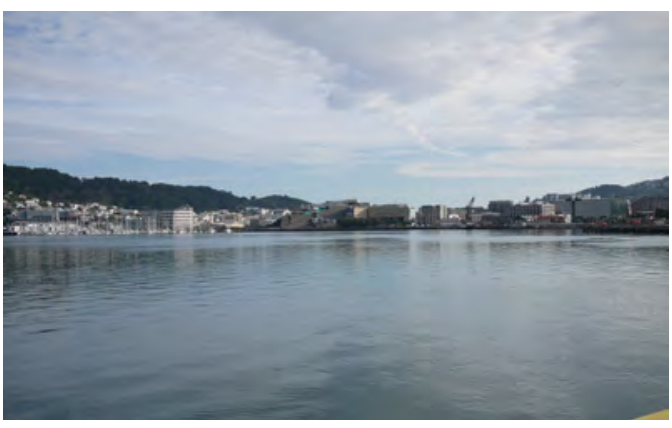

Fig. 130 - The view south from Interisland Wharf towards Te Papa.

Interisland Wharf is the proposed site for a new 5-star hotel, for which several sites along the Lambton waterfront have been investigated in the past. This particular site has direct precedent in the Auckland Hilton, a much larger hotel that is also situated on a finger wharf. The wharf is currently used as a public car park and berth for tug boats and other small vessels. As the photograph above illustrates, the wharf offers desirable views over the water, and provides a feeling of isolation from the city while remaining in excellent proximity to it. Easy access to local and national transport that the site offers is also a boon.

Underground service access and car parking (figure 65) to the north of the hotel operates in much the same way as underground parking at Queens Wharf to the south. 


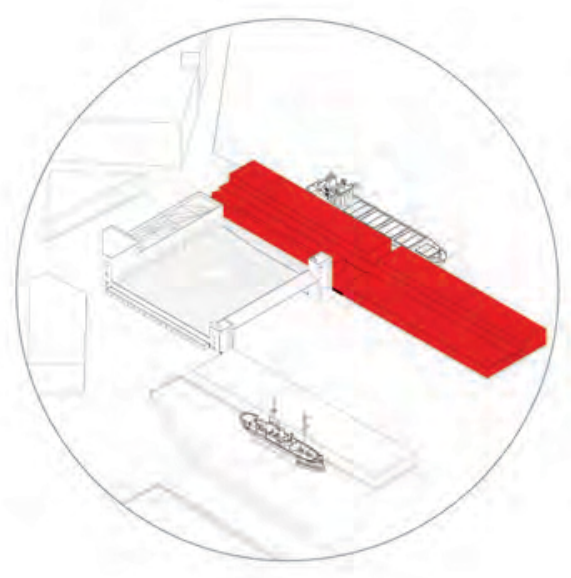

\section{COMMERCIAL WHARF (HORIZONTAL SKYSCRAPER)}

Glasgow Wharf, to the east of the proposed ferry terminal, is reconceptualised as a 'horizontal sky-scraper'. This definition is helpful in arranging programmatic functions, with the 'base' of the development engaging with public space through commercial activity and the more isolated 'top' housing private offices and conference facilities. The skyscraper analogy carries through in that access is from the base only, and the views get better the further up you go.

While this development is only designed to programmatic and massing resolution, there are specifics that need to be considered. Restricted access to a tugboat berth is required on the western edge - this is accounted for in the site plan by a narrow strip created by setting the building back from the wharf edge. On the eastern side, provision for berthing of interisland ferries should be maintained. This could feasibly occur at roof level, as the ferries are currently accessed from the rear only. Such an arrangement also holds provision for dedicated pedestrian access to interisland ferries (as the Interislander ferries currently do).

Also worth noting is the external envelope of the development. The massing suggested here indicates 4 separate structures - this should be considered an indication of primary circulation only, as it may prove desirable for the development to read as a single 


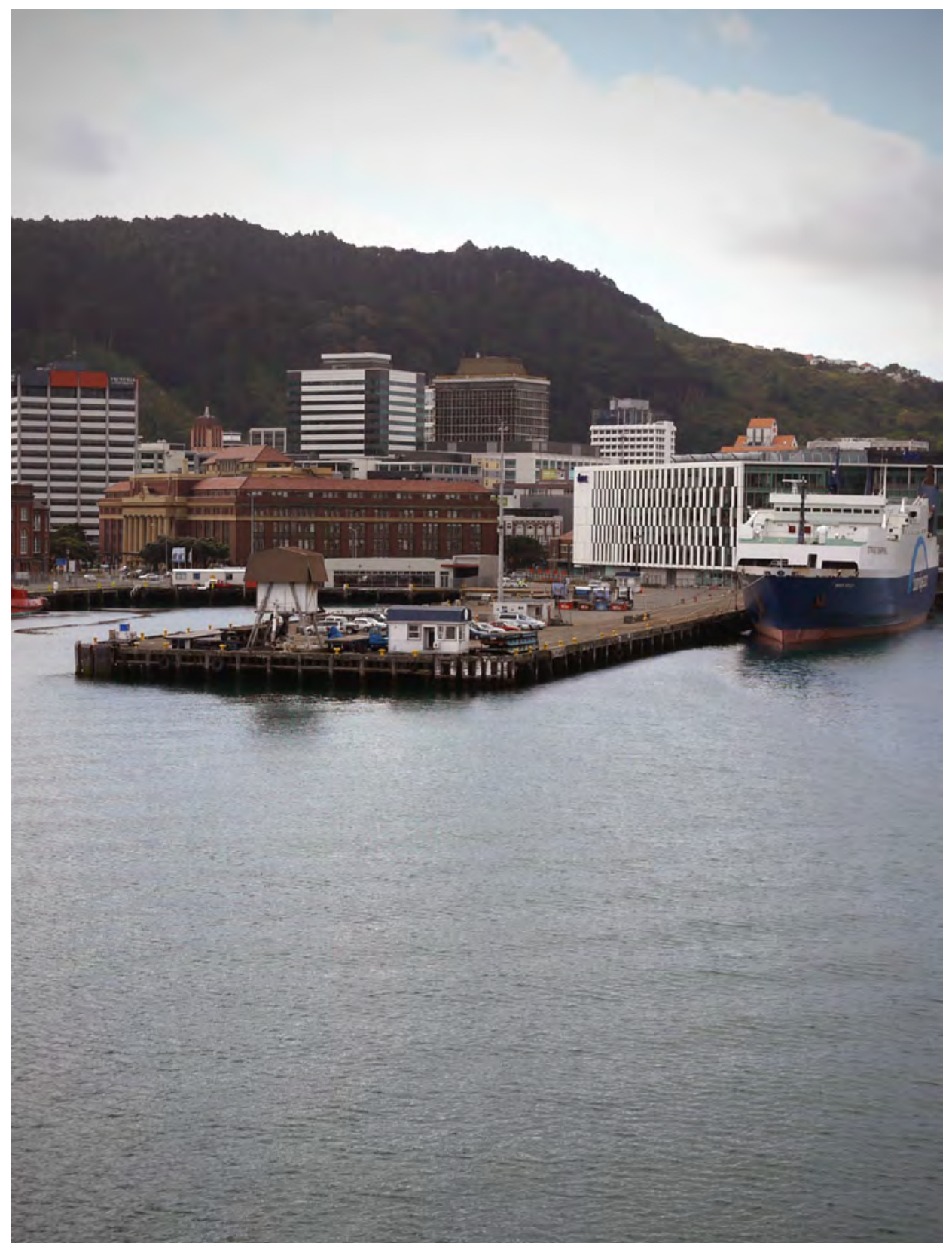

Fig. 131 - Glasgow Wharf, currently a working port area used by Bluebridge

structure (i.e. wrapping the four indicated footprints in a single skin). This is particularly apt when considering that the central spine runs in line with the prevailing wind, and if left exposed would function as a wind tunnel. 


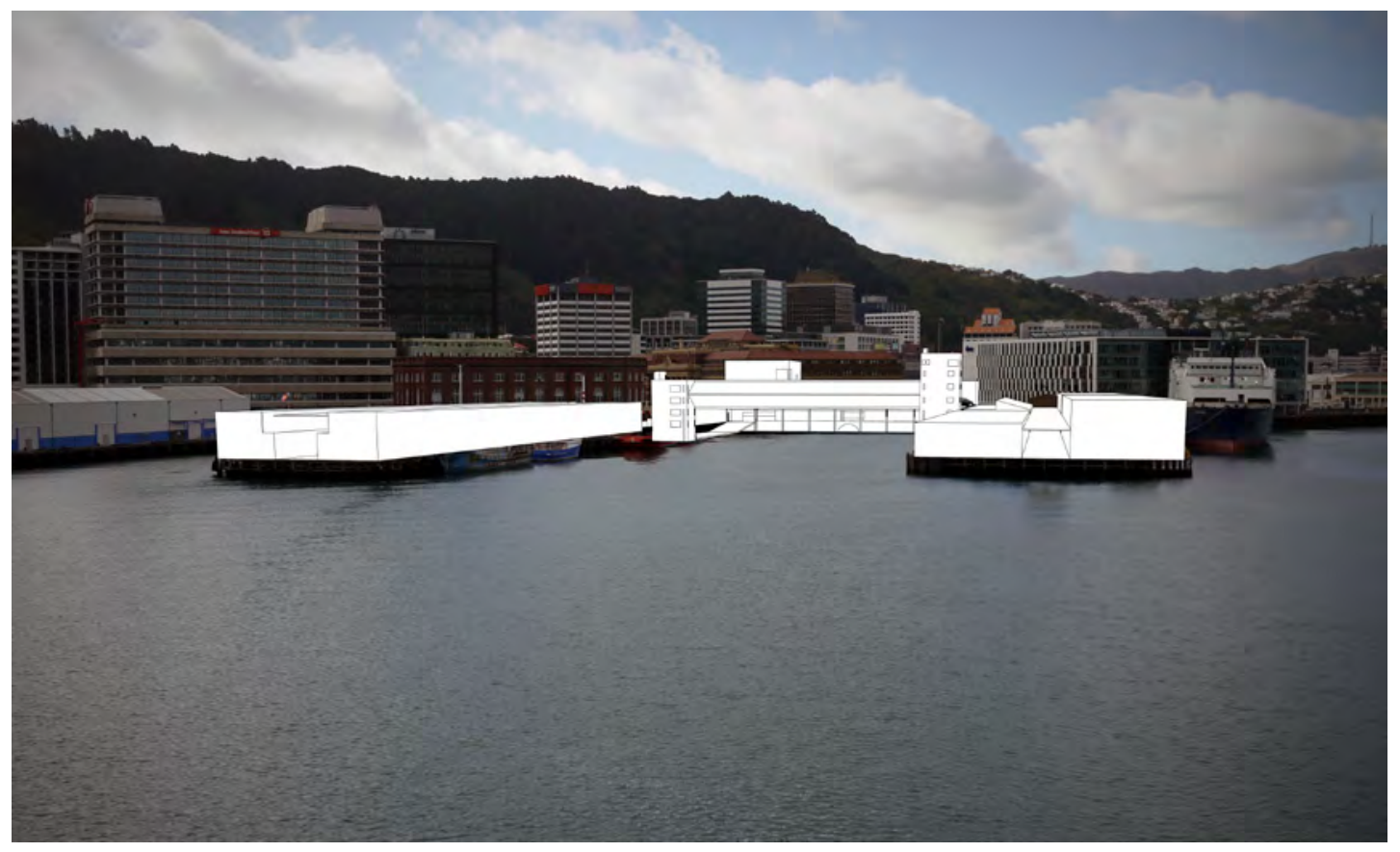

Fig. 132 - Aerial perspective from the south showing massing of proposed buildings 



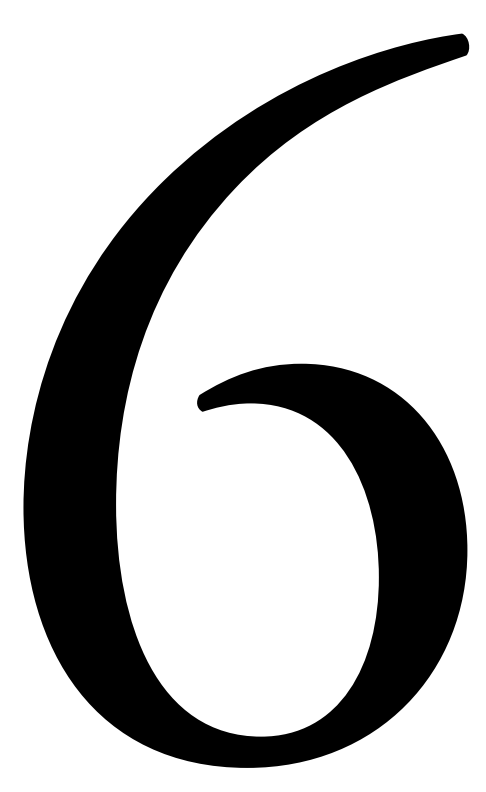

CONCLUSION 
$\mathrm{T}_{\mathrm{r}}$ he instrumental view that constitutes our conceptual framework for transport infrastructure, as embodied by the economic imperative prescribed for such works, belies its broader sociocultural value. As a result the current framework construes the commute as a disutility to be mitigated, rather than a valuable parcel of space-time to be celebrated.

The failure of the status quo to capture this extra-economic value suggests a fundamental systemic fault that is captured by writers such as Saul, Rifkin, and Bourdieu, following a line of Marxist critique of capitalism and its drive for commodification.

Applying a sociological framework to transport infrastructure as a corrective to this fault, as explored in this research through framing the commute as a ritual, is beneficial in teasing out the sociocultural function of transport infrastructure and suggesting how we may align the architecture of such work more effectively with this broader remit.

The sociological theories adopted are also helpful in suggesting spatial qualities that may enrich the experience of transport infrastructure, as exemplified in the design work. This implies architectural considerations that begin to address Bourdieu's suggestion of economic relationships recontextualised as part of a broader system of human practice as corrective to economic imperialism, achieved in this design work through the identification and attenuation of spatial characteristics derived from a sociocultural 
framework.

It must be noted that a fundamental link between capital and architecture problematises the discussion of transport infrastructure outside economic concerns. This research is intended as a corrective to the entrenched economic world-view; a counter balance to the often unchallenged argument that infrastructure works such as that proposed in this thesis must first and foremost make economic sense. Indeed, the implementation of a broad sociocultural framework for transport infrastructure at a strategic level would in all probability be impossible, as the rational quantification of cause and effect that economics provides is not achievable through sociological theory.

Additionally, the fact that extra-economic concerns are currently considered in relation to transport infrastructure works should be noted. Many government departments take part in the appraisal of infrastructure proposals, yet as Arthur Grimes points out, the economic remains the deciding factor and the extra-economic is factored in to the economic evaluation process (as 'discount rates' for example), with limited success.

This raises the question of qualitative versus quantitative approaches in the evaluation of transport infrastructure works, with the status quo decidedly quantitative. Framing the commute as a ritual is helpful in suggesting a framework that deals with the qualitative aspects of transport infrastructure, which are generally missed, or addressed at the tail end of a project, under the instrumental framework. This is evident in the (erroneous) 
identification of the commute as a disutility by the instrumental framework. The design work presented here acts as a counterpoint to this quantitative practice through prioritization of the qualitative, as derived from the ritual framework.

As a piece of infrastructure then, the design functions well - as both a ritual device and a pragmatic concern - leveraging off the increasing popularity of ferry transport to promote a more ritually, and pragmatically, sound public transport scenario in Wellington.

As a piece of architecture the design also meets its criteria of attenuating ritual aspects of the commute, programmatically as a terminal, and urbanistically as a continuation of the waterfront development and a rationalisation of the public transport hub.

As an object the design is more contentious. The paring back of the positive space that frames the programmatic functions of the building (which, it must be noted, are the primary focus of the research) to little more than the essential massing and material may give the impression of poor resolution. This is, however, entirely intentional, intending to draw on the reduction to essential meaning that Kahn's work at Exeter began with, and the abstraction inherent in symbolism.

During the course of this design research the work of Claude Megson was raised as precedent for the geometric abstraction that the design was exhibiting. Particularly in 
relation to the representational technique used in this thesis:

"Megson's perspective drawings show a remarkable degree of correspondence between the line on paper and the form as built. This is not merely a question of accuracy or fastidiousness... rather, the built work is no more elaborate than the drawing. This lends the buildings their abstract quality." (Reid 2000: 89).

Perhaps more relevant is the work of Stan Allen on 'infrastructural urbanism', which addresses the "...representational imperative in architecture" (1997: 52). In this Allen calls for an architecture that is "... less concerned with what things look like and more concerned with what they can do." (Ibid: 53). While this design proposition is to a large degree aligned with this thinking, the binary of appearance / function that Allen presents as the basis for his argument is somewhat problematic. Indeed, the research presented here on symbolic interaction and mnemonic shows how this binary begins to break down through discussion of the agency of 'how things look'. The hierarchy that Allen proposes remains intact however when we define the representational as shallow aestheticism (or architecture as graphic art). In this way we could adapt Allen's thesis to address sociocultural function over aestheticism.

Despite these intentions, the simplicity of the design language in relation to the object itself (that is, the harbour ferry terminal building) must be recognized as a weakness in the proposal. In focusing on the function of the architecture, and how this relates to an alternative conceptual framework for transport infrastructure, the intricacies of the building have been 
somewhat neglected.

Ultimately, the commute ritual can be understood as a vital part of contemporary life. Its function is anterior to the economic imperative ascribed to transport infrastructure by the current conceptual framework. Rather, transport infrastructure provides the site for an increasingly rare parcel of non-commodified time, within which base sociocultural functions occur. Framing the commute as a ritual begins to investigate the architectural implications of transport infrastructure as a sociocultural entity. 


\section{WORKS CITED}

Adams, T. (2011). "How the internet created an age of rage". The Observer.

Allen, S. (1997). "Infrastructural urbanism.” Scroope: Cambridge architectural journal(9): 9.

Appleyard, D., Lynch, K., \& Myer, J. R. (1964). The view from the road: Massachusetts, M.I.T. Press.

Augé, M. (2002). In the metro. Minneapolis, University of Minnesota Press.

Bocock, R. (1974). Ritual in industrial society; a sociological analysis of ritualism in modern England. London, George Allen \& Unwin Ltd.

Bourdieu, P. (2005). The social structures of the economy. Cambridge: Polity Press.

Butler, J. (1993). Bodies that matter: on the discursive limits of "sex". New York, Routledge.

Farnell, B. (1999). "Moving bodies, acting selves." Annual Review of Anthropology(28): 341-373.

Fergusson, P. (2006). "Modernization and mnemonics at Christ Church, Canterbury." Journal of the Society of Architectural Historians, 65(1), 50-67.

Graham, S., \& Marvin, S. (2001). Splintering urbanism: networked infrastructures, technological mobilities and the urban condition. London: Routledge.

Greater Wellington Regional Council. (2008). "Procurement Strategy for Bus and Ferry Services". 
Grimes, A. (2010). The economics of infrastructure investment: beyond simple cost benefit analysis. Wellington: Motu Economic and Public Research.

Hoete, A., Ed. (2003). Reader on the aesthetics of mobility. London, Black Dog Publishing Limited.

Houben, F., \& Calabrese, L. M. (Eds.). (2003). Mobility: a room with a view. Rotterdam: NAi Publishers.

Jones, P. B. (1996). "An anthropological view of architecture." Architectural Design 66(11/12): 22-25.

Kimmelman, M. (2012, January 2). The grid at 200: lines that shaped Manhattan, The New York Times.

Kohane, P. (2001). "Louis Khan's theory of 'inspired ritual' and architectural space." Architectural Theory Review 6(1): 87-95.

Leighninger, R. D. (1996). Cultural infrastructure: the legacy of new deal public space. Journal of Architectural Education, 49(4).

Mare, H. d. and A. Vos, Eds. (1993). Urban rituals in Italy and the Netherlands. Assen, Van Gorcum.

Marshall, R. (Ed.). (2001). Waterfronts in post-industrial cities: Spon Press.

Melhuish, C. (1996). "Editorial: why anthropology?” Architectural Design 66(11/12): 7-8.

Ministry of Infrastructure. (2011). National Infrastructure Plan 2011

Moore, S. F. and B. G. Myerhoff, Eds. (1977). Secular ritual. Assen, Van Gorcum.

Oxford University Press. (2012). "Oxford Dictionaries Online." from http://oxforddictionaries.com/

Parker, S. (2004). Urban theory and urban experience: encountering the city. London, Routledge.

Reid, G. (2000). "Degrees of freedom". architecture new zealand, July/August, 84-96. 
Rifkin, J. (2000). The age of access: how the shift from ownership to access is transforming modern life. London: Penguin.

Rostas, S. (1996). "The dance of architecture: from ritualisation to performativity and... back again?” Architectural Design 66(11/12): 19-21.

Saul, J. R. (2004). “The collapse of globalism and the rebirth of nationalism”. Harper's Magazine, 308(1846), 33.

Saul, J. R. (2005). The collapse of globalism: and the reinvention of the world: Overlook Press.

Schechner, R. (1993). The future of ritual: writings on culture and performance. London, Routledge.

Schechner, R. and W. Appel, Eds. (1990). By means of performance: intercultural studies of theatre and ritual. Cambridge, Cambridge University Press.

Smith, R. W. and V. Bugni (2006). "Symbolic interaction theory and architecture." Symbolic Interaction 29(2): 32.

Snow, R. P. and D. Brissett (1986). "Pauses: explorations in social rhythm." Symbolic Interaction 9(1): 1-18.

Spencer, D. (2010). "Replicant urbanism: the architecture of Hadid's Central Building at BMW, Leipzig." The Journal of Architecture 15(2): 181-207.

Statistics New Zealand. (2006). Commuting Patterns in New Zealand: 1996-2006.

Steg, L. (2003). "Can public transport compete with the private car?” IATSS Research 27(2): 27-35.

Steg, L. (2005). "Car use: lust and must. Instrumental, symbolic and affective motives for car use.” Transportation Research Part A 39: 147-162.

Stickells, L. (2010). "Conceiving an architecture of movement". Arq, 14(1).

Thorns, D. C. (1997). "The global meets the local: tourism and the representation of the New Zealand city". Urban Affairs Review, 33. 
Tiwari, R. (2010). Space - body - ritual : performativity in the city. Plymouth, Lexington Books.

Tran, A. (2011). Ferry oriented development: a Miramar case study. Master of Architecture, Victoria University of Wellington, Wellington.

Turner, V. (1995). The ritual process: structure and anti-structure, Transaction Publishers.

Wallis, I. and C. O'Fallon (2012). A wider look at how travellers value the quality and quantity of travel time. Wellington, NZ Transport Agency.

Wellington City Council (2006). Urban Development Strategy

Wiggins, G. E. (1997). Louis I. Kahn: the library at Phillips Exeter Academy. New York, Van Nostrand Reinhold.

World Bank. (2008). "Passenger cars (per 1,000 people)". 2011, from http://data.worldbank. org/indicator/IS.VEH.PCAR.P3 


\section{IMAGE CREDITS}

Fig. 03 - Retrieved from http://booksfilmtheater.blogspot.co.nz/2011/12/public-librar ies.html

Fig. 04 - BMW Leipzig vector diagram, courtesy of Zaha Hadid Architects

Fig. 06 - Retrieved from Bing Maps nz.bing.com/maps/

Fig. 07 - Photo courtesy of Dan Smith

Fig. 08 - Photo courtesy of Sputnikcccp

Fig. 09 - Photo courtesy of Ruth Mitchener

Fig. 10 - Photo courtesy of Ruth Mitchener

Fig. 11 - 13 Docks de Paris, courtesy of Jakob + MacFarlane

Fig. 14 - Courtesy of LINZ. Sourced from BQ31, BQ32. Crown Copyright Reserved.

Fig. 15 - Courtesy of LINZ. Crown Copyright reserved.

Fig. 16 - Source: National Infrastructure Plan 2011

Fig. 18 - Source: Wellington Regional Public Transport Plan 2011-2021

Fig. 19 - Source: Wikipedia user Vardion

Fig. 20 - Source: NZTA

Fig. 21 - Courtesy of LINZ. Crown Copyright reserved.

Fig. 22 - GWRC public transport plan for the next decade.

Fig. 23 - WCC urban development strategy, showing explicit link to GWRC plan

Fig. 24 - Retrieved from: http://www.metlink.org.nz/network-map/

Fig. 32 - Retrieved from Bing Maps nz.bing.com/maps/

All other images: A R Mitchener 
